University of Rhode Island

DigitalCommons@URI

Open Access Dissertations

1992

\title{
A Measurement Model for Spectral Analyzed EEG
}

Michael David Weiler

University of Rhode Island

Follow this and additional works at: https://digitalcommons.uri.edu/oa_diss

\section{Recommended Citation}

Weiler, Michael David, "A Measurement Model for Spectral Analyzed EEG" (1992). Open Access

Dissertations. Paper 941.

https://digitalcommons.uri.edu/oa_diss/941

This Dissertation is brought to you for free and open access by DigitalCommons@URI. It has been accepted for inclusion in Open Access Dissertations by an authorized administrator of DigitalCommons@URI. For more information, please contact digitalcommons-group@uri.edu. 


\section{BF321 1445 1992}

A MEASUREMENT MODEL FOR SPECTRAL ANALYZED EEG BY

MICHAEL DAVID WEILER

A DISSERTATION SUBMITTED IN PARTIAL FULFILLMENT OF THE REQUIREMENTS FOR THE DEGREE OF DOCTOR OF PHILOSOPHY

IN

PSYCHOLOGY

29204770

UNIVERSITY OF RHODE ISLAND

1992 
ABSTRACT

The purpose of this study was to determine whether linear combinations of absolute-power beta waves were predictive of changes in vigilance. Spectral analyzed EEG data were collected across eight bipolar sites from 102 , right-handed adults during a resting condition and during an auditory continuous performance test. The most normal distribution of absolute power ( $A P$ ) scores was produced by a $\log _{10}(\mathrm{AP})$ transformation and the most normal distribution of relative power (RP) scores was produced by a $\log _{10}(\mathrm{RP} / 1-\mathrm{RP})$ transformation. Absolute power had greater short-term reliability than relative power.

Components were derived from Principal Components Analysis performed on AP, RP, $\log _{10}(A P)$, and $\log _{10}(R P / 1-$ RP). A component comprising frontal, RP theta was negatively correlated with omission errors. Changes in components comprising right-sided, AP beta were negatively correlated with changes in omission errors. Changes in frontal, AP beta and posterior, RP theta components were positively correlated with changes in omission errors. None of the multiple regression equations using these components, however, accounted for more than $13 \%$ of the variance. Right-sided and frontal AP beta components appeared, however, to warrant a follow-up study for purposes of cross validation. The AP, 12-component solution provided the best model of EEG activity during a vigilance task. 


\section{ACKNOWLEDGEMENT?}

It would be impossible to adequately express my gratitude to all those who have provided, assistance, support, and guidance in the preparation of this manuscript.

In particular I wish to express my gratitude to the members of my committee, in particular $W$. Grant Willis and Dominic Valentino, my mentors over the last few years. In fact, it would be appropriate to extend my thanks to all of the faculty because each has influenced my development in their own way.

I would however had been lost without my colleagues in graduate school; the members of my class and my comembers of the EEG research team. I would have been Iost without the friendship, support, and guidance of James Arruda, and in particular, Mary Lynne Kennedy. 


\section{TABLE OF CONTENTS}

ABSTRACT. . . . . . . . . . . . . . . . . . . i

ACKNOWLEDGEMENT . . . . . . . . . . . . . . . . . . . .iii

IIST OF TABLES. . . . . . . . . . . . . . . . . . .vii

IIST OF FIGURES . . . . . . . . . . . . . . . . . . . . ix

I. INTRODUCTION . . . . . . . . . . . . . . . . . .

Vigilance and Brain Activity, . . . . . . . . . . . . 1

Positron Emission Tomography and Brain Activity . . . 5

Brain Activity and EEG. . . . . . . . . . . . . . 6

Vigilance and EEG . . . . . . . . . . . . . . . 7

Normality of Absolute-power Distributions . . . . . .9

Absolute vs. Relative Power. . . . . . . . . . . 11

Principal Components Analysis . . . . . . . . . 14

Significance of the Study . . . . . . . . . . . . 19

Predictions. . . . . . . . . . . . . . . 20

I. METHOD . . . . . . . . . . . . . . . . . 22

Subjects . . . . . . . . . . . . . . . 22

Main study. . . . . . . . . . . . . . . . 22

Test-retest reliability study . . . . . . . . 22

Apparatus . . . . . . . . . . . . . . . . . 23

Procedure . . . . . . . . . . . . . . . . 23

Design . . . . . . . . + . . . . . . . . . 24

III. RESULTS. . . . . . . . . . . . . . . . . 25

Reliability of Measurements . . . . . . . . . . 26

Transformation of EEG Variables . . . . . . . . . 26

Reliability of Transformations. . . . . . . . . 28 
The Effect of Unreliable Variables on

Calculations of Relative Power. . . . . . . . . 33

Changes in Levels of Brain Wave Activity

Between Resting and CPT. . . . . . . . . . 35

Principal Components Analysis. . . . . . . . . . 37

The choice of a PCA . . . . . . . . . . . 37

Sample size and component saturation . . . . . 37

Correlation or covariance matrix. . . . . . . . . 41

Determining the number of components to

retain using empirical criteria . . . . . . . . 42

Determining the number of components to

retain using theoretical criteria . . . . . . . 43

Calculating Scores. . . . . . . . . . . . . 49

Component Reliability . . . . . . . . . . . 50

Six-Minute Test-Retest Reliability of

Performance Measures. . . . . . . . . . . 52

Multiple Regression on Level of Performance. . . 53

Multiple Regression on Change in Level of

Performance (Vigilance Decrement) . . . . . 55

Post-hoc Multiple Regressions . . . . . . . . . 59

IV. DISCUSSION . . . . . . . . . . . . 61

Transformation of Scores ........... . 61

Absolute-Power and Relative-Power Reliability . . . 63

PCA and Component Scores. . . . . . . . . . . 64

PCA Solution. . . . . . . . . . . . . . 66

CPT Performance Measures. . . . . . . . . . . 69

Changes in Levels of EEG Activity . . . . . . . 72 
Predicting Level of Performance . . . . . . . . 74

Predicting Changes in Level of Performance. . . . . 74

Post-hoc Analyses . . . . . . . . . . . . 76

V. SUMMARY. . . . . . . . . . . . . . . 79

APPENDIX A HANDEDNESS INVENTORY . . . . . . . . . . . 82

APPENDIX B SUPPLEMENTARY TABles . . . . . . . . . . . . 83

APPENDIX C SUPPLEMENTARY FIGURES. . . . . . . . . . . . . 104

APPENDIX D COMPONENT LOADINGS . . . . . . . . . . . . 112

BIBLIOGRAPHY . . . . . . . . . . . . . . . . . . . . . . . . . . . 


\section{LIST OF TABLES}

1. Skewness and Kurtosis of the Various Transformations............ . . . 27

2. Six-Minute Test-Retest Correlations . . . . . . 31

3. Double Cross-validation Correlations. . . . . 32

4. Changes in Relative Power Reliability . . . . . 34

5. Differences in Level of EEG Activity. . . . . . 36

6. Comparison of Absolute Power (AP) PCAs. . . . 38

7. Comparison of $\log _{10}(\mathrm{AP})$ PCAs. . . . . . . . 39

8. Comparison of Relative Power (RP) PCAs . . . . .40

9. Comparison of $\log _{10}(\mathrm{RP} / 1-\mathrm{RP})$ PCAs... . . . . . 41

10. Skewness and Kurtosis of Component Scores . . .50

11. Reliability of AP Component Scores . . . . . . . 51

12. Reliability of $\log 10(\mathrm{AP})$ Component Scores. . . .51

13. Reliability of RP Component Scores . . . . . . .51

14. Reliability of $\log _{10}(\mathrm{RP} / 1-\mathrm{RP})$ Component Scores .52

15. Descriptive Statistics of Performance Indexes. . 53

16. Multiple Regression (MR) Results . . . . . . .54

17. Standard MR of RP.5 on Omission Errors . . . .54

18. Correlations of LRP.9 Component Scores . . . . . 55

19. Standard MR of LRP.9 on Omission Errors. . . . .55

20. Correlations of AP.8 Component Scores. . . . .56

21. Standard MR of AP.8 on Change in Omissions . . .56

22. Correlations of AP.12 Component Scores . . . . .57

23. Standard MR of AP.12 on Omission Errors. . . . .57

24. Correlations of RP.7 Component Scores. . . . . .57 
25. Standard MR of RP.7 on Change in Omissions. . .58

26. Correlations of RP.8 Component Scores. . . . . .58

27. Standard MR of RP.8 on Omission Errors . . . .58

28. Standard MR of CPT1 and CPT2 AP scores . . . .60

29. Standard MR of CPTI ans CPT2 RP Scores.,.,.61 


\section{LIST OF FIGURES}

1. Format of EEG Channels and PCA Figures . . . . 8

2. Relative Power, 5-Component Extraction . . . . .46

3. $\log _{10}(\mathrm{RP} / 1-\mathrm{RP}), 9$-Component Extraction . . . . 46

4. Absolute Power, 8-Component Extraction. . . . .47

5. Absolute Power, 12-Component Extraction. . . . 47

6. Relative Power, 7-Component Extraction . . . . .48

7. Relative Power, 8-Component Extraction . . . . .48

8. Absolute Power, 12-Component Solution. . . . . .68

9. Percent Omission Errors CPTl . . . . . . . .70 
Introduction

The primary purpose of this study was to determine whether linear combinations of spectral analyzed electroencephalograms (EEG), specifically, linear combinations of absolute-power beta waves, were predictive of changes in attention and verbal information processing. The following review begins with an examination of previous research pertaining to: (a) vigilance tasks and their relationship to brain activity, (b) brain activity and its relationship to EEG, and (c) vigilance tasks and their relationship to EEG. Ongoing measurement questions within the field of EEG research and a model for investigating those questions is then proposed. Finally, predictions are specified regarding: (a) the outcome of the measurement questions, and (b) the manner in which changes in levels of vigilance relate to EEG. Vigilance and Brain Activity

Attention often is differentiated into selective and sustained operations. Vigilance refers to the sustained aspects of attention. A vigilance decrement is taken to mean the reduction in level of performance associated with time on task and thus is distinguished from the overall level of performance (Parasuraman, 1984).

The modern study of vigilance dates back to world war II. It started with the observation of attentional lapses among radar operators whose job it was to detect infrequent events under monotonous conditions. Controlled 
laboratory studies of vigilance began with the work of Mackworth (1948). His research confirmed the suspicion that sustained attention decreased rapidly during monitoring tasks. This pattern was seen for both auditory and visual monitoring tasks (Warm, 1984).

The literature suggests that the most appropriate measures of the vigilance decrement are either the drop in the number of correct signal detections or the increase in response time to signals (Warm, 1984). In many vigilance tasks the decrease in the detection rate is also accompanied by a decrease in commission errors (i.e., false alarms), The decrease in detection efficiency associated with time on task could be explained by signal detection theory (Swets, Tanner, \& Birdsall, 1961), either by parameters of sensitivity (i,e., the person's ability to distinguish between targets and non-targets) or response bias (i.e., the willingness to call an ambiguous signal a target). It has been demonstrated that a sensitivity decrement can be produced under conditions where the stimulus rate is high and the task has memory demands, that is, the individual must compare stimuli with earlier stimuli maintained in memory (Parasuraman, 1984). The continuous performance test (CPT) was introduced in 1956 by Rosvold, Mirsky, Sarason, Bransome, and Beck. It was designed as a measure of vigilance or selective attention for infrequently occurring stimuli (Eliason \& Richman, 1987; Haperin, Sharma, Greenblatt, \& Schwartz, 
1991). The original purpose of the CPT was to compare brain-damaged with non-brain-damaged individuals on their abilities to sustain attention. The individuals were to respond whenever they saw an "A" followed by an " $\mathrm{X}$ " (Halperin et al., 1991). CPTs subsequently have been used in a number of ways. For example, evoked response potentials (ERPs) have been collected while participants performed CPT tasks. Here, Herning, Hooker, and Jones (1987) demonstrated that cocaine altered particular aspects of ERP wave forms (i.e., N 100 and CNV amplitudes). However, Friedman, Cornblatt, Vaughan, and Erlenmeyer-Kimling (1986) found that ERP collected during CPT did not distinguish among normal controls, psychiatric controls, and children at risk for schizophrenia. CPTs have been used to differentiate referred from non-referred children. O'Dougherty, Nuechterlein, and Drew (1984) were able to distinguish children with Attention-deficit Hyperactivity Disorder from normal controls. Eliason and Richman (1987) demonstrated that learning-disabled children made more omission errors and had slower reaction times than a matched control group. Despite the empirical support, CPTs have not proven to be clinically useful. CPT performance does not reliably distinguish between clinical groups nor do all members of any group consistently perform at any particular level (Halperin et al., 1991). 
A variety of indexes has been suggested to describe performance on the CPT including: the Omission Error Index (Io = omission errors/omission opportunities), the Detection Index $(P(D)=1$ - Io - Co; where co = commission errors/commission opportunities), and the Error Index (Io $+2 \mathrm{Co})$. The commission error ratio is doubled in the last index because, among the brain-injured population, errors of commission are considered more serjous than errors of omission (Pigache, 1976). $D^{\prime}$ also is used in CPT work. D' is derived from signal detection theory and is defined as the $\mathrm{z}$ score distance between 1 - Io and co or $\mathrm{d}^{\prime}=$ F(hits/targets) - F(false alarms/non-targets) where $F$ is equal to the $z$ score probability (Herring et al., 1987). In classification studies, significant findings have been reported when using correct responses (Eliason \& Richman, 1987; Friedman et al., 1986; Grant et al., 1990; Halperin et al., 1991), d' (Herning et al., 1987), false alarms, and reaction times (Halperin et al, 1991) as dependent variables.

Gordon and Mettelman (1988) demonstrated high testretest reliabilities in a nine-minute vigilance task where the participants were requested to press a button every time they saw a "g" preceded by "l." Here, 32 children were retested between 2 and 22 days after the initial administration. The test-retest correlation for total correct was .72; for total commissions it was .84 . Another 20 children were retested at one year. 
Correlations for total correct dropped to .68 and total commissions rose to .94. All correlations were significant at the $\mathrm{p}<.001$ level.

In the present study, short-term (i.e., six-minute) and longer term (i.e., one-week) test-retest correlations were calculated to assess the stability of the CPT performance measures and to permit the identification of the most reliable index for use as the criterion in the multiple regression equations. It was predicted that reliabilities would exceed .80 and that the detection index would have the highest test-retest reliability score.

Positron Emission Tomography and Brain Activity Petersen, Fox, Posner, Mintun, and Raichle (1988) used Positron Emission Tomography (PET) to measure blood flow in the brain during processing of visually and auditorily presented words (i.e., a non-CPT activitiy). During auditory processing, bilateral activity was seen in the primary auditory cortex. Activation also was seen on the left side in the temporo-parietal cortex, anterior superior temporal cortex, and the inferior anterior cingulate cortex.

In another study (Cohen et al., 1987), PET was recorded after 35 minutes of eyes-closed CPT. Twentyseven healthy adults pressed a hand-held response button whenever the lowest of three $500 \mathrm{~Hz}$ tones sounded. Cohen et al. (1987) reported a significant ( $\underline{p}<.05$, uncorrected 
for the 55 comparisons) negative Pearson product-moment correlation between metabolic rate in middle pre-frontal cortex and false alarms. This negative relationship showed that higher relative (region/global) metabolic rates were associated with fewer false alarms. Relative metabolic rate was uncorrelated with hits in this area. Buchsbaum et al. (1990) used PET to compare relative glucose use (mean/whole-slice mean) between no-task (visual fixation on flashing stimuli) controls and visualCPT-task (pressing a button whenever a "0" was presented) controls. Occipital metabolic rates between the two groups were comparable. There were metabolic increases in the right frontal and right temporo-parietal regions associated with task performance. The participants who performed the best on the CPT had higher relative metabolic rates in the right parietal area. Brain Activity and EEG

According to Matejcek (1982), much is still unknown about the relationship between brain activity and EEG. EEG records brain activity on the surface of the cerebral cortex (Buchsbaum, Coppola, \& Cappelletti, 1982; Matejcek, 1982). A scalp EEG does not detect electrical activity from deep structures nor from the approximately two thirds of the cerebral cortex that lie within sulci. It is known, however, that the amplitude of scalp EEG depends on: (a) the number of synchonously firing neurons, (b) the neuroanatomical structure in which the neuron is located, 
and (c) the distance between the neurons and the recording electrode (Matejcek, 1982). Homan, Herman, and Purdy (1987) demonstrated that for most individuals, a standard 10-20 electrode-placement system provides reliable localization of the underlying cortical structures. Vigilance and EEG

Many studies of vigilance and brain wave activity have noted a relationship between performance and EEG activity in the alpha ( 7 to $13 \mathrm{~Hz}$ ) and theta ( 3 to $7 \mathrm{~Hz}$ ) frequency bands. In one study, participants performed a radar-detection simulation for a two-hour period.

Relative EEG power was recorded from occipital and parietal lobes. The decrease in detection accuracy with time was shown to be associated with increases in alpha and theta activity and decreases in beta activity (Davies \& Parasuraman, 1982; Parasuraman, 1984). The electrode arrangement used in this study did not allow an examination of the parietal areas of the brain.

Researchers have noted changes in EEG power associated with changes in levels of cortical arousal. (Parasuraman, 1984). In both head-injured and non-headinjured control individuals, Randolph and Miller (1988) noted that heightened states of arousal were associated with increases in delta and beta activity and decreases in alpha and theta activity. Matejcek (1982) reported a number of studies that associated relaxed wakefulness with alpha activity and alert attentiveness with beta activity. 
8

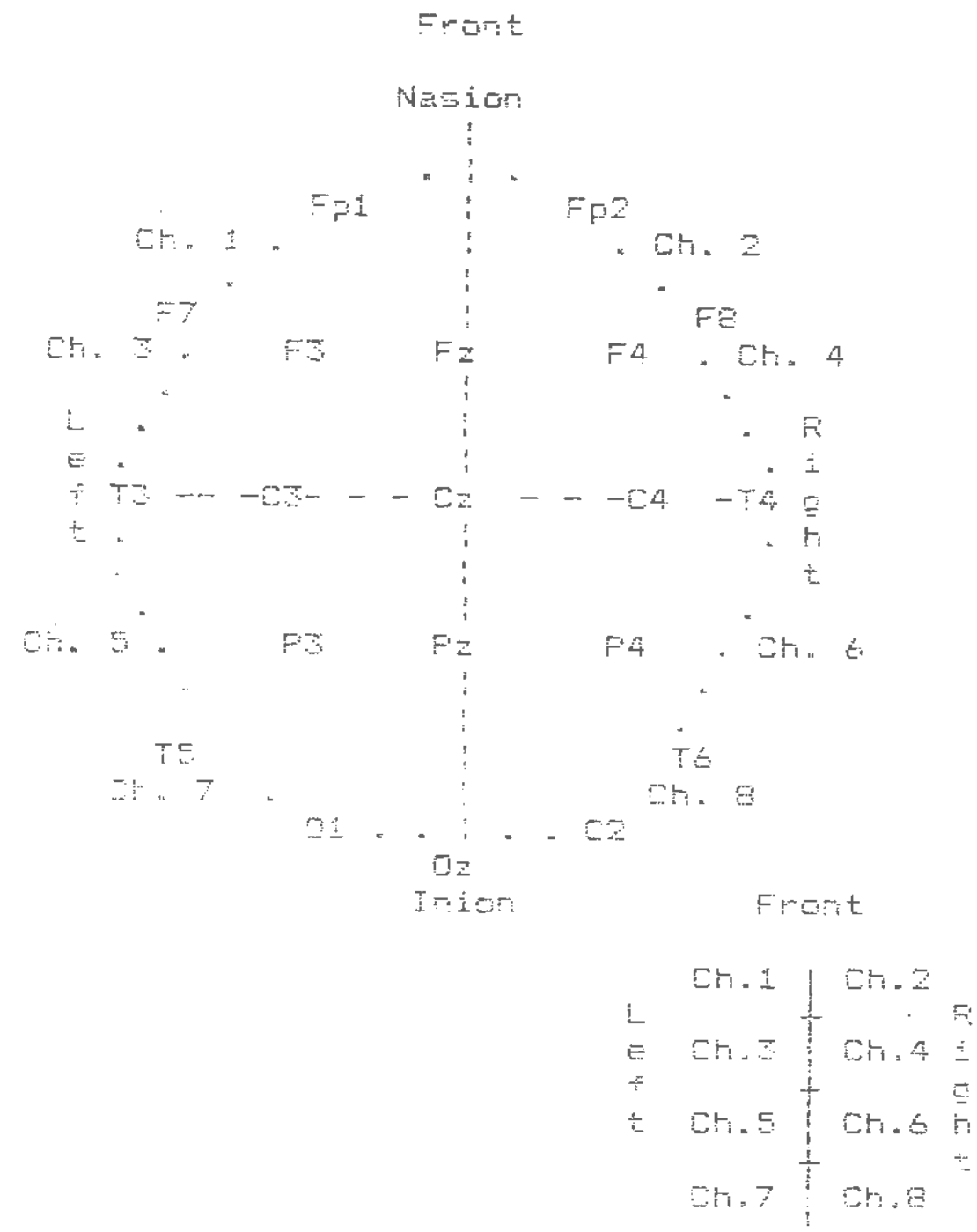

Future - Interratione: (10-20j electrode piacenert

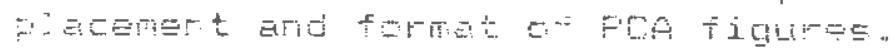


Figure 1 illustrates the electrode placement used in this study. Because of the auditory information processing demands of the CPT task, increases (in comparison with resting EEG) in beta activity in channels 3 and 5 on the left side and 6 on the right were anticipated. Further, beta increases (over resting EEG) in regions 1,2 , and 4 associated with the attentional aspects of the CPT also were expected. The overall pattern of change between the resting condition and the CPT's was expected to show increases in the levels of delta and beta activity and decreases in the levels of alpha and theta activity.

Finally, the attentional characteristics of the current investigation (i.e., memory load and rapid event rate) were expected to produce a sensitivity decrement over time. This sensitivity decrement was expected to be associated with an increase in occipital theta and alpha activity, and a decrease in occipital beta activity. Based on the previously cited PET studies, it also was expected that beta activity in the right frontal (channel 2) and right fronto-temporal (channel 4) regions would be negatively correlated with decreases in vigilance. Normality of Absolute-Power Distributions

Complex wave forms recorded during an EEG are separated into a series of simpler sine-wave frequency patterns (or wave bands); the area bounded by these sine waves (i.e., one half amplitude squared) is termed 
absolute-power. For each EEG channel (corresponding to a single hemisphere's cortical region), relative power is calculated by dividing the absolute power of a particular wave band by the sum of the absolute powers of all the wave bands at that region. Previous studies have examined and transformed EEG data collected during resting conditions in a variety of ways. There is consensus that, for EEG collected during resting conditions, a log transformation produces the most normal distributions of absolute-power variables and that a $\log (x /(1-x))$ normalizes relative power distributions (Amador et al., 1989; Gasser, Bacher, \& Mocks, 1982; John et al., 1988; Oken \& Chiappa, 1988; Pollock, Schneider, \& Lyness, 1990). There may be some waveband differences, however, that influence these generalizations. For instance, Pollock et al. (1990) reported that absolute-theta amplitude was not normalized with the log transformation. Moreover, oken and Chiappa (1988) found that relative power had fewer skewed results than absolute power. Among absolute-power variables, the delta band had the most skewed variables and the beta 2 band variables were least skewed.

The present study examined seven transformations selected from a review of earlier EEG studies (Amador, Sosa, Marqui, Garcia, Lirio, \& Bayard, 1989; Gasser, Bacher, \& Mocks, 1982; Oken \& Chiappa, 1988; Pollock, Schneider, \& Lyness, 1990): $\log 10(\mathrm{AP}), \log 10(1+\mathrm{AP})$, square $\operatorname{root}(\mathrm{AP})$, cube $\operatorname{root}(\mathrm{AP})$, and $1 /$ square $\operatorname{root}(\mathrm{AP})$ for 
absolute-power (AP); and arc-sin square root(RP) and $\log 10(R P /(1-R P))$ for relative power (RP). It was predicted that $\log 10(\mathrm{AP})$ and $\log 10(\mathrm{RP} /(1-\mathrm{RP}))$ transformations would result in the most normal distributions of EEG variables collected during a CPT.

Skewness and kurtosis of the seven transformations were examined by calculating the number of variables exceeding critical values for skewness and kurtosis after correcting for family-wise errors (Stevens, 1986). Using the multiple-regression procedure noted previously, absolute-power scores, relative-power scores, and the most normal distributions of absolute-power and relative-power scores were contrasted on their accuracy in predicting criterion scores. As before, it was predicted that the non-transformed absolute-power variables would explain more of the variance than the other options and significantly predict performance. Absolute vs. Relative Power

There is disagreement in the scientific literature as to whether absolute power or relative power better reflects measures of EEG cerebral functioning. The choice of using either relative power or absolute power in an analysis is significant because varying outcomes may result depending on the metric used (Byring, salmi, Sainio, \& Orn, 1991; Randolph \& Miller, 1988).

Relative-activity measures are used in other fields of brain research as well as in EEG studies. For example, 
in PET research, investigators standardize absolute glucose metabolic variables by dividing regional glucose metabolic rates by global glucose metabolic rates, thereby attempting to adjust for inter-individual variation (Cohen et al., 1987).

John and his colleagues (John et al., 1977; John, Ahn, \& Prichep, 1980; John, Prichep, Fridman, \& Easton, 1988), reported that absolute-power measures were less reliable than indexes of relative-power. In contrast, Fein et al. (1983) demonstrated that, among their sample of children, absolute power was as reliable a measure of resting EEG activity as relative power. They also noted that changes in relative-power measures were difficult to interpret because of the correlations between the scores. As an example, a decrease in a relative-power waveband may be the result of a decrease in the power of that waveband, an increase in power in other wavebands, or a combination of these two processes (Fein et al, 1983). Fein et al. (1983) argued it would be difficult to imagine a situation that simultaneously would produce instability of the individual wave bands (i.e., absolute-power reliability) yet, at the same time, greater stability in the relationship between bands (i.e., relative-power reliability).

Pollock et al. (1991) examined Pearson product-moment correlations for log-transformed relative amplitude and log-transformed absolute amplitude. They used this 
statistic because they felt that amplitude met the assumptions of a parametric statistic (i.e., amplitude was a ratio scale and a log transformation normalized the distributions). At four and one-half months, most testretest reliabilities were in an acceptable range although delta reliability tended to be low. They suggested that, for samples similar to the one they studied (i.e., healthy older individuals), absolute-power rather than relativepower measures would be preferable.

Gasser, Bacher, and Steinberg (1985) examined tenmonth test-retest reliability on a sample of children using the non-parametric spearman rank-order correlation. On the average, absolute and relative power were similarly reliable. They found higher beta-band reliability in relative power compared to absolute power, Reliability was comparable in the alpha and theta bands. In the delta wave band, absolute-power reliability was low but higher than relative-power reliability.

In the present study, absolute power and relative power were contrasted in four ways. First, short-term (i.e., six-minute) test-retest reliability of absolutepower and relative-power variables was compared. Second, consistency in the relationship of absolute- and relativepower variables across groups was compared using a double cross-validation procedure. Third, the effect of the interdependence of relative-power scores on reliability was explored. It was proposed that the reliability of any 
relative-power waveband would be limited by the lack of reliability in other bands. Therefore, removal of the most unreliable waveband from the calculation of relative power would result in increased test-retest reliabilities for the remaining wavebands. Fourth, the capacity of relative-power and absolute-power variables to predict performance was contrasted. Components derived from principal components analyses (PCA) of absolute- and relative-power variables were entered into a standard multiple-regression equations with performance scores on an auditory CPT as the criterion. It was predicted that a multiple-regression equation based on components derived from the absolute-power PCA would better predict performance and explain more of the variance than components from the other transformations.

\section{Principal Components Analysis}

Principal components analysis (PCA) has been used in the past to investigate brain-wave activity (Amador et al., 1989; Bente, 1979; Friedman, Cornblatt, Vaughan, \& Erlenmeyer-Kimling, 1986; Gasser, Jennen-Steinmetz, Sroka, Verleger, \& Mocks, 1988; Gasser, Mocks, \& Bacher, 1983; Ott, McDonald, Fichte, \& Herrmann, 1982; Schenk et al., 1982). For example, Bente (1979) reported an attempt to minimize vigilance fluctuations during EEG recording by requiring participants $(\underline{\mathrm{N}}=12$ ) to perform a visualtracking task under placebo and drug (Viloxazine) conditions. Although the procedure was not described 
explicitly in this report, it appeared that EEG was recorded from the right occipital region, and that the 32 , 1-Hz relative-power spectral variables were analyzed using a PCA with a varimax rotation. Bente's PCA produced five factors with positive (+) and negative (-) loadings: F1 30 $\mathrm{Hz}(+) ; \mathrm{F2} 9 \mathrm{~Hz}$ (+) and $3 \mathrm{~Hz}(-) ; \mathrm{F} 313 \mathrm{~Hz}$ (+); F4 $17 \mathrm{~Hz}$ (-); and F5 $7 \mathrm{~Hz}(+)$ and $11 \mathrm{~Hz}(-)$. These factors explained $91 \%$ of the variance. Bente (1979) also performed a PCA on resting EEG. He compared factor scores obtained under placebo and Viloxazine conditions using Hotellings $\mathrm{T} 2$. Bente found a significant difference ( $\mathrm{P}<$ $.01)$ on a factor consisting of 2 to $6 \mathrm{~Hz}(+)$ and $10 \mathrm{~Hz}(-)$ EEG. He suggested that this factor could be interpreted as a vigilance factor.

Ott et al. (1982) recorded eyes closed resting EEG from the 02-A2 (right occipital - right ear) channel on 60 males between the ages of 21 and 45 . Twenty minutes later, the same participants completed a series of $\mathbf{s i x}$ behavioral tests of reaction time, visual sensitivity, continuous addition, and manual dexterity. Ott et al. performed a PCA on the six behavioral measures and seven EEG parameters (total power and relative-powers of theta, alphal, alpha2, betal, and beta3). Using a criterion of eigenvalue greater than 1 and a varimax rotation, they identified a four-factor solution accounting for 658 of the variance. The first factor ( $27 \%$ of the variance) consisted of delta $(1.5 \mathrm{hz}$ to $6.0 \mathrm{~Hz})$, negative alphal 
$(8.5 \mathrm{~Hz}$ to $10.5 \mathrm{~Hz})$, Betal $(12.5 \mathrm{~Hz}$ to $18.5 \mathrm{~Hz}), \operatorname{Beta} 3$ (21 $\mathrm{Hz}$ to $30 \mathrm{~Hz}$ ), and negative total power. The second and third factors ( 30 of the variance) consisted of the behavioral measures. The fourth factor (88 of the variance) consisted of theta $(6.0 \mathrm{~Hz}-8.5 \mathrm{~Hz})$ and negative alpha $2(10.5 \mathrm{~Hz}-12.5 \mathrm{~Hz})$. The absolute values of all loadings were greater than or equal to .60 . The correlation between EEG variables and the behavioral measures were low $\left(\underline{r}_{\max }=-.28\right)$ explaining less than 8 s of the variance.

Schenk et al. (1982) calculated factor and component scores on absolute-power EEG collected during freefloating vigilance conditions (i.e., resting without stage B sleep). Their variables consisted of $34,0.95-\mathrm{Hz}$ frequency bands between $0.5 \mathrm{~Hz}$ and $32.8 \mathrm{~Hz}$, collected on 41 participants, from two bipolar EEG leads (C4-P4, P402). They identified an identical five-factor solution for both factor analysis and PCA that accounted for $85 \%$ of the variance. Factor 1 consisted of fast alpha $(10 \mathrm{~Hz}$ to $13.8 \mathrm{~Hz})$ and medium beta $(19.5 \mathrm{~Hz}$ to $24.5 \mathrm{~Hz})$, and accounted for $20 \%$ of the variance. Factor 2, a broad band factor, consisted of fast delta-theta (2.4 Hz to $9.05 \mathrm{~Hz})$ plus slow alpha-slow beta $(13.8 \mathrm{~Hz}$ to $18.55 \mathrm{~Hz})$, and accounted for 248 of the variance. Factor 3 consisted of fast beta activity $(22.35 \mathrm{~Hz}$ to $31.85 \mathrm{~Hz})$, and accounted for $24 \%$ of the variance. Factor 4 consisted of delta activity $(.05 \mathrm{~Hz}$ to $3.35 \mathrm{~Hz})$, and accounted for 98 of the 
variance. Factor 5 consisted of slow to medium beta (16.65 Hz to $19.5 \mathrm{~Hz})$, and accounted for $7 \%$ of the variance. They went on to examine test-retest reliability for the factor scores at 1, 2, 3, and 4 hours. Factors 1 and 2 were stable with correlation coefficients ranging from .81 to .92. The delta factor was unstable at the P402 lead. Test-retest reliabilities were calculated on the same participants at four separate days. Factor 1 reliability ranged from .57 to .87 , factor 2 from 09 to .65, factor 3 from. 75 to .87, factor 4 from .23 to.55, and factor 5 from. 59 to .81 .

In 1983, Gasser, Mocks, and Bacher, investigating mental retardation and learning disability in children, recorded eyes-closed resting EEG from eight locations (F4, $\mathrm{F} 3, \mathrm{C} 4, \mathrm{C} 3, \mathrm{Cz}, \mathrm{Pz}, \mathrm{O} 2, \mathrm{O} 1$ with linked earlobe reference) and six bands in both absolute and relative power. They attempted to reduce the set of 48 variables by performing a PCA for each band, in both absolute and relative power, using the recordings from the eight locations as variables. Based on their normative group of 31,10 to 13 year olds, they decided on a three-factor solution (explaining $95 \%$ of the variance) for reasons of interpretability. They did not rotate the axes further because it eliminated the first factor as a general topographic factor. The first factor (81.98 of the variance) appeared to be a general spectral band acrossall-locations factor, the second (9.48) discriminated 
anterior from posterior locations, and the third ( 3.28 ) discriminated frontal from central and parietal locations. There were few differences between the absolute-power and relative-power solutions. Compared to absolute-power, relative-power scores had lower loadings on factor 1 , but higher loadings on factors 2 and 3 . Gasser and his colleagues (1983) went on to replicate an earlier classification study in which the 48 individual parameters had been used. When they replaced the 48 variables with the 18 factor scores (three factors by 6 bands) the results were identical. Greater parsimony was achieved without any significant loss of information.

In 1988, Gasser et al. replicated their earlier study using 158 children and adolescents between 6 and 17 years of age. This time they restricted the PCA to three- and four-component solutions explaining 958 of the variance. In the two solutions the first three factors were identical. The third and fourth components accounted for approximately $2.5 \%$ and $2 \%$ of the variance, respectively. The fourth component discriminated the left from the right hemisphere for some of the bands.

In the present study, a PCA was performed on absolute-power variables, relative-power variables, and the most normal transformations of absolute-power and relative-power variables. The axes were rotated orthogonally (using a varimax rotation). Component scores were generated by unit weighting normalized deviation 
scores. Short-term test-retest reliabilities were calculated for these component scores by comparing the two minutes of artifact-free EEG data collected, starting at the 45 th second of the continuous performance test (CPT1), with the two minutes of artifact-free EEG data collected, starting at the 405th second (CPT2) of the task. These orthogonal component scores were used in multipleregression equations to predict performance scores. It was predicted that the PCA would allow the 40 variables to be reduced to a smaller set of components (i.e., less than 10), that these components would be reliable (i.e., testretest reliabilities greater than .80), and that they collectively would predict performance.

\section{Significance of the study}

The present study differs from previous research in a number of important ways. First, EEG was collected during a CPT condition rather than during a resting condition. It was expected that the CPT condition would standardize the participants' mental state and thus provide a more stable format for comparing relative-power and absolutepower reliability. The present study did not test the assumption that CPT provided more stable EEG scores than a resting condition. It did however, contrast relativepower and absolute-power reliability, and these results were compared to those results from other studies obtained during a resting condition. Second, the study allowed a rudimentary comparison of EEG and PET findings. PET 
studies have localized activity to particular areas of the brain during verbal tasks and during CPTs. The results of this study indicated whether, at the sites used in the present study, scalp EEG was sensitive to similar kinds of brain activity. Third, this study was unique in EEG literature in terms of providing a homogeneous group with an adequate sample size for conducting a PCA. EEG was collected from a variety of cortical regions and all wavebands were analyzed simultaneously. Finally, the study provided a mechanism for identifying the EEG components that were associated with attention and vigilance.

\section{Predictions}

Because of the need to identify the optimal variables for use in the subsequent analyses, the first set of predictions concerned the psychometric properties of the variables.

1. The $\log 10$ transformation would normalize absolute power and the $\log 10(x / 1-x)$ transformation would normalize relative power.

2. Absolute-power variables would be more reliable than relative-power variables.

3. Unit-weighted, normalized-deviation component scores derived from PCAs on absolute and relative-power variables would be reliable ( $\mathrm{rtt}>0.80$ ).

4. The detection index of CPT data would be the most reliable measure of CPT performance. 
The second set of predictions concerned the relationship between EEG variables and measures of vigilance.

5. The absolute power of beta activity during CPT1 in channels $1,2,3,4,5$ and 6 would increase over resting .

6. The absolute power of alpha and theta activity would decrease between resting and CPT.

7. Unit-weighted, normalized-deviation component scores from components consisting of absolute-power beta from channels $1,2,3,4,5$, and 6 would be predictive of level of performance during CPT1.

8. Changes in unit-weighted, normalized-deviation component scores from components consisting of absolutepower beta from channels 2 and 4 would be negatively correlated with performance change (i.e., as the number of omission errors increases beta would decrease).

9. Changes in unit-weighted, normalized-deviation component scores from components consisting of absolutepower beta from channels 7 and 8 would be negatively correlated with performance change.

10. Changes in unit-weighted, normalized-deviation component scores from components consisting of absolutepower theta and alpha from channels 7 and 8 would be positively correlated with performance change. 
Method

Subjects

Main study. Participants ( $\underline{\underline{N}}=102$ ) were selected from 298 consecutive cases drawn from an undergraduate psychology course and enrolled between october, 1989 and April, 1991. They reported no history of neurological conditions, birthing complications, or loss of consciousness greater than two minutes. Handedness was assessed using a modified version of the Edinburgh Handedness Inventory (Oldfield, 1971). Appendix A presents the modified Edinburgh Handedness Inventory. All participants were right-hand dominant for writing their names, with laterality quotients (Oldfield, 1971) between

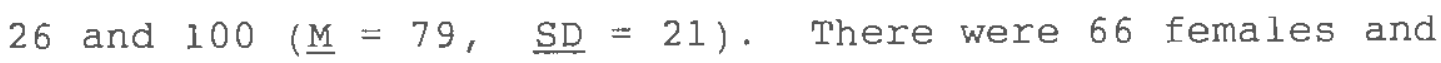
36 males, aged 17.7 years to 25.5 years $\langle\underline{M}=19.8, \underline{S D}=$ $1.49)$.

Test-retest reliability study. Participants for this study were 16 consecutive cases drawn from an undergraduate psychology course, enrolled during April, 1992. All participants were examined one week after their initial evaluations, at the same time of day, by the same team of technicians. All participants were right-hand dominant for writing their names; laterality quotients calculated from the initial evaluation ranged between 38 and $100(\underline{M}=78, \underline{S D}=17)$. There were 11 females and 5 males, aged 18.5 years to 23.2 years $(\underline{M}=19.8, \underline{\mathrm{SD}}=$ $1.28)$. 


\section{Apparatus}

EEG activity was recorded across eight bipolar channels (impedance < 10K ohm): channel $1=$ Fp1-F7, channel $2=\mathrm{Fp} 2-\mathrm{F} 8$, channel $3=\mathrm{F} 7-\mathrm{T} 3$, channel $4=\mathrm{F} 8-\mathrm{T} 4$, channel $5=\mathrm{T} 3-\mathrm{T} 5$, channel $6=\mathrm{T} 4-\mathrm{T} 6$, channel $7=\mathrm{T} 5-01$, channel $8=$ T6-02. Figure 1 illustrates the electrode positions which are in accordance with the 10-20

International Federation of Electroencephalography and Clinical Neurophysiology system (Jasper, 1958). A spectral analysis of the brain-wave activity from each of these sites was performed using a Fast Fourier Transformation. These analyses separated the complex wave forms into a series of simpler sine-wave frequency patterns or bands (i.e., delta $=1$ to $3.5 \mathrm{~Hz}$; theta $=3.5$ to $7.5 \mathrm{~Hz}$; alpha $=7.5$ to $12.5 \mathrm{~Hz}$; betal $=12.5$ to 17.5 $\mathrm{Hz}$; beta2 $=17.5$ to $25.0 \mathrm{~Hz}$ ) (Matousek \& Petersen, 1973). The spectral analysis was accomplished using a sentinal-8 System designed by Axon Inc., Deer Park, NY.

CPT performance was recorded via a button held in the participant's right hand and transcribed on a paper tape. The paper tape was compared with a template of the correct responses and hand scored.

\section{Procedure}

First, the task was explained to the participants, they completed informed consent forms, and answered a questionnaire on their medical history and hand preference. They were then asked to close their eyes and 
relax in a comfortable chair facing a blank wall. The lights were dimmed and 45 seconds later resting EEG data were collected. This continued until two minutes of artifact-free (on-line automatic artifacting) EEG was obtained.

Participants then listened to a computer-generated audio tape (presented from a speaker placed directly in front of them) and were instructed to press a button held in the right hand whenever a letter was presented twice in succession (CPT). Letters occurred with a sound onset-toonset interval of 0.5 seconds. Double-letter targets occurred at random intervals with an average of ten targets per minute. Forty-five seconds after the start of the CPT, EEG data collection began for CPTI and continued until two minutes of eyes-closed artifact-free EEG was obtained. Most participants completed this phase of the investigation after about three minutes. After 6.75 minutes of task performance, a second two-minute sample of artifact-free EEG (CPT2) was obtained.

The procedure for the reliability study was identical except that the sessions were discontinued after CPTl was collected. Before the participants began the second session they completed the handedness inventory.

\section{Design}

This study used a multiple-regression procedure to predict a behavioral measure (level of vigilance or vigilance decrement during a CPT) from a physiological 
measure (EEG collected during a CPT) (Hiscock \& Kinsbourne, 1987). There is disagreement in the literature as to which variables are the most valid measures of EEG and vigilance. These variables were evaluated using criteria of short-term reliability and predictability (ability to predict the behavioral measure) for the EEG measures and short-term and long-term reliability for the behavioral measures.

PCAs were used to reduce these sets of variables to more parsimonious, orthogonal components that then were entered into standard multiple regression equations. The size of the resulting $\underline{R}^{2}$ statistic was used to evaluate the extent to which the EEG components could predict performance on the CPT. The size of the zero order correlations was used to evaluate the predictability of a component within a set of components.

\section{Results}

This section begins with a description of the psychometric properties of the variables and their transformations (i.e., distribution and reliability) and the changes in brain-wave activity between tasks. The process of deriving components using a PCA and the psychometric properties of those components then is described. Finally, the results of the multipleregression equations, which used these components to predict performance on the CPT, are reported. 
Reliability of Measurements

Test-retest reliability scores were obtained for the laterality quotient and the various error indexes on the 16 participants from the test-retest reliability study. Because all these scores were normally distributed, the Pearson product-moment correlation coefficient (rtt) was used to calculate reliability. The handedness inventory was found to be reliable (rtt $=.93$ ). The reliabilities of the Omission Exror Index (rtt =.37), Detection Index (rtt $=.35$ ), and Error Index (rtt $=.33$ ) were all poor but roughly comparable.

\section{Transfoxmation of EEG Variables}

Table 1 provides a comparison of distributions of the two non-transformed and seven transformed distributions. Neither absolute-power (AP) variables nor relative-power (RP) variables were normally distributed. The loglo(AP) transformation produced the most normal distribution of absolute-power variables. The $\log 10(\mathrm{RP} / 1-\mathrm{RP})$ produced the most normal distribution of relative-power variables, although the arc sin square root of relative power was comparable with two fewer leptokurtic values and five more skewed values. Appendix B contains the descriptive statistics on the two non-transformed and seven transformed distributions. 
Table 1

Skewness and Kurtosis of the Various Transformations Transformation (N)

\begin{tabular}{|c|c|c|c|c|}
\hline Absolute Powera (AP) & 95 q & (38) & 1008 & $(40)$ \\
\hline $\log 10(A P)$ & $12.5 \%$ & (5) & 17.58 & $(7)$ \\
\hline $\log 10\left(\mathrm{AP}^{\prime}+1\right)$ & 27.5 웅 & (11) & 458 & $(18)$ \\
\hline$(\mathrm{AP}) 1 / 2$ & 808 & (32) & 92.5 g & $(37)$ \\
\hline $1 /(\mathrm{AP}) 1 / 2$ & 17.58 & $(7)$ & $35 \%$ & $(14)$ \\
\hline$(\mathrm{AP}) 1 / 3$ & 62.58 & $(25)$ & 77.58 & (31) \\
\hline Relative Power (RP) & 358 & $(14)$ & 57.5 용 & (23) \\
\hline Arc $\operatorname{Sin}(\mathrm{RP}) 1 / 2$ & 17.5 & $(7)$ & 308 & $(12)$ \\
\hline $\log 10(R P / 1-R P)$ & 22.58 & (9) & $17.5 \%$ & $(7)$ \\
\hline
\end{tabular}

Note, a all values greater than 0 .

Stevens (1986) provides formulas for calculating critical values for skewness and kurtosis. The critical value for skewness was calculated with the formula:

$+z=s[(N+1)(N+3) / 6(N-2)] 1 / 2$

where $\mathrm{z}=\mathrm{z}$ score; $\mathrm{s}=$ skewness; and $\mathrm{N}=$ sample size. The critical value for kurtosis was calculated with the formula:

$$
\begin{aligned}
& +z=[k-3+6 /(N+1)]\{[(N+1) 2(N+3)(N+5)] /[24 N(N \\
& -2)(N-3)]\} 1 / 2
\end{aligned}
$$

where $z=z$ score; $k=$ kurtosis; and $N=$ sample size. Because of the large number of tests (i.e., 2 tests times 40 variables) alpha was set at $.0005(\underline{z}=3.3)$. This follows the Bonferroni procedure and yields an overall type-I error rate of .04 (80 x .0005). With a 
sample size of 102 the critical value for skewness (equation 1 ) was +.777 . The critical values for kurtosis (equation 2) were calculated to be 4.30 and 1.45 . The formulas used by some statistical packages to evaluate kurtosis are different than the one used here and require that 3 be subtracted from the calculated critical values (Stevens, 1986). Therefore, the critical values used for these comparison were recalculated to 1.30 and -1.55 . None of the distributions were platykurtic. For the 40 (i.e., five bands by eight channels) non-transformed absolute-power distributions, 95 (38) were leptokurtic and $100 \%$ (40) were skewed. After a $\log 10$ transformation, $12.5 \%$ (5) of the absolute-power distributions were leptokurtic and $17.5 \%$ (7) were skewed. For the nontransformed relative-power distributions, 358 (14) were leptokurtic and $57.5 \%$ (23) were skewed. After a $\log 10(\mathrm{x} / 1-\mathrm{x})$ transformation $22.5 \%$ (9) were leptokurtic and $17.5 \%$ (7) were skewed. Table 1 shows the number of skewed and leptokurtic variables for each of the transformations. $\underline{\text { Reliability of Transformations }}$

Absolute-power variables were found to be significantly more reliable than relative-power variables. Table 2 shows six-minute test-retest reliabilities for each of the 40 EEG absolute-power variables (AP), relative-power variables (RP), $\log l 0(A P)$ variables (LAP), and $\log 10(\mathrm{RP} / 1-\mathrm{RP}$ ) variables (LRP). Reliability coefficients were calculated by correlating cPTl scores 
with CPT2 scores using both the Pearson product-moment correlation coefficient and spearman rho. Spearman rho is the more appropriate of the two statistics because, even after transformation, the distributions were not bivariate normal (Marascuilo \& McSweeney, 1977). Data for the Pearson product-moment correlation are presented to aid in comparison with previous research. Because the spearman rho is a rank ordered test, correlations would be identical for transformed and non-transformed scores. Therefore, only two spearman correlations were calculated; $A P$ and RP.

Because high correlations yield non-normal distributions, the non-parametric Sign test was used to compare the four sets (i.e., 40 correlation coefficients) of Pearson product-moment coefficients and the two sets of Spearman-rho coefficients. Among the Pearson product moment correlations, AP correlations were not different from LAP correlations (two tailed $\mathrm{p}=.749$ ) but were higher than RP (two tailed $\mathrm{p}<.01$ ). LAP correlations were higher than RP (two tailed $\mathrm{p}<.0001$ ) and LRP (two tailed $\underline{p}<.01)$. Spearman rho correlations of AP were higher than RP (two tailed $\underline{p}<.01$ ).

The consistency of the absolute and relative-power variables was compared using a double cross-validation design such as illustrated in Table 3. The sample of 102 participants was divided in half. A linear regression was used on the first 51 cases predicting CPT2 scores from 
CPT1 scores. This regression formula was applied to CPT1 scores from the second 51 cases. This calculated CPT2 score (CPT2') was correlated with the observed CPT2 score using Spearman's rho. This procedure was done on both AP and RP scores, resulting in two sets of correlations: CV.AP1 and CV.RP1.

In a similar fashion, a regression formula derived from the second group of 51 cases was used to calculate CPT2' in the first group. The Spearman rho correlations of CPT2' and CPT2 resulted in two sets of correlations: CV.AP2 and CV.RP2. CV.AP1 scores were not different than CV.RP1 scores (two tailed $p=.268$ ) but CV.AP2 scores were higher than CV.RP2 (two tailed $p<.01$ ). 
Table 2

Six-Minute (CPT1:CPT2) Test-Retest Correlations of Transformed and Non-Transformed EEG Variables

\begin{tabular}{|c|c|c|c|c|c|c|}
\hline Variable & $\begin{array}{l}A P \\
\text { Spea rman }\end{array}$ & $\begin{array}{l}\text { RP } \\
\text { rho }\end{array}$ & $\overline{A P}$ & $\begin{array}{c}\text { RP } \\
\text { Pearson }\end{array}$ & $\begin{array}{l}L(A P) \\
\underline{r}\end{array}$ & $\mathrm{~L}(\mathrm{RP})$ \\
\hline 1. Delta & .7348 & .6914 & .7292 & $.7 \overline{344}$ & .7535 & .7539 \\
\hline 2. Delta & .6125 & .6231 & .7305 & .6160 & .6698 & .6206 \\
\hline 3. Delta & .6844 & .6811 & .7247 & .7158 & .7016 & .7284 \\
\hline 4. Delta & .7196 & .6744 & .7407 & .7288 & .7516 & .7460 \\
\hline 5. Delta & .8873 & .9002 & .9393 & .9098 & .9147 & .9054 \\
\hline 6. Delta & .9191 & .8399 & .9422 & .8637 & .9309 & .8762 \\
\hline 7. Delta & .9622 & .8538 & .8737 & .9535 & .9535 & .9002 \\
\hline 8. Delta & .9357 & .8542 & .9317 & .8620 & .9457 & .8610 \\
\hline 1. Theta & .7827 & .7498 & .8240 & .7844 & .8075 & .7649 \\
\hline 2. Theta & .7574 & .6682 & .7758 & .7015 & .7719 & .6829 \\
\hline 3. Theta & .9014 & .7692 & .9120 & .7838 & .9190 & .7782 \\
\hline 4. Theta & .8278 & .7566 & .8725 & .7703 & .8769 & .7642 \\
\hline 5. Theta & .9265 & .8720 & .9685 & .8638 & .9550 & .8793 \\
\hline 6. Theta & .9361 & .8748 & .9412 & .8635 & .9542 & .8760 \\
\hline 7. Theta & .9465 & .8346 & .9460 & .8139 & .9559 & .8360 \\
\hline 8. Theta & .9480 & .8466 & .9347 & .8422 & .9501 & .8538 \\
\hline 1. Alpha & .8762 & .8233 & .9416 & .9091 & .9228 & .8424 \\
\hline 2. Alpha & .8789 & .7452 & .9449 & .7832 & .9163 & .7484 \\
\hline 3. Alpha & .9304 & .8583 & .9487 & .9018 & .9487 & .8995 \\
\hline 4. Alpha & .9436 & .8285 & .9472 & .8507 & .9539 & .8458 \\
\hline 5. Alpha & .9592 & .9393 & .9336 & .9438 & .9635 & .9402 \\
\hline 6. Alpha & .9500 & .9315 & .9533 & .9315 & .9570 & .9266 \\
\hline 7. Alpha & .9551 & .9282 & .9697 & .9425 & .9595 & .9440 \\
\hline 8. Alpha & .9358 & .9183 & .9047 & .9173 & .9374 & .9131 \\
\hline 1. Beta 1 & .7782 & .7252 & .9230 & .7429 & .8311 & .7831 \\
\hline 2. Beta 1 & .7829 & .6348 & .7939 & .6450 & .7869 & .6756 \\
\hline 3. Beta 1 & .8345 & .7284 & .8298 & .8122 & .8273 & .7917 \\
\hline 4. Beta 1 & .8085 & .6939 & .8333 & .7181 & .8097 & .7844 \\
\hline 5. Beta 1 & .9134 & 9212 & .8816 & .9182 & .9134 & .9138 \\
\hline 6. Beta 1 & .9024 & .8826 & .8889 & .8982 & .9109 & .9000 \\
\hline 7. Beta 1 & .8411 & .9129 & .7431 & .9029 & .8459 & .9130 \\
\hline 8. Beta 1 & .8910 & 8747 & .7409 & .8863 & .8811 & .8891 \\
\hline 1. Beta 2 & .7525 & .7543 & .7959 & .6856 & .8032 & .7581 \\
\hline 2. Beta 2 & .7223 & .6966 & .7963 & .6040 & .7356 & .6485 \\
\hline 3. Beta 2 & .7850 & .8078 & .8480 & .7906 & .8080 & .8091 \\
\hline 4. Beta 2 & .8007 & .8011 & .7534 & .7355 & .8062 & .8023 \\
\hline 5 . Beta 2 & .8107 & .8591 & .8277 & .8256 & .8300 & .8620 \\
\hline 6. Beta 2 & .8699 & .8832 & .8937 & .8690 & .8814 & .8845 \\
\hline 7. Beta 2 & .7875 & .8467 & .6351 & .8172 & .7610 & .8405 \\
\hline 8. Beta 2 & .8161 & .8714 & .8509 & .8759 & .8471 & .8881 \\
\hline
\end{tabular}

\footnotetext{
Note.1. Delta $=$ region 1 (left frontal) delta $(1-3.5 \mathrm{~Hz})$ 2. Theta = region 2 (right frontal) theta $(3.5-7.5 \mathrm{~Hz}$ ) 3.Alpha = region 3 (left fr.-temp.) alpha $(7.5-12.5 \mathrm{~Hz}$ ) 5. Betal = region 5 (left temporal) betal $(12.5-17.5 \mathrm{~Hz}$ ) 7 . Beta 2 region 7 (left temp-occip) beta 2 (17.5-25 Hz)
} 
Table 3

Double Cross-validated Correlations of Observed and Predicted CPT2 Scores Calculated From CPTl Scores

\begin{tabular}{|c|c|c|c|c|}
\hline & & & rho & \\
\hline & Absolute & Power & Relative & Power \\
\hline Variable & lst & $2 \mathrm{nd}$ & lst & $2 n d$ \\
\hline 1.Delta & .7823 & .6934 & .7800 & .5822 \\
\hline 2. Delta & .5951 & .6231 & .6299 & .5862 \\
\hline 3. Delta & .6914 & .6861 & .7358 & .6242 \\
\hline 4. Delta & .7037 & .7605 & .6992 & .6538 \\
\hline 5. Delta & .8267 & .9300 & .9036 & .8822 \\
\hline 6. Delta & .9207 & .9102 & .8500 & .8168 \\
\hline 7. Delta & .9626 & .9625 & .8485 & .8666 \\
\hline 8.Delta & .9454 & .9147 & .8393 & .8609 \\
\hline 1. Theta & .7232 & .8368 & .8044 & .6639 \\
\hline 2. Theta & .6829 & .8232 & .7375 & .5819 \\
\hline 3. Theta & .8422 & .9405 & .7279 & .8039 \\
\hline 4. Theta & .7218 & .8905 & .8186 & .7068 \\
\hline 5. Theta & .9567 & .8958 & .8736 & .8384 \\
\hline 6. Theta & .9448 & .9259 & .8912 & .8576 \\
\hline 7. Theta & .9471 & .9438 & .8106 & .8462 \\
\hline 8. Theta & .9411 & .9535 & .8633 & .8226 \\
\hline 1. Alpha & .8715 & .8751 & .8927 & .7379 \\
\hline 2.Alpha & .8499 & .8905 & .8117 & .6834 \\
\hline 3.Alpha & .9286 & .9265 & .8861 & .8213 \\
\hline 4. Alpha & .9318 & .9542 & .9074 & .7829 \\
\hline 5.Alpha & .9558 & .9506 & .9315 & .9205 \\
\hline 6. Alpha & .9282 & .9559 & .9285 & .9397 \\
\hline 7. Alpha & .9342 & .9643 & .9341 & .9032 \\
\hline 8.Alpha & .8907 & .9488 & .8969 & .9341 \\
\hline 1. Beta 1 & .7652 & .8055 & .7775 & .6528 \\
\hline 2. Beta 1 & .7870 & .7728 & .6563 & .6159 \\
\hline 3. Beta 1 & .8122 & .8948 & .6350 & .8150 \\
\hline 4. Betal & .7761 & .8358 & .5741 & .7931 \\
\hline 5. Beta 1 & .9099 & .9218 & .8970 & .9394 \\
\hline 6. Betal & .9390 & .8731 & .9046 & .8591 \\
\hline 7. Beta 1 & .8849 & .8025 & .9169 & .9024 \\
\hline 8. Beta 1 & .9161 & .8813 & .8461 & .8936 \\
\hline 1. Beta 2 & .7227 & .7617 & .7276 & .7670 \\
\hline 2. Beta 2 & .7373 & .7091 & .7008 & .6920 \\
\hline 3. Beta 2 & .7600 & .8140 & .7775 & .8344 \\
\hline 4. Beta 2 & .8003 & .8032 & .7552 & .8266 \\
\hline 5. Beta 2 & .8372 & .7908 & .8580 & .8472 \\
\hline 6. Beta 2 & .9141 & .8308 & .8820 & .8755 \\
\hline 7. Beta 2 & .7608 & .7949 & .8097 & .8451 \\
\hline 8. Beta 2 & .8306 & .8107 & .8693 & .8816 \\
\hline
\end{tabular}

Note, CPTl scores were used to predict CPT2. Predicted CPT2 correlated with observed CPT2, lst = First half of sample used to derive the regression formula. 2 = Second half of sample used to derive the regression formula. 


\section{The Effect of Unreliable Variables on Calculations of}

\section{Relative Power}

Removal of the four least reliable absolute-power variables from the calculation of relative power improved the reliability of the remaining relative-power variables. The four variables with the lowest spearman reliabilities were identified: 2. Delta $=.6125,3$. Delta $=.6844,4$. Delta $=.7196,2$. Beta $2=.7223$. To ensure that the method of calculating relative power was consistent within the comparison, new relative-power reliability scores were calculated (note the differences due to rounding error). Adjusted relative-power scores were calculated by dividing the absolute power of a score by the sum of the absolutepowers of the other scores at that region, without the deleted score. Table 4 shows that for the Spearman correlations, 12 of the 16 reliability scores rose when the four unreliable scores were removed. Removal of the unreliable scores improved the reliability of the other scores (two tailed $\underline{p}<.05$ ). 
Table 4

Changes in Relative Power Reliability After Removal of one Unreliable Variable

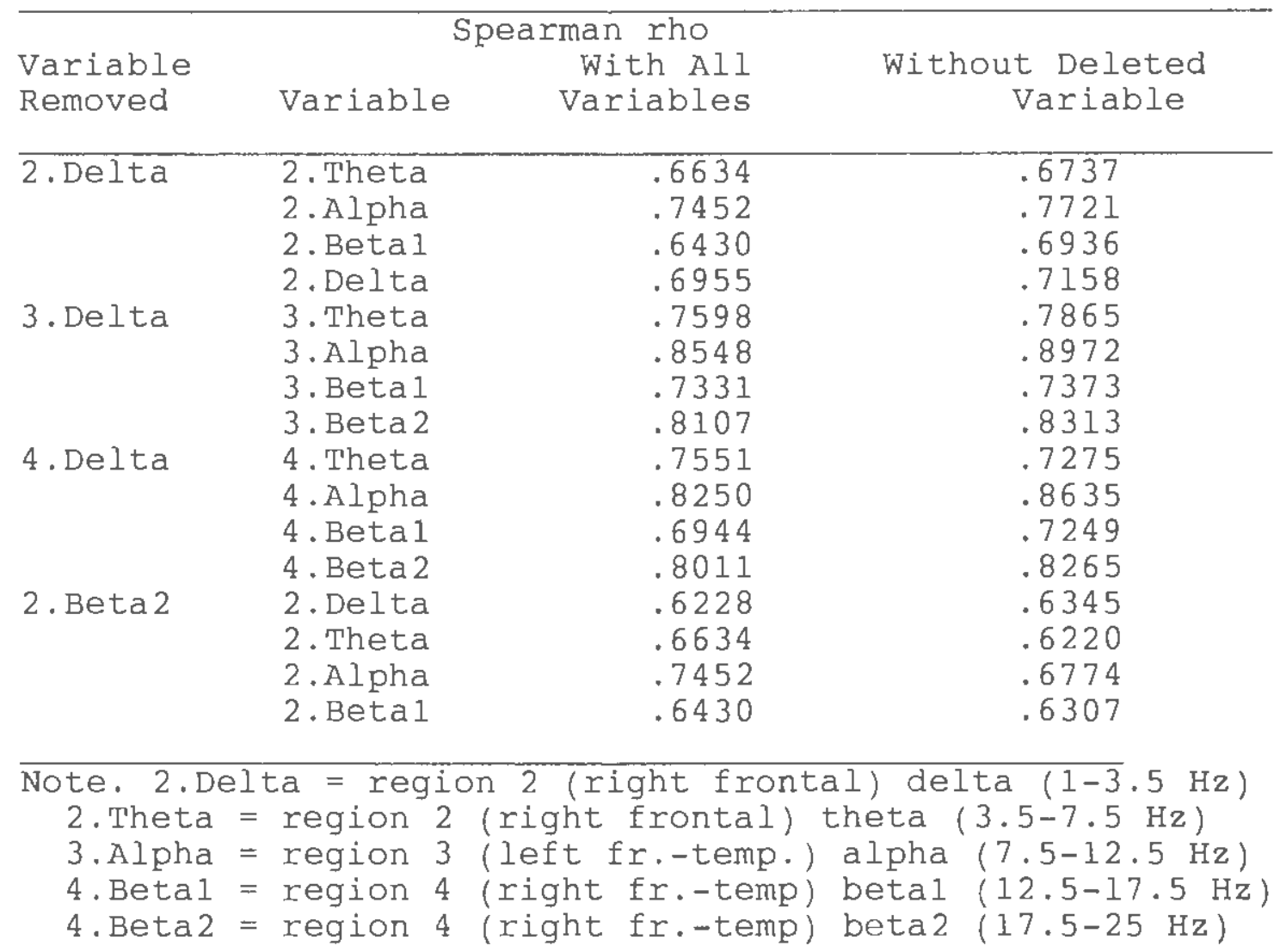


Changes in Levels of Brain-Wave Activity between Resting and the CPT Task

Changes seen in the level of brain wave activity between resting and the CPT are presented in Table 5. In order for a regional difference to be considered significant, dependent t-tests for Resting - CPT1 had to be significant at the .001 level. This resulted in an overall probability level of $.04(.001 \times 40$ variables $=$ $.04)$. According to this criterion, activity in a number of bands increased significantly between resting and the CPT1. These included frontal delta, fronto-temporal delta, frontal theta, left fronto-temporal betal, left and right fronto-temporal beta2, left temporal beta2, and left occipital beta2. Left temporal theta, occipital theta, fronto-temporal alpha, and temporal alpha decreased significantly between resting and the CPTs . 
Table 5

Differences in Level of EEG Activity

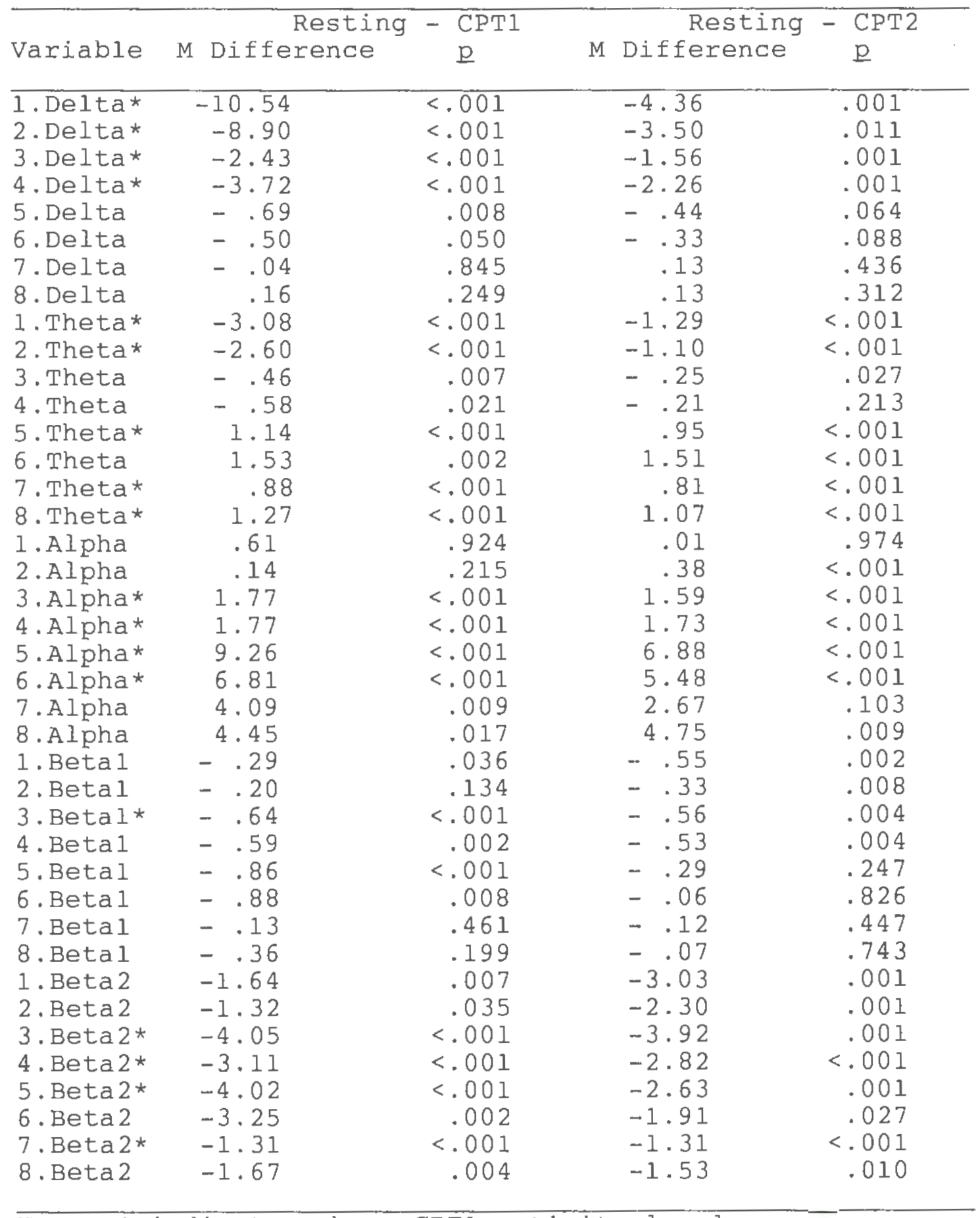

Note. * indicates where CPTl activity levels was significantly different than resting at the .04 level $(.001 \times 40=.04)$ 


\section{Principal Components Analysis}

The choice of a PCA. PCA was used to reduce the dimensionality of the 40 EEG variables. It has been demonstrated that there is little difference between the solutions derived from factor analyses and principal components analyses (Fava \& Velicer, in press a; Gasser et al., 1983; Schenk et al., 1982; Velicer, 1974; Velicer, 1977; Velicer \& Fava, 1987, 1990; Velicer, Peacock, \& Jackson, 1982). In the present study (where computational demands were limited and reliable criteria were employed for determining the number of factors/components to extract) there were few practical implications to choosing a principal-components versus a factor analysis (Velicer \& Jackson, 1990).

Sample size and component saturation. As a result of the high average loadings, a sample size of 102 was deemed adequate for deriving a reliable PCA solution. Many rules have been suggested for determining the minimum sample size needed for deriving stable and reliable component patterns that would replicate those derived from the population. Using a data simulation study, Guadagnoli and Velicer (1988) demonstrated that component saturation and sample size were the two most important parameters in determining pattern stability. Patterns in which there were more variables per component also tended to be more stable. Neither type-I errors, that is, the incorrect demonstration of a salient loading, nor type-II errors, 
that is, the failure to identify a salient loading,

occurred with sample sizes greater than 100 and saturation levels greater than or equal to .60 .

Table 6

Number of Complex and Unique Absolute-Power (AP) Variables Resulting From Extracting \# Components at .60 and .50 Salience Levels

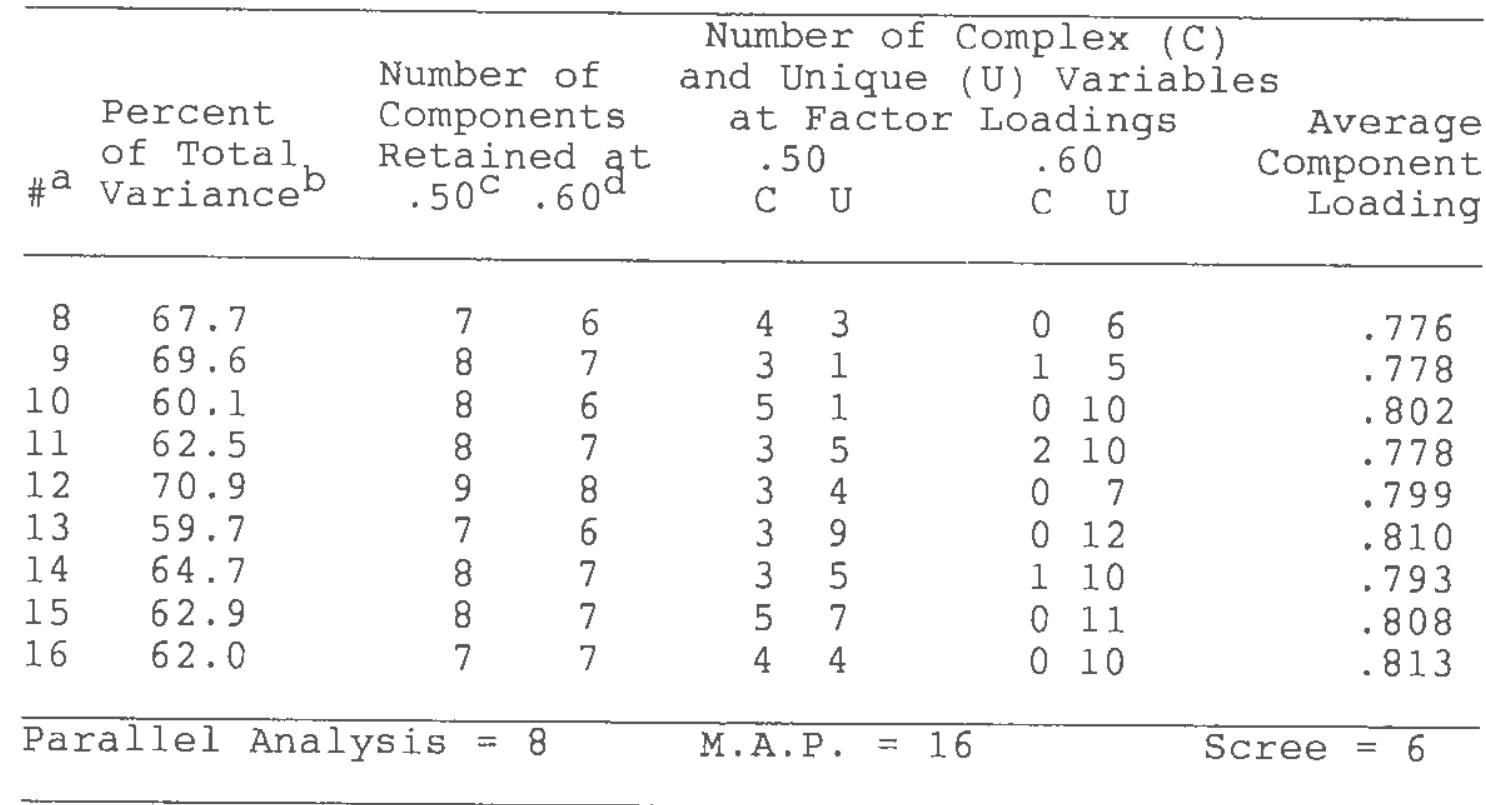

\footnotetext{
a Number of components extracted

b percent of total variance explained after retaining components with $>2$ variables loading at .60

$c$ Number of components retained with $>2$ variables

d loading at .50 or greater

d Number of components retained with > 2 variables loading at .60 or greater
}

A number of investigators (Anderson \& Rubin, 1956; Velicer \& Fava, 1987,1990; Zwick \& Velicer, 1986) have suggested that components with less than three high loadings should not be interpreted. Thus, rather than recalculate the PCA with a smaller component solution, components with less than three variables loading at .60 or greater were discarded. Tables $6,7,8$, and 9 show 
that the average loadings for all of the PCA solutions were quite high, ranging from .737 to .810. This suggests that the sample size ( $\underline{N}=102)$ was sufficient to allow the reliable identification of components.

Table 7

Number of Complex and Unique Log(AP) Variables, Resulting From Extracting \# Components at .60 and .50 salience Levels

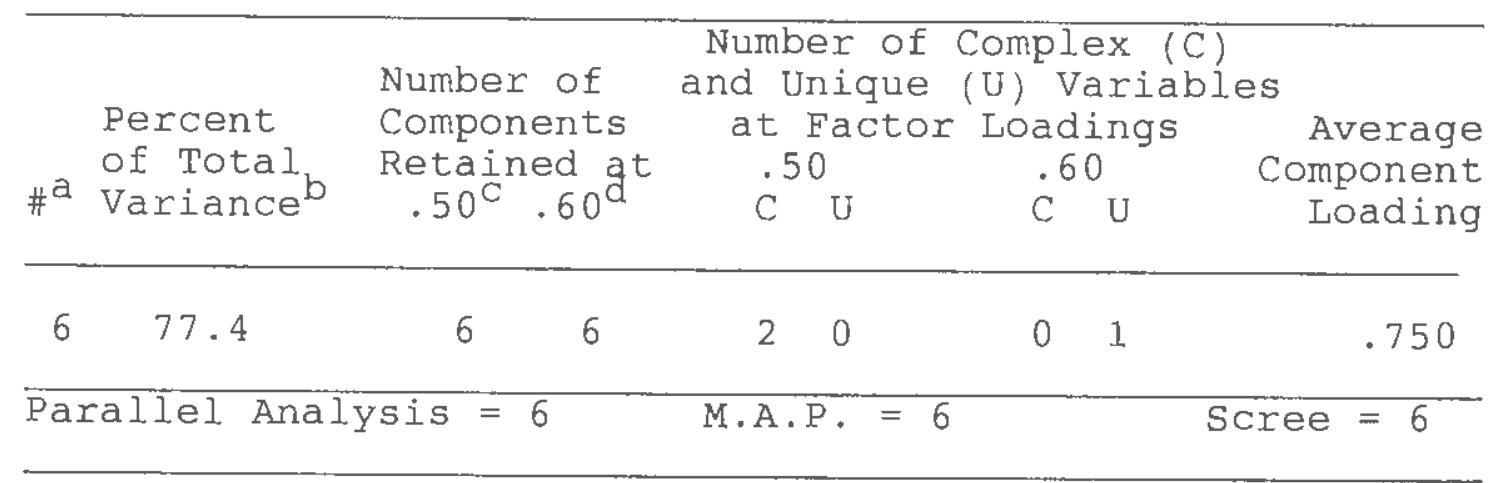

\footnotetext{
a Number of components extracted

b Percent of total variance explained after retaining components with $>2$ variables loading at .60

$c$ Number of components retained with $>2$ variables doading at . 50 or greater

$\mathrm{d}$ Number of components retained with $>2$ variables loading at .60 or greater
} 
Table 8

Number of Complex and Unique Relative Power (RP)

Variables, Resulting From Extracting \# Components at .60 and .50 Salience Levels

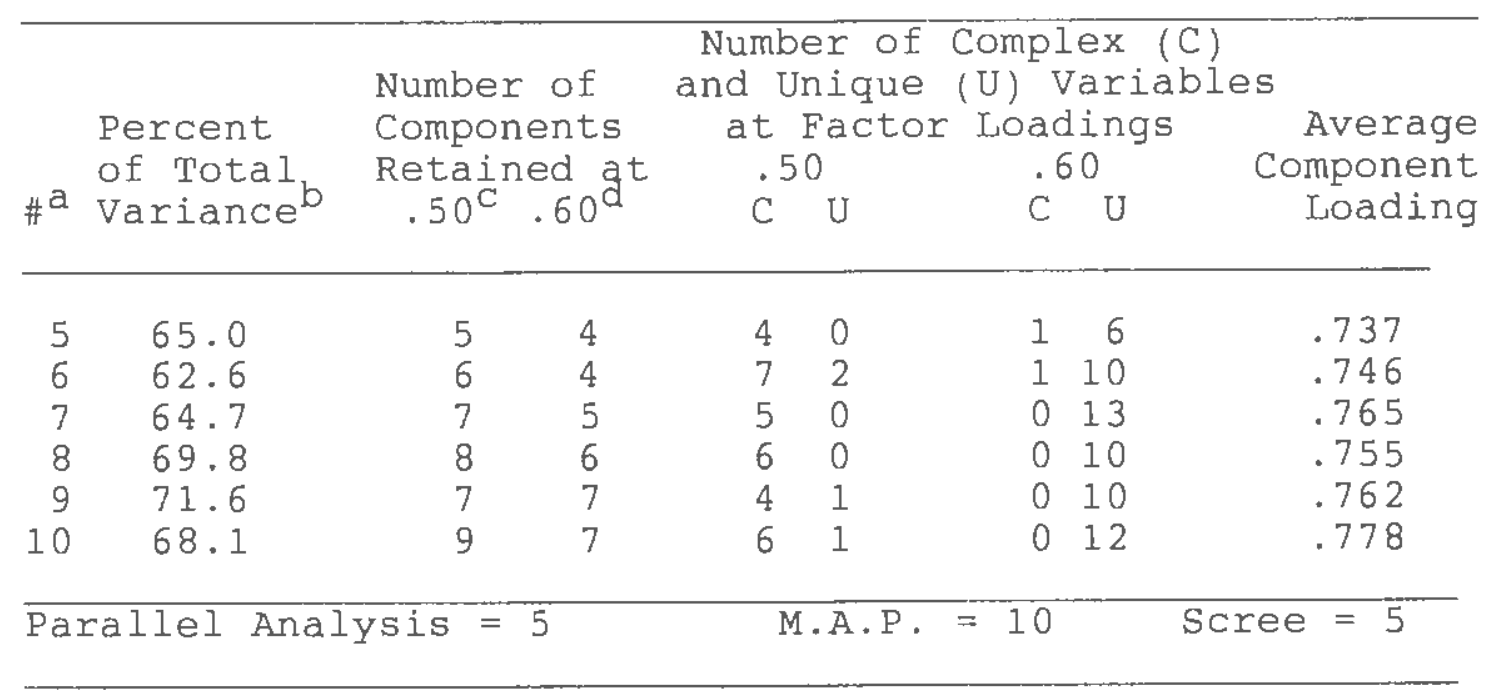

\footnotetext{
a Number of components extracted

$b$ percent of total variance explained after retaining components with $>2$ variables loading at .60

C Number of components retained with $>2$ variables loading at .50 or greater

d Number of components retained with > 2 variables loading at .60 or greater
} 
Table 9

Number of Complex and Unique Logl0((RP/(1-RP) Variables, Resulting From Extracting \# Components at.60 and .50 Salience Levels

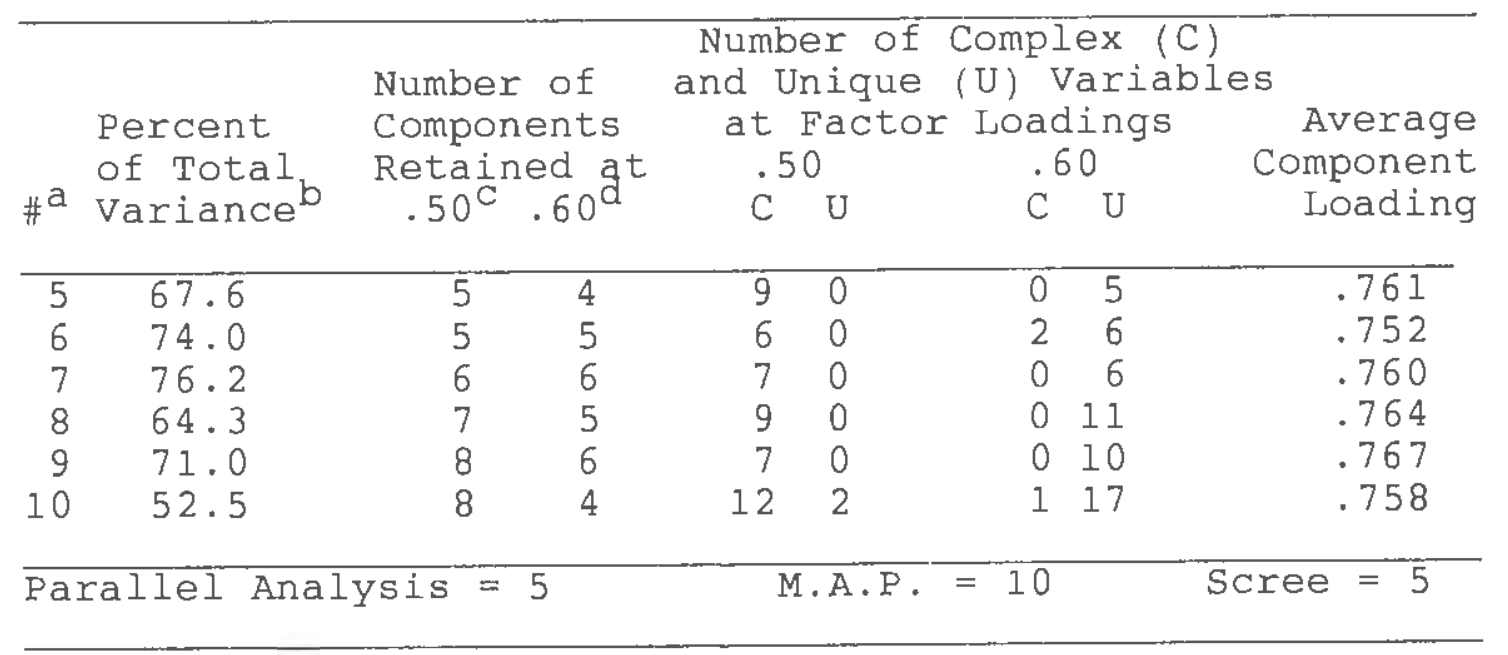

a Number of components extracted

$b$ Percent of total variance explained after retaining components with $>2$ variables loading at .60

C Number of components retained with $>2$ variables loading at . 50 or greater

d Number of components retained with $>2$ variables loading at .60 or greater

Correlation or covariance matrix. Correlation

matrices were used for the PCAs. A PCA may be done on a covariance matrix if the variables are all in the same metric and if the variances do not differ significantly. As can be seen in Appendix Bl, however, there are marked differences among variances. For example, the variance for region six, absolute-power alpha waves (6.Alpha) was 2111.23 , whereas the variance for region two, absolutepower beta 1 (2.Betal) was only 1.95 . Moreover, it theoretically is unlikely that a 2 microvolt change in an alpha variable is equivalent to a 2 microvolt change in theta. Therefore, it was necessary to use standardized scores as provided with the correlation matrix. 
Determining the number of components to retain using empirical criteria. Absolute-power variables (AP), relative-power variables (RP), $\log 10(A P)$, and $\log 10(R P / 1-$ RP) collected during CPT1 were subjected to a PCA using CAX (Velicer, Fava, Zwick, \& Harrop, 1988). Components Analysis Extended (CAX) calculates Parallel Analysis (PA) (Allen \& Hubbard, 1986) and Minimum Average Partial (MAP) (Velicer, 1976) scores. Scree criteria were calculated by hand. Tables $6,7,8$, and 9 summarize the results of these analyses. PA, MAP, and scree all agreed on a sixcomponent solution for $\log 10(A P)$. In the other three cases, $\mathrm{PA}$ and scree indicated somewhat similar results whereas MAP suggested retaining twice the number of components as PA.

Problems associated with underextraction (i.e., loss of important information) or overextraction followed by rotation (i.e,, low reliability and uninterpretability) make accurate identification a crucial stage in a PCA (Zwick \& Velicer, 1986). Fava and Velicer (in press b) demonstrated that PCA solutions were degraded when overextraction occurred. They found that clear factor patterns with high loadings (i.e., greater than .40) and simple factor patterns (i.e., few mixtures of high and low loadings) appeared to be robust to overextraction. Degradations were most pronounced with small sample sizes and low loadings after three overextractions. 
Three decision rules were used to determine the number of components to extract. In the scree test (Cattel, 1966), eigenvalues falling above a line drawn through a plot of the smaller values are retained. The scree test has a tendency to overestinate the number of components to retain with low component saturation or when there are unique or complex variables (Zwick \& Velicer, 1986). MAP (Velicer, 1976) identifies all components above the one that consists of only one variable. This unique component is indicated by an increase in the average squared partials after the extraction of that component. Under conditions of low component saturation and few variables per component, MAP tended to underestimate the number of components (Zwick \& Velicer, 1986). In PA (Horn, 1965), eigenvalues of a correlation matrix of uncorrelated variables of the same sample size are compared with the obtained eigenvalues. Eigenvalues greater than those from the random matrix are retained. PA was found to be the most accurate of the three methods having a slight tendency towards overestimation (Zwick \& Velicer, 1986).

Determining the number of components to retain using theoretical criteria. The range of solutions suggested by the three empirical criteria also was evaluated from a theoretical standpoint. The .60 salience level was chosen instead of a .50 cutoff level. Ten of the 22 possible solutions were selected for further analysis in the 
multiple-regression stage. These included the 5-, 7-, 8-, and 10-component solutions for relative power; the $5-, 7-$, and 9-component solutions for log-transformed relative power; the 8- and 12-component solutions for absolute power; and the 6-component solution for log-transformed absolute power.

First, the implications of choosing a .60 rather than a .50 cutoff for salience loading are demonstrated in Tables 6, 7, 8, and 9. Any component that did not have at least three variables loading at the cutoff level was dropped. Using a salience cutoff of .50 instead of .60 generally led to the retention of one or two more components. In addition, the number of complex variables, that is, variables that loaded highly on more than one component (Zwick \& Velicer, 1986) increased. At the same time, the number of unique variables, that is, those that loaded on only one component with no other variables loading on the same component (Zwick \& Velicer, 1986), decreased. Variables with only one other variable loading on the same component also were considered unique. According to the criterion of three or more salient loadings, these components also would be dropped. The .60 level was selected for use because of replicability concerns due to a relatively small sample size. In addition, it was assumed that there would be redundancy in the information contained in the 40 variables. Thus, dropping unique varjables (12.58 to 
32.58 of the variables) was not expected to be problematic.

All of the component patterns for the range of solutions suggested by the three rules were plotted out and compared. The plots are presented in Figures 2, 3, 4, $5,6,7$ and Appendix C. Solutions were selected for the multiple regression if (a) they were theoretically significant, (b) they sumarized the other solutions (i.e., contained stable component patterns observed in solutions that were not going to be analyzed), (c) they added to the explained variance, or (d) they provided additional components for analysis. When ambiguous, solutions were included rather than eliminated from further analysis. This resulted in the selection of five solutions from relative power, four from $\log 10(\mathrm{RP} / 1-\mathrm{RP})$, two from absolute power, and one from $\log 10(\mathrm{AP})$. 


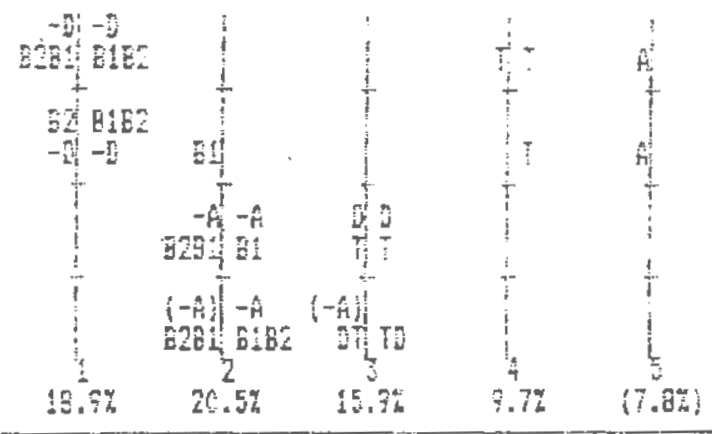

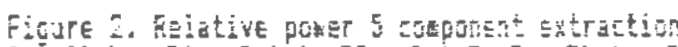

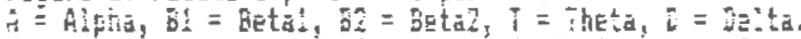

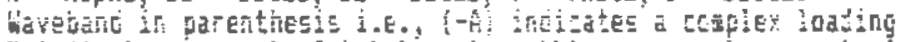

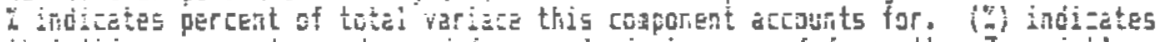

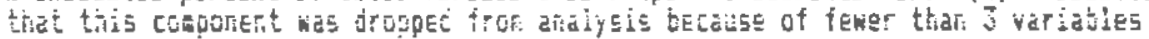
ioacing at sot or greater.

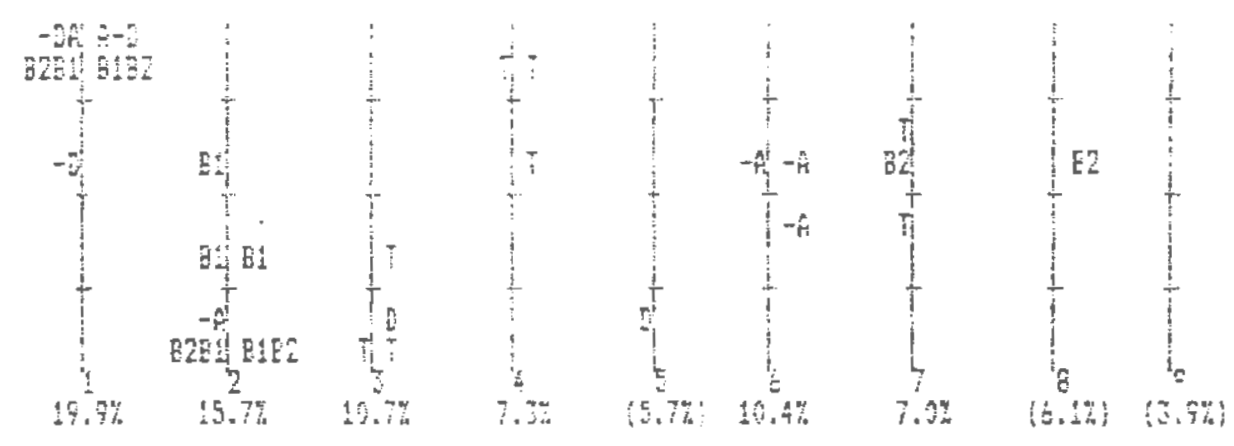

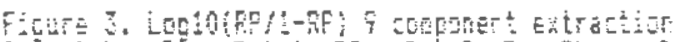

A E E E

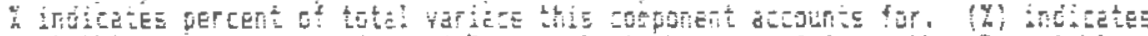

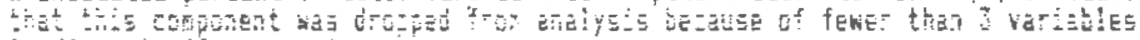

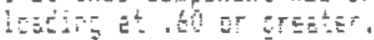




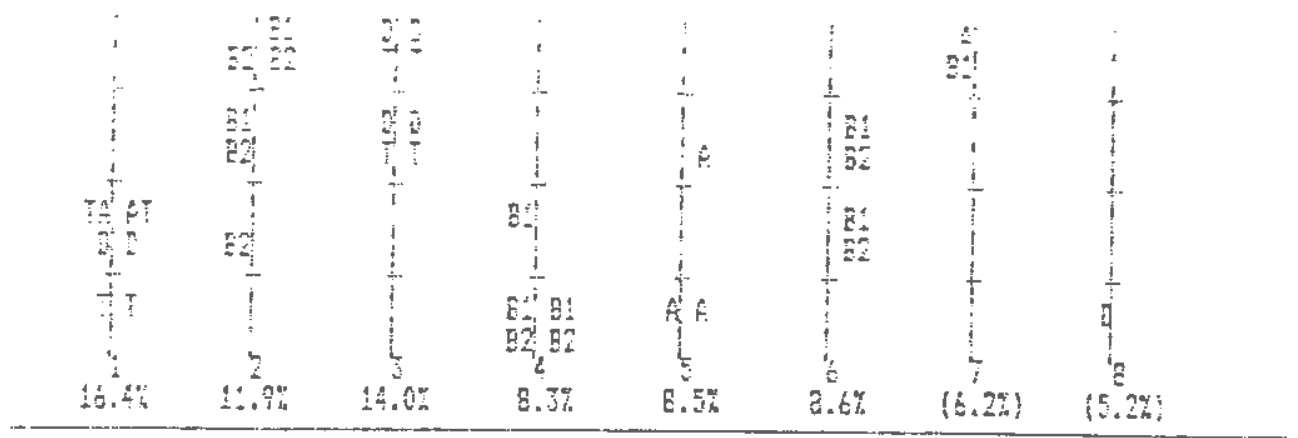

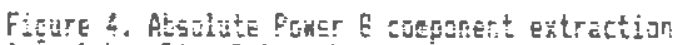

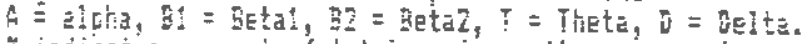

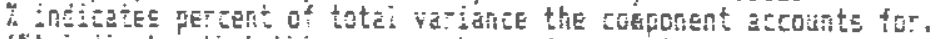

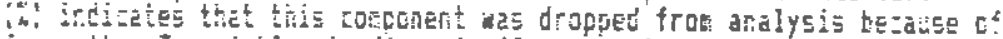

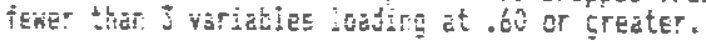
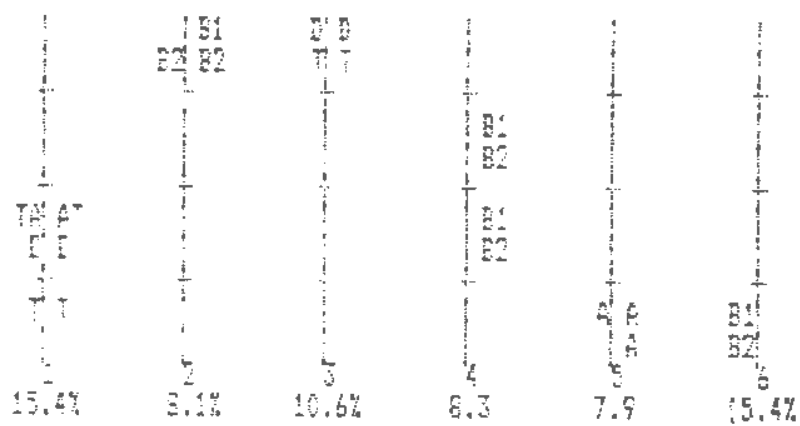

7.9

$(5,47)$
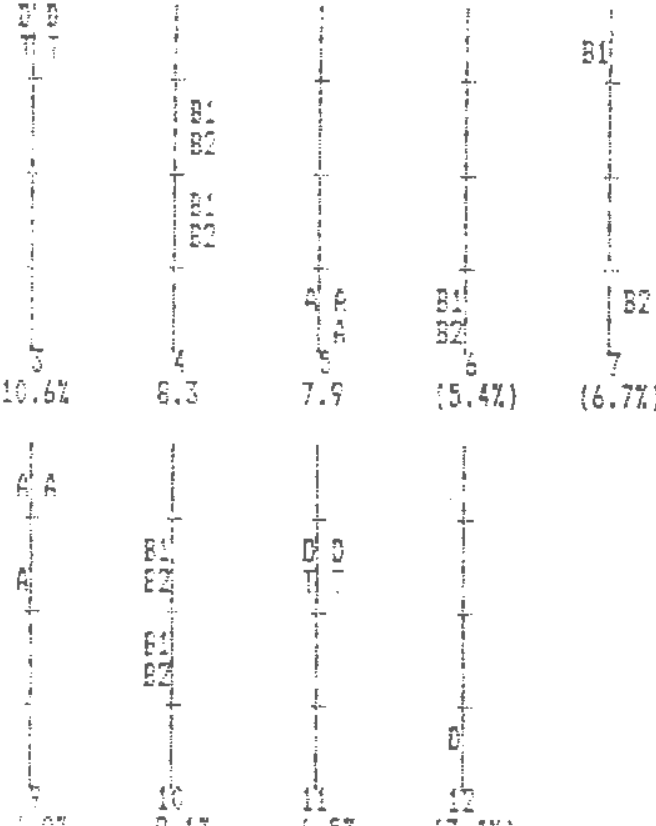

:

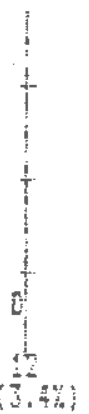

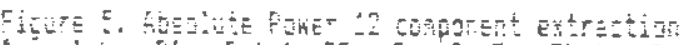

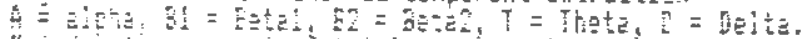

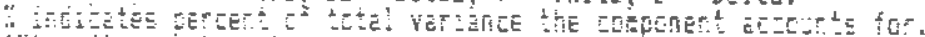

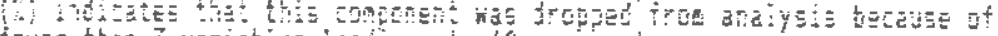

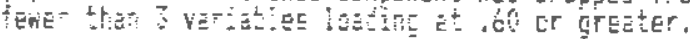




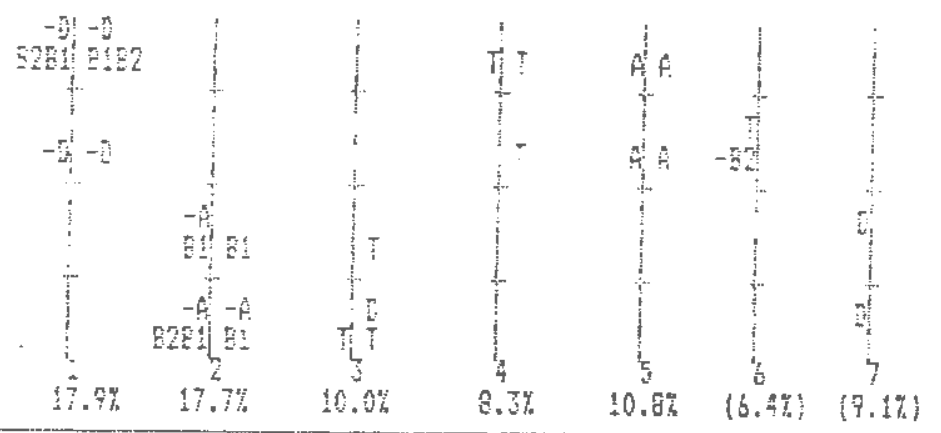

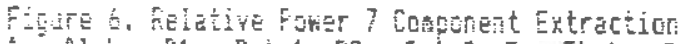

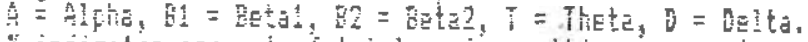

o

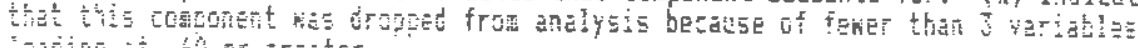

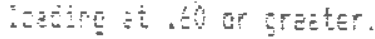

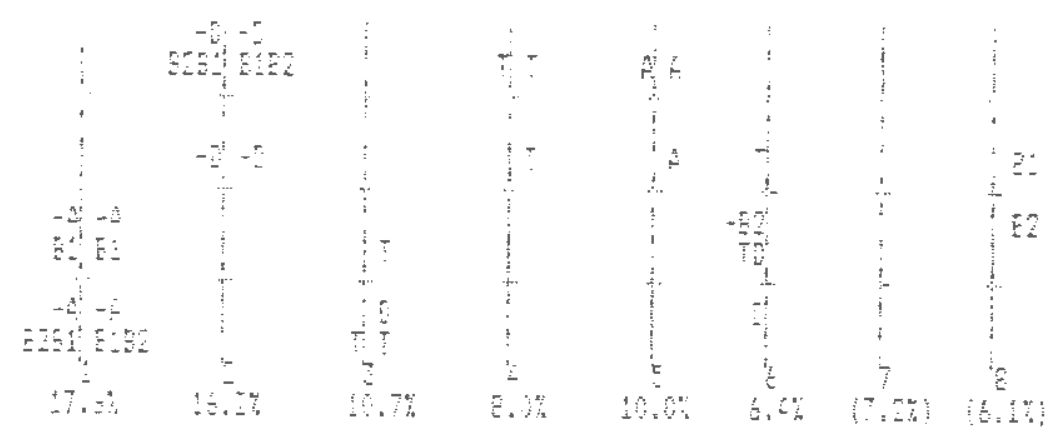

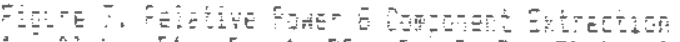

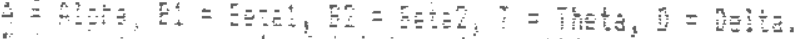

it

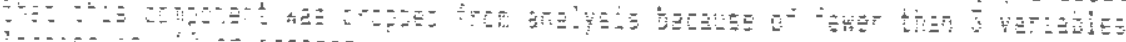

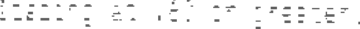




\section{Calculating Scores}

Component scores were derived by unit weighting (Fava \& Velicer, in press a) normalized deviation scores (Fava \& Velicer, in press b). A participant's component scores were calculated by summing the person's z-scores on the variables that loaded at .60 or greater. The z-scores were multiplied by 1 or -1 , depending on whether the loading of the variable on the component was positive or negative.

Using the conservative criteria employed previously for identifying skewed and kurtotic variables, Table 10 shows that all of the absolute-power component scores were found to be skewed and kurtotic. Many of the other component scores were nearly normaliy distributed. The most notable exception was the ten-component, relativepower solution (RPlO) where four component scores were positively skewed, one was negatively skewed, and one was leptokurtic. Appendix B contains descriptive statistics of the component scores of relative power (RP) and $\log 10$ (RP/1-RP) (LRP) and of absolute-power (AP) and $\log 10(A P)$ (LAP) variables. 
Table 10

Skewness and Kurtosis of the Component scores From the Various Extractions

\begin{tabular}{lrrrr}
\hline $\begin{array}{l}\text { Extraction } \\
\text { (N) }\end{array}$ & kurtotic & $(\mathrm{N})$ & s & Skewed \\
& & & & \\
\hline AP8 & 1008 & $(6)$ & 1008 & $(6)$ \\
AP12 & 1008 & $(8)$ & 1008 & $(8)$ \\
LAP6 & 178 & $(1)$ & 178 & $(1)$ \\
RP5 & 08 & $(0)$ & 08 & $(0)$ \\
RP7 & 08 & $(0)$ & 208 & $(1)$ \\
RP8 & 178 & $(1)$ & 08 & $(0)$ \\
RP10 & 148 & $(1)$ & 718 & $(5)$ \\
LRP5 & 258 & $(1)$ & 08 & $(0)$ \\
LRP7 & 178 & $(1)$ & 178 & $(1)$ \\
LRP9 & 08 & $(0)$ & 08 & $(0)$ \\
& & & &
\end{tabular}

Note. AP8 $=8$ component extraction Absolute Power

LAP6 = 6 component extraction Log10(AP)

RP5 $=5$ component extraction Relative Power

LRP5 = 5 component extraction Log (RP/l-RP)

\section{Component Reliability}

Because of the non-normality of the component scores Spearman rho correlations were used to evaluate reliability. Tables $11,12,13$, and 14 show the sixminute test-retest spearman correlation coefficients that were calculated for the set of components by correlating component scores from CPT1 with the component scores from CPT2, Twenty five percent of the AP12 components, $17 \%$ of the AP8 components, and 338 of the LAP6 components had correlations less than .80 and greater than .70. Twentynine percent of the RP10 components, $33 \%$ of the RP 8 components, $40 \%$ of the RP7 components, $50 \%$ of the RP5 components, 33\% of the LRP9 components, $33 \%$ of the LRP7 components, and 508 of the LRP 5 comporents had correlations between .62 and .76 . Test-retest correlations of the remaining components were above .80 . 
Table 11

Six-Minute Test-Retest Reliability of Absolute Power (AP) Component Scores (CPT1:CPT2) Spearman rho Correlations

\begin{tabular}{lccc}
\hline Component & rho & Component & rho \\
\hline 12.1 & .9387 & 8.1 & .9387 \\
12.2 & .7658 & 8.2 & .8115 \\
12.3 & .7130 & 8.3 & .7668 \\
12.4 & .8622 & 8.4 & .8678 \\
12.5 & .9480 & 8.6 & .8622 \\
12.9 & .9162 & & \\
12.10 & .8615 & & \\
12.11 & .8032 & &
\end{tabular}

Note. $8.1=$ component 1 of the AP 8 component extraction.

Table 12

Six-Minute Test-Retest Reliability of Logl0(AP) Component Scores (CPT1:CPT2) Spearman rho Correlations

\begin{tabular}{cc}
\hline Component & rho \\
\hline 6.1 & .9578 \\
6.2 & .7750 \\
6.3 & .7565 \\
6.4 & .8510 \\
6.5 & .8589 \\
6.6 & .9375
\end{tabular}

Note. $6.1=$ component 1 LAP 6 component extraction.

Table 13

Six-Minute Test-Retest Reliability of Relative Power (RP) Component Scores (CPT1:CPT2) Spearman rho Correlations

\begin{tabular}{lccccccc}
\hline Comp. & rho & Comp. & rho & Comp. & rho & Comp. & rho \\
\hline 10.1 & .6703 & 8.1 & .9288 & 7.1 & .6307 & 5.1 & .6498 \\
10.2 & .9035 & 8.2 & .6307 & 7.2 & .9274 & 5.2 & .9234 \\
10.3 & .8931 & 8.3 & .8721 & 7.3 & .8721 & 5.3 & .9104 \\
10.4 & .7559 & 8.4 & .7559 & 7.4 & .7559 & 5.4 & .7559 \\
10.5 & .8099 & 8.5 & .8134 & 7.5 & .8099 & & \\
10.6 & .8069 & 8.6 & .8385 & & & & \\
10.9 & .9097 & & & & &
\end{tabular}

Note. $5.1=$ component 1 of the RP 5 component extraction. 
Table 14

Six-Minute Test-Retest Reliability of Logl0(RP/1-RP)

Component Scores (CPT1:CPT2) Spearman rho Correlations

\begin{tabular}{lccccc}
\hline Comp. & rho & Comp. & rho & Comp. & rho \\
\hline 9.1 & .6226 & 7.1 & .6232 & 5.1 & .6290 \\
9.2 & .9142 & 7.2 & .9118 & 5.2 & .9315 \\
9.3 & .8632 & 7.3 & .8668 & 5.3 & .8978 \\
9.4 & .7498 & 7.4 & .7498 & 5.4 & .7498 \\
9.6 & .8842 & 7.6 & .8825 & & \\
9.7 & .8114 & 7.7 & .8114 & &
\end{tabular}

Note. $9.1=$ component 1 of the LRP 9 component extraction.

Six-Minute T'est-Retest Reliability of Performance Measures

Table 15 shows test-retest reliability scores for the various error indexes obtained on the 102 participants by correlating performance scores from CPT1 with performance scores from CPT2. Error indexes were normally

distributed. Pearson product-moment correlation

coefficients (rtt) were used to calculate reliability.

The reliability of the omission Error Index ( ${ }^{\text {tt }}=.48$ ),

Detection Index $\left(r^{t t}=.48\right)$, and Error Index $\left(r^{t t}=.49\right)$

were all poor but roughly comparable. 
that two of the components, RP5.4 and LRP9.4 were correlated with performance at the .05 level.

Table 16

Multiple Regression Results

\begin{tabular}{|c|c|c|c|c|c|c|c|c|}
\hline \multirow[b]{2}{*}{ Extractio } & \multicolumn{2}{|c|}{ Omission } & \multicolumn{2}{|c|}{$\begin{array}{l}\text { Errors CPTl } \\
\text { Significant } \\
\text { Components }\end{array}$} & \multicolumn{2}{|c|}{ Error } & \multicolumn{2}{|c|}{$\begin{array}{r}\text { Change CPTI-CPT2 } \\
\text { Significant } \\
\text { Components }\end{array}$} \\
\hline & $n \quad \underline{E}$ & $\mathrm{p}$ & \# & $\mathrm{p}$ & & E & \# & $\mathrm{p}$ \\
\hline $\begin{array}{l}\overline{A P B} \\
\mathrm{AP} 12\end{array}$ & $\begin{array}{l}.04 \\
.08\end{array}$ & $\begin{array}{l}.64 \\
.42\end{array}$ & & & $\begin{array}{l}.08 \\
.13\end{array}$ & $\begin{array}{l}.21 \\
.10\end{array}$ & $\begin{array}{r}\operatorname{AP} 8.6 \\
\operatorname{AP} 12.2 \\
\operatorname{AP} 12.4\end{array}$ & $\begin{array}{l}.039 \\
.020 \\
.048\end{array}$ \\
\hline LAP 6 & .03 & .83 & & & .06 & .42 & & \\
\hline $\begin{array}{l}\text { RP5 } \\
\text { RP7 } \\
\text { RP8 } \\
\text { RP10 }\end{array}$ & $\begin{array}{l}.06 \\
.07 \\
.09 \\
.09\end{array}$ & $\begin{array}{l}.20 \\
.23 \\
.16 \\
.27\end{array}$ & RP5. 4 & .036 & $\begin{array}{l}.03 \\
.05 \\
.09 \\
.05\end{array}$ & $\begin{array}{l}.52 \\
.38 \\
.17 \\
.69\end{array}$ & $\begin{array}{l}\operatorname{RP7} .3 \\
\operatorname{RP} 8.3\end{array}$ & $\begin{array}{l}.047 \\
.017\end{array}$ \\
\hline $\begin{array}{l}\text { LRP } 5 \\
\text { LRP } 7 \\
\text { LRP } 9\end{array}$ & $\begin{array}{l}.05 \\
.07 \\
.06\end{array}$ & $\begin{array}{l}.25 \\
.33 \\
.39\end{array}$ & LRP9. 4 & .046 & $\begin{array}{l}.03 \\
.07 \\
.07\end{array}$ & $\begin{array}{l}.61 \\
.29 \\
.29\end{array}$ & & \\
\hline
\end{tabular}

Note. AP $8.6=$ component 6 of the AP 8 component extraction. RP5. $4=$ component 4 of the RP 5 component extraction.

Table 17

Standard Multiple Regression of Component Scores From Five Component Relative Power Extraction or Omission Errors in CPT1

\begin{tabular}{|c|c|c|c|c|c|c|}
\hline Comp. & $\begin{array}{l}\text { Omissions } \\
\text { (DV) }\end{array}$ & 5.4 & 5.3 & 5.2 & Beta & $\begin{array}{l}\text { Semi Partial } \\
\text { Correlation }\end{array}$ \\
\hline $\begin{array}{l}5 \cdot 4 \\
5 \cdot 3 \\
5 \cdot 2 \\
5.1\end{array}$ & $\begin{array}{r}-.166 \\
.073 \\
-.061 \\
-.085\end{array}$ & $\begin{array}{l}-.117 \\
-.100 \\
-.193\end{array}$ & $\begin{array}{r}.293 \\
-.117\end{array}$ & .409 & $\begin{array}{r}-.218891 \\
.139402 \\
-.093938 \\
-.072856\end{array}$ & 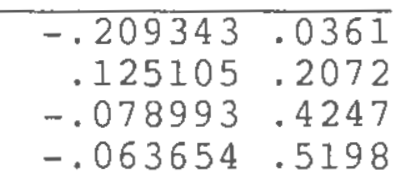 \\
\hline \multicolumn{3}{|c|}{$\begin{array}{l}\text { Multiple } \underline{\mathrm{R}} \\
\mathrm{R} \text { squared } \\
\text { Adjusted } \underline{\mathrm{R}} \text { squared }\end{array}$} & $\begin{array}{l}.24167 \\
.05841 \\
.01958\end{array}$ & & $\begin{array}{c}F(4,97) \\
P\end{array}$ & $\begin{array}{c}1.50418 \\
.2070\end{array}$ \\
\hline
\end{tabular}


Table 18

Correlations of CPT1 Component Scores From Nine Component Log10(RP/1-RP) Extraction Multiple Regression on CPT1 Omission Errors

$9.1-9.2-9.3-9.496$

\begin{tabular}{|c|c|c|c|c|c|}
\hline 9.2 & .157 & & & & \\
\hline 9.3 & -.087 & .181 & & & \\
\hline 9.4 & -.073 & -.098 & .295 & & \\
\hline 9.6 & -.131 & .663 & .309 & -.169 & \\
\hline 9.7 & -.317 & -.239 & .433 & .462 & -.137 \\
\hline
\end{tabular}

Table 19

Standard Multiple Regression of Component Scores From Nine Component Loglo(RP/1-RP) Extraction on Omission Errors in CPT 1

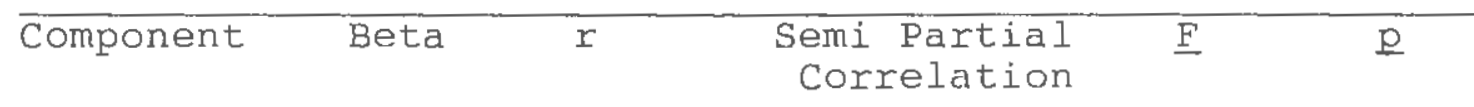

\begin{tabular}{lrrrrr}
\hline 9.1 & -.059928 & -.112609 & -.053058 & .285 & .5945 \\
9.2 & -.066364 & -.044300 & -.046367 & .218 & .6417 \\
9.3 & .011219 & .023803 & .008956 & .008 & .9284 \\
9.4 & -.233260 & -.157946 & -.200460 & 4.072 & .0464 \\
9.6 & .066323 & .051569 & .043757 & .194 & .6606 \\
9.7 & .156434 & .079212 & .116871 & 1.384 & .2423
\end{tabular}

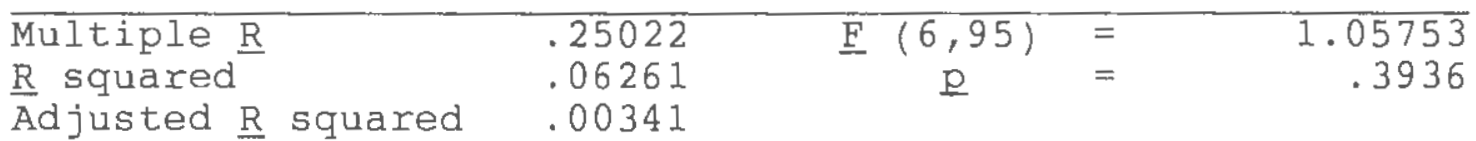

Outliers on the criterion were identified using studentized residuals. Outliers on the predictors were identified by examining the Mahalanobis distances ( $\underline{P}<$ $.001)$. None of these outliers appeared to be influential however; Cook's distances were all below 1 , thus they were left in the analyses (Stevens, 1986). Multiple Regression on Change in Ievel of Performance (Vigilance Decrement)

Table 16 shows that none of the multiple regressions predicted change (CPT1-CPT2) in omissjon errors (i.e., 
vigilance decrement) to any significant degree. Tables $21,23,25$, and 27 show that the sixth component from the absolute-power, eight-component solution (AP8.6); the second and fourth components from the absolute-power, 12component solution (AP12.2 and AP12.4); the third component from the relative-power, seven-component solution (RP7.3), and the third component from the relative-power eight-component solution (RP8.3) were significantly correlated with the vigilance decrement at the .05 level.

Table 20

Correlations of Component Scores From Eight Component Absolute Power (AP) Extraction Multiple Regression on CPT1-CPT2 Omission Error Change Scores

\begin{tabular}{lllll}
\hline 8.1 & 8.2 & 8.3 & 8.4 & 8.5
\end{tabular}

\begin{tabular}{|c|c|c|c|c|c|}
\hline 8.2 & .003 & & & & \\
\hline 8.3 & .300 & -.087 & & & \\
\hline 8.4 & .264 & .300 & -.097 & & \\
\hline 8.5 & .580 & -.143 & .158 & .275 & \\
\hline 8.6 & -.007 & .532 & .054 & .308 & -.065 \\
\hline
\end{tabular}

Table 21

Standard Multiple Regression of Component Scores From Eight Component Absolute Power (AP) Extraction on Change in Percent Omission Errors (CPT1-CPT2)

$\begin{array}{lllll}\text { Component Beta } & r & \begin{array}{l}\text { Semi Partial } \\ \text { Correlation }\end{array} & \underline{F} & \text { P }\end{array}$

\begin{tabular}{|c|c|c|c|c|c|}
\hline $\begin{array}{l}8.6 \\
8.5 \\
8.4 \\
8.3 \\
8.2 \\
8.1\end{array}$ & $\begin{array}{r}-.251398 \\
.098389 \\
-.122960 \\
.129495 \\
.227288 \\
-.042855\end{array}$ & $\begin{array}{r}-.167384 \\
.044091 \\
-.129200 \\
.110883 \\
.031135 \\
.023026\end{array}$ & $\begin{array}{r}-.205744 \\
.076879 \\
-.105622 \\
.119444 \\
.184461 \\
-.032963\end{array}$ & $\begin{array}{r}4.384 \\
.612 \\
1.155 \\
1.478 \\
3.524 \\
.113\end{array}$ & $\begin{array}{l}.0389 \\
.4359 \\
.2851 \\
.2272 \\
.0636 \\
.7380\end{array}$ \\
\hline $\begin{array}{l}\mathrm{Mu} \\
\mathrm{R}\end{array}$ & $\underline{\underline{R}}$ & $\begin{array}{l}.28767 \\
.08275\end{array}$ & $\begin{array}{c}F(6,95) \\
\mathrm{P}\end{array}$ & \multicolumn{2}{|c|}{1.42847} \\
\hline
\end{tabular}

Adjusted $\underline{R}$ squared .02482 
Table 22

Correlations of Component Scores From Twelve Component Absolute Power (AP) Extraction Multiple Regression on CPT1-CPT2 Omission Error Change Scores

\begin{tabular}{rrrrrrrr}
\hline & 12.1 & 12.2 & 12.3 & 12.4 & 12.5 & 12.9 & 12.10 \\
\hline 12.2 & -.044 & & & & & & \\
12.3 & .279 & -.082 & & & & & \\
12.4 & -.007 & .440 & .009 & & & & \\
12.5 & .603 & -.151 & .244 & -.096 & & & \\
12.9 & .384 & .192 & .123 & .010 & .302 & & \\
12.10 & .061 & .335 & -.117 & .439 & -.065 & .288 & \\
12.11 & .293 & .036 & .804 & .102 & .179 & .239 & -.071 \\
\hline
\end{tabular}

Table 23

Standard Multiple Regression of Component Scores From Twelve Component Absolute Power (AP) Extraction on Change in Percent Omission Errors (CPT1-CPT2)

$\begin{array}{lllll}\text { Component } & \text { Beta } & r & \begin{array}{l}\text { Semi Partial } \\ \text { Correlation }\end{array} & \text { F }\end{array}$

\begin{tabular}{|c|c|c|c|c|c|}
\hline $\begin{array}{l}12.1 \\
12.2 \\
12.3 \\
12.4 \\
12.5 \\
12.9 \\
12.10 \\
12.11\end{array}$ & $\begin{array}{r}-.106787 \\
.267685 \\
.262349 \\
-.239158 \\
.115466 \\
.115966 \\
-.055000 \\
-.149925\end{array}$ & $\begin{array}{r}.023026 \\
.126504 \\
.136678 \\
-.167384 \\
.109614 \\
.139497 \\
-.071069 \\
.067460\end{array}$ & $\begin{array}{r}-.080324 \\
.228138 \\
.149665 \\
-.193938 \\
.088465 \\
.095256 \\
-.045141 \\
-.083533\end{array}$ & $\begin{array}{r}.690 \\
5.563 \\
2.394 \\
4.020 \\
.837 \\
.970 \\
.218 \\
.746\end{array}$ & $\begin{array}{l}.4084 \\
.0204 \\
.1252 \\
.0479 \\
.3628 \\
.3273 \\
.6418 \\
.3900\end{array}$ \\
\hline $\begin{array}{l}\text { Multiple } \\
\text { R squared } \\
\text { Ad justed }\end{array}$ & $\begin{array}{l}\underline{R} \\
\underline{R} \text { squared }\end{array}$ & $\begin{array}{l}.36045 \\
.12992 \\
.05508\end{array}$ & $\begin{array}{c}\mathrm{E}(8,93) \\
\mathrm{D}\end{array}$ & $\begin{array}{l}= \\
=\end{array}$ & $\begin{array}{c}1.73586 \\
.1003\end{array}$ \\
\hline
\end{tabular}

Table 24

Correlations of Component Scores From Seven Component Relative Power ( $R P$ ) Extraction Multiple Regression on CPT1-CPT2 Omission Error Change Scores

$\begin{array}{llll}7.1 & 7.2 & 7.3\end{array}$

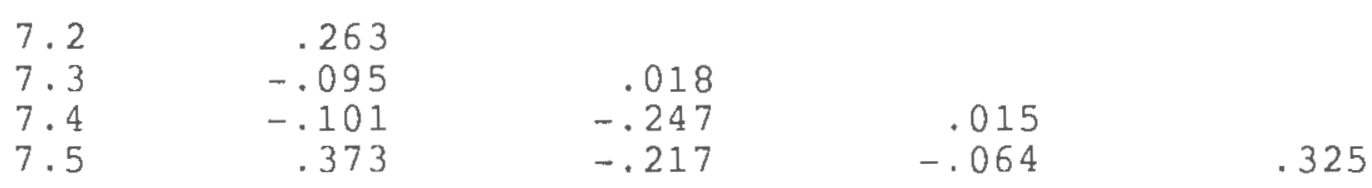


Table 25

Standard Multiple Regression of Component Scores From Seven Component Relative Power (RP) Extraction on Change in Percent Omission Errors (CPT1-CPT2)

$\begin{array}{lllll}\text { Component } & \text { Beta } & \begin{array}{l}\text { Semi Partial } \\ \text { Correlation }\end{array} & \underline{F} & \underline{p}\end{array}$

\begin{tabular}{lrrrrr}
\hline 7.1 & .091179 & .011793 & .076472 & .593 & .4431 \\
7.2 & -.128444 & -.078151 & -.115244 & 1.347 & .2487 \\
7.3 & .200297 & .194023 & .199125 & 4.021 & .0477 \\
7.4 & -.023729 & -.023523 & -.021582 & .047 & .8284 \\
7.5 & -.077848 & -.036515 & -.063527 & .409 & .5239 \\
& & .23103 & $\underline{F}(5,96)$ & & 1.08261 \\
Multiple $\underline{R}$ & .05338 & $\underline{p}$ & $=$ & .3750 \\
R squared & .00407 & & &
\end{tabular}

Table 26

Correlations of Component Scores From Eight Component

Relative Power Extraction Multiple Regression on CPT1-CPT2 Omission Error Change Scores

\begin{tabular}{|c|c|c|c|c|c|}
\hline & 8.1 & 8.2 & 8.3 & 8.4 & 8.5 \\
\hline $\begin{array}{l}8.2 \\
8.3 \\
8.4 \\
8.5 \\
8.6\end{array}$ & $\begin{array}{r}.297 \\
-.077 \\
-.249 \\
-.205 \\
-.474\end{array}$ & $\begin{array}{r}-.095 \\
-.101 \\
-.332 \\
-.272\end{array}$ & $\begin{array}{r}.015 \\
-.055 \\
.360\end{array}$ & $\begin{array}{l}.310 \\
.365\end{array}$ & .121 \\
\hline
\end{tabular}

Table 27

Standard Multiple Regression of Component Scores From Eight Component Relative Power Extraction on Change in Percent Omission Errors (CPT1-CPT2)

$\begin{array}{lllll}\text { Component } & \text { Beta } & \begin{array}{l}\text { Semi Partial } \\ \text { Correlation }\end{array} & \underline{F} & p\end{array}$

\begin{tabular}{lrrrrr}
\hline 8.1 & -.228117 & -.106913 & -.188845 & 3.722 & .0567 \\
8.2 & .080715 & .011793 & .068247 & .486 & .4874 \\
8.3 & .258194 & .194023 & .237053 & 5.865 & .0173 \\
8.4 & .036876 & -.023523 & .032435 & .110 & .7411 \\
8.5 & -.100998 & -.057228 & -.084996 & .754 & .3874 \\
8.6 & -.222831 & -.042566 & -.171521 & 3.071 & .0829 \\
\hline Multiple & .29972 & $\underline{\mathrm{R}}(6,95)$ & $=$ & 1.56275 \\
R squared & .08983 & $\mathrm{P}$ & $=$ & .1665 \\
Adjusted R squared & .03235 & & &
\end{tabular}


A series of standard multiple regressions were performed using absolute change in component scores (CPT1CPT2) as the predictors and absolute change in percent omission errors (CPTl-CPT2) as the criterion. Appendix $B$ contains the descriptive statistics of the absolute-power and relative-power component change scores and the descriptive statistics of the omission-error change scores. The multiple regression formulas explained between 38 and $13 \%$ of the variance in change of omission errors. Table 17 shows that none of these regressions were significant. Tables $20,21,22,23,24,25,26$, and 27 show that five of the components, AP8.6, AP12.2, AP12.4, RP7.3, and RP8.3 were correlated with change in performance at the .05 level. Once again, none of the outliers appeared to be influential (i.e., Cook's D below 1)

\section{Post-hoc Multiple Regressions}

As a post hoc analysis, four components were selected for further investigation. These included absolute-power frontal beta (AP12.2); absolute-power right frontotemporal and right temporal-occipital beta (AP12.4); relative-power frontal and right fronto-temporal theta (RP5.4); and relative-power occipital theta, right occipital delta, and right temporal theta (RP8.3). These were selected because the planned analyses had shown them to be correlated with level of omission errors in CPT1 or change in omission errors (CPT1-CPT2). LRP9.4, AP8.6, and 
RP7.3 were not used because they were identical to other components.

Two multiple regressions were conducted with level of omission errors in CPT2 as the criterion. In the first multiple regression equation, component scores of AP12.4 and AP12.2 at CPT1 and CPT2 were used as predictors. In the second multiple regression equation, component scores of RP5.4 and RP8.3 at CPT1 and CPT2 were used as predictors.

Table 28 shows that $\underline{R}^{2}$ for the absolute-power multiple regression was .09. Although this regression was not significant at conventional alpha levels $(\mathrm{p}=.06$ ), all of the variables significantly correlated with the level of CPT2 omission errors ( $\mathrm{p}<.05)$.

Table 28

Standard Multiple Regression of CPTI (A) and CPT2 (B) Component Scores From Twelve Component Absolute Power Extraction on Omission Errors in CPT2

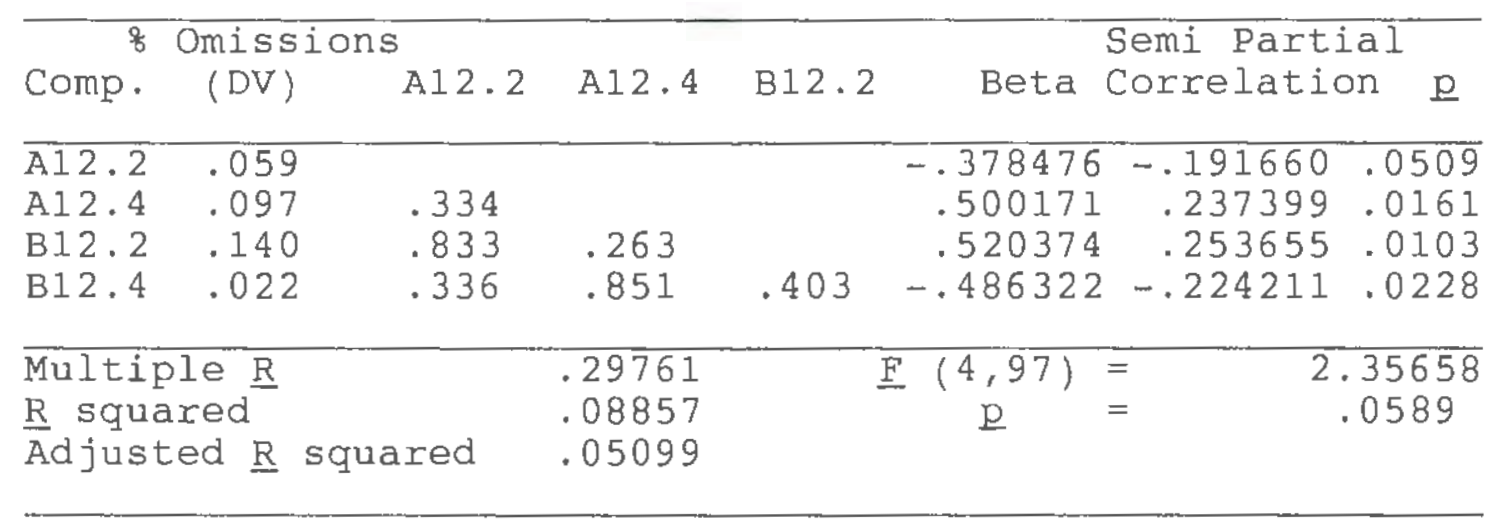

Table 29 shows that $\underline{\mathrm{R}}^{2}$ for the relative-power multiple regression was .06. This regression was not 
significant $(\underline{Q}=.42)$. Only RP5.4 at CPT2 was correlated with the level of CPT2 omission errors $(\mathrm{p}<.05)$.

Table 29

Standard Multiple Regression of CPT1 (A) and CPT2 (B) Component Scores From Five and Eight Component Relative Power Extraction on Omission Errors in CPT2

\begin{tabular}{|c|c|c|c|c|c|c|}
\hline Comp. & $\begin{array}{l}\text { Omissions } \\
\text { (DV) }\end{array}$ & A 5.4 & A 8.3 & B5. 4 & Beta & $\begin{array}{l}\text { Semi Partial } \\
\text { Correlation }\end{array}$ \\
\hline $\begin{array}{l}\text { A5. } 4 \\
\text { A8.3 } \\
\text { B5. } 4 \\
\text { B8. }\end{array}$ & $\begin{array}{r}-.079 \\
-.001 \\
-.069 \\
.105\end{array}$ & $\begin{array}{l}.321 \\
.763 \\
.237\end{array}$ & $\begin{array}{l}.364 \\
.858\end{array}$ & .286 & $\begin{array}{r}-.048280 \\
-.308644 \\
-.031625 \\
.390430\end{array}$ & $\begin{array}{rr}-.031068 & .7546 \\
-.153099 & .1257 \\
-.020049 & .8401 \\
.199666 & .0467\end{array}$ \\
\hline $\begin{array}{l}\text { Multi } \\
\text { R squ } \\
\text { Adjus }\end{array}$ & $\begin{array}{l}\text { le } \underline{R} \\
\text { red } \\
\text { zed } \underline{R} \text { squas }\end{array}$ & & $\begin{array}{l}.21718 \\
.04717 \\
.00787\end{array}$ & & $\begin{array}{c}E(4,97) \\
\underline{P}\end{array}$ & $\begin{array}{c}1.20041 \\
.3156\end{array}$ \\
\hline
\end{tabular}

Discussion

In this section, the ten predictions regarding the transformations of scores and the psychometric properties of variables, component scores, and performance indexes are discussed. The predictions regarding changes in EEG variables between Resting and CPT1 subsequently are considered. The outcome of the set of planned multiple regression equations is then described. Finally, the results of the post-hoc multiple regression equation are examined.

Transformation of Scores

The first prediction was that the $\log 10$ transformation would normalize absolute power and that the $\log 10(x / 1-x)$ transformation would normalize relative power. Findings for EEG collected during an auditory CPT were consistent with the literature on resting EEG. 
Log10(AP) produced the most normal distribution of absolute-power scores and logl0(RP/1-RP) produced the most normal distribution of relative-power scores (see Table 1).

These transformations, however, were not perfect. For example, after transformation, for absolute-power variables, 12.58 of the $\log 10(\mathrm{AP})$ variables remained leptokurtic and $17.5 \%$ of the variables remained skewed. For relative-power variables, $22.5 \%$ of the $\log 10$ (RP/I-RP) variables were leptokurtic and $17.5 \%$ of these variables were skewed.

In contrast to pollock et al. (1990) who reported that absolute theta amplitude (powerl/2) was not normalized with the log transformation, loglo(AP) theta at six of eight channels in the present study was nomally distributed. There was no evidence of excessive amounts of theta non-normality using their more stringent criteria for skewness and kurtosis, under either resting or CPT conditions. Pollock et al. (1990) however, did record EEG from a number of locations that were not monitored in the present study. Oken and Chiappa (1988) reported that relative power had fewer skewed results than absolute power. In the present study, this was supported for nontransformed but not for log-transformed scores. Finally, although some authors have used the natural log instead of $\log 10$ to normalize scores, this does not present a problem for the present study because logarithms are constant 
multiples of each other (Tukey, 1977), therefore, results of the two transformations would be equivalent.

\section{Absolute-Power and Relative-Power Reliability}

The second prediction was that absolute-power variables would be more reliable than relative-power variables. This prediction was supported. Among young adults, short term (i.e., six-minute) test-retest reliability was significantly greater for absolute power than for relative power, for EEG collected during a auditory continuous performance test. This was true regardless of whether transformed or non-transformed values were analyzed or whether the non-parametric Spearman rank-order correlation or the parametric Pearson product-moment correlation was used to assess reliability.

Pollock et al. (1991) reported that delta amplitude reliability was low. Gasser et al. (1985) found that this was true for absolute-power delta and even more so for relative-power delta. Low reliabilities among anterior but not posterior delta scores were found in the present study. Reliabilities of right frontal theta, alpha, betal, and beta 2 also tended to be low, particularly for relative-power measures.

The double cross-validation procedure demonstrated that the relationship of relative-power variables across groups was not more consistent than the relationship of absolute-power variables across groups. One of the crossvalidations showed that absolute-power variables were more 
consistent than relative-power variables, the other crossvalidation showed no difference.

It was hypothesized that absolute-power reliability would be greater than relative-power reliability because relative-power reliability would be limited by unreliability among the constituent dependent scores. In other words, the least reliable score would reduce the reliabilities of the other scores that use that variable in their calculations of relative power. Removal of the least reliable variables significantly improved shortterm, test-retest reliability. In terms of enhancing reliability, however, removal of one unreliable score was not particularly meaningful. For example, the largest change only acounted for an additional one-half of one percent of error variance in the scores.

PCA and Component Scores

The third prediction was that component scores derived from PCAs on absolute- and relative-power variables would be reliable with short-term test-retest correlations greater than .80 (i.e., error variance < 20\%). This prediction was supported for 778 of the nontransformed absolute-power components, $66 \%$ of the $\log 10(\mathrm{AP})$ components, 648 of the non-transformed relativepower components, and 63\% of the loglo(RP/l-RP) components (see Tables 11, 12, 13, and 14).

Components derived in the present study are not directly comparable to those reported in other studies. 
For example, in the present study a PCA was performed on EEG collected during a continuous performance test whereas in other studies (e.g., Ott et al.,1982; Schenk et al., 1982; Gasser et al., 1983) PCAs were performed on EEG data collected during eyes-closed resting conditions. Bente (1979) conducted one PCA on EEG data collected during resting and another on EEG data collected during a visual tracking task. In addition, these other PCAs were conducted on EEG data collected from one or two channels in contrast to the present eight-channel study. Bente and ott et al. collected EEG from occipital leads. Schenk et al. collected EEG from bipolar right occipital and right parietal leads (C4-P4, P4-02). Finally, Bente, Schenk et al, and ott et al. derived different wavebands than the ones used in the present study. Gasser et al, defined their bands similarly to the present study with the exception that they divided alpha into two bands, (i.e.r 7.5 to $9.5 \mathrm{~Hz}$ and 9.5 to $12.5 \mathrm{~Hz})$.

The other PCA studies also suffered from methodological shortcomings, particularly, small sample sizes. Bente (1979), Schenk et al. (1982), Ott et al. (1982), and Gasser et al. (1983) used sample sizes of 12 , 41,60 , and 31 respectively. Guadagnoli and Velicer (1988) demonstrated that PCAs derived on small samples were unlikely to replicate the population pattern adequately. Gasser et al. (1983) chose not to rotate their PCA solution because it eliminated the general 
topographic factor. Given a hypothesis of taskassociated, regional differences in brain activity, it is unclear why a general topographic factor would be necessary. In any event, this procedure resulted in a two-factor solution, not a three-factor solution as they suggested. The average loading on factor 1 was 0.87 , on factor 2 it was 0.31 , and on factor 3 it was 0.17 . Factor 1 was a general topographic factor as they suggested. Factor 2 contained left- and right-sided positive occipital variables plus negative frontal delta and beta variables. Factor 3 only comprised one variable that loaded above 0.40 .

Bente's (1979) fifth factor was somewhat comparable to RP5.3. The first factor that ott et al. (1982) described contained elements of RP5.3, RP10.9, and RP8.3. The second factor that Schenk et al. (1982) described seems similar to the first factor of the absolute-power solution (i.e., API2.1).

PCA Solution

Five component pattern solutions were hypothesized prior to conducting the PCA. The first possibility was that a two-component solution that divided the brain either sagitally (.e., into left and right hemispheres) or coronally (i.e., into anterior and posterior sections) would emerge. The second possibility combined these two options into a four-component solution (i.e., left anterior, right anterior, left posterior, and right 
posterior). The third possibility was a four-component solution that separated the brain by region (i.e., frontal, fronto-temporal, temporal, and temporaloccipital). The fourth possibility was a five-component solution with each band (i.e., delta, theta, alpha, betal, and beta2) emerging as a separate component. The fifth possibility was that the component would emerge as a combination of the other patterns. In fact, the observed patterns appeared consistent with the fifth possibility in that combinations of region-, hemisphere-, and bandrelated components emerged. More specifically, delta- and theta-wave bands tended to emerge together. Similarly, betal- and beta2-activity was highly correlated. Anterior and posterior components were found. In the frontotemporal and temporal regions, beta sometimes split into left- and right-hemisphere components.

A theoretically interesting pattern discussed here as an illustration was that of the 12-component, absolutepower solution. Four components from this solution were dropped from analysis because fewer than three variables loaded on those components at .60 or greater. After removing those variables, the remaining eight components accounted for $70.9 \%$ of the total variance. The multipleregression equation that used the eight remaining components for predicting CPTI - CPT2 omission-error changes accounted for the greatest amount of variance (13\%) of any of the multiple-regression equations. Figure 
8 displays the 12-component, varimax-rotation, absolutepower solution without the four omitted components. Appendix D displays the varimax and promax rotations of the 12-component, absolute-power extraction.

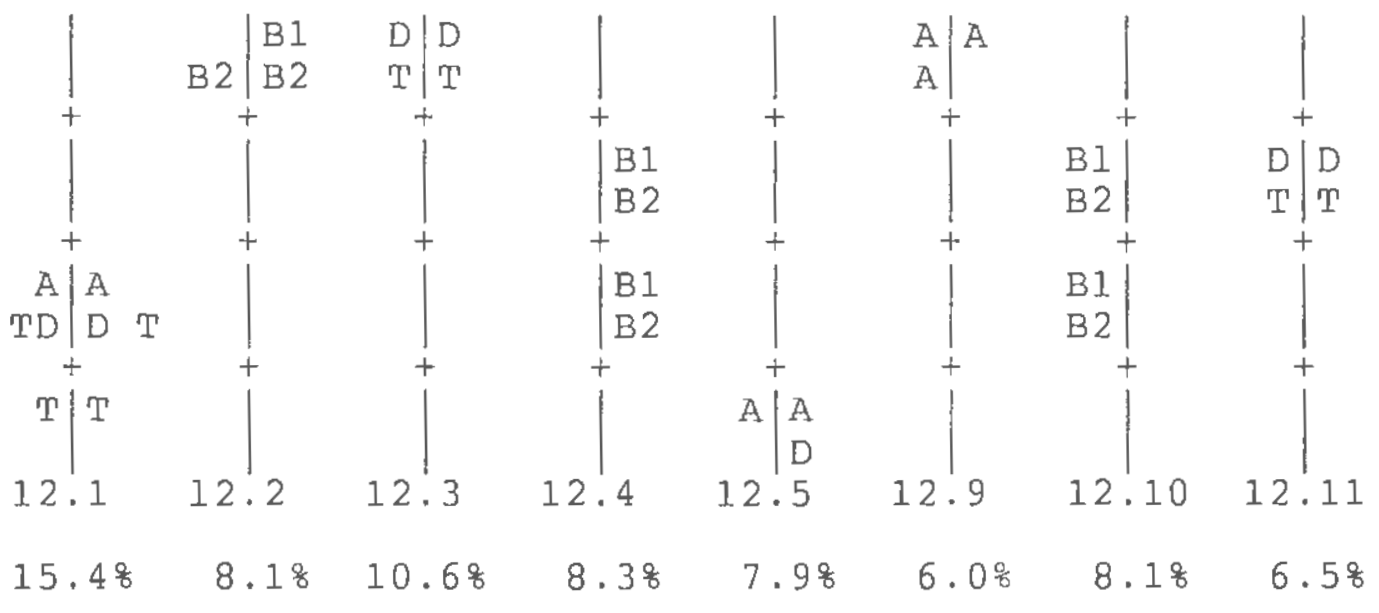

Figure 8. Absolute Power 12-component extraction. $\mathrm{A}=$ alpha, $\mathrm{B} 1=$ Betal, $\mathrm{B} 2=$ Beta2, $\mathrm{T}=$ Theta, $\mathrm{D}=$ Delta. $12.1=$ component 1 of the 12 -component extraction. $\%=$ the amount of total variance accounted for by this component. Four components were dropped because of fewer than 3 variables loading at .60 or greater.

When these components are considered in the context of the previously cited theoretical research relating EEG activity to vigilance, several hypotheses can be advanced. For example, component 12.1 may be a posterior tonic arousal component reflecting the individual's overall level of alertness. Component 12.2 , which is positively correlated with omission errors, may reflect activity in the frontal lobes. This could involve planning activities unrelated to the CPT task. Components 12.3 and 12.11 , which are both anterior phasic arousal components, may reflect the amount of resources directed to performing the 
task. As the task is mastered individuals may decrease their phasic arousal yet still perform well. Supporting this hypothesis, these components were moderately positively correlated with omission errors. Component 12.4, which was negatively correlated with omission errors, may reflect activity in the vigilance center of the right hemisphere. Components 12.5 and 12.9 which were positively correlated with omission errors, may reflect a level of inattention and underutilized processing resources. Component 12.10 may reflect processing in the language and phonemic decoding center. As such it is unlikely that brain-wave activity ith these channels would be influenced by memory operations in deep structures such as the hippocampus and amygdala. Because the language area is being constantly stimulated throughout the language task, activity in this area would be expected to remain constant throught the task. Again, supporting this hypothesis, the component was uncorrelated with omission errors.

\section{CPT Performance Measures}

The fourth prediction was that the detection index would be the most reliable measure of CPT performance. This prediction was not supported among either the sixminute or one week, test-retest, Pearson product-moment correlations. Reliabilities were low at one week (.33 to $.37)$ and at six minutes (.48 to .49). The omission error index, which had been used in other research studies, had 
slightly higher reliability than the others (i.e., .37 at one week and .48 at six-minutes) and was chosen as our criterion measure.

These low reliabilities are perhaps not unexpected in view of the fact that vigilance, as measured by these performance indexes, may be an unstable trait. Level of attention conceivably could vary from week to week (one week correlations) or change over time, in different ways, across subjects (six-minute correlations). Figures 9, 10, and 11 and Table 15 demonstrate that these scores were also not normally distributed and had restricted ranges.

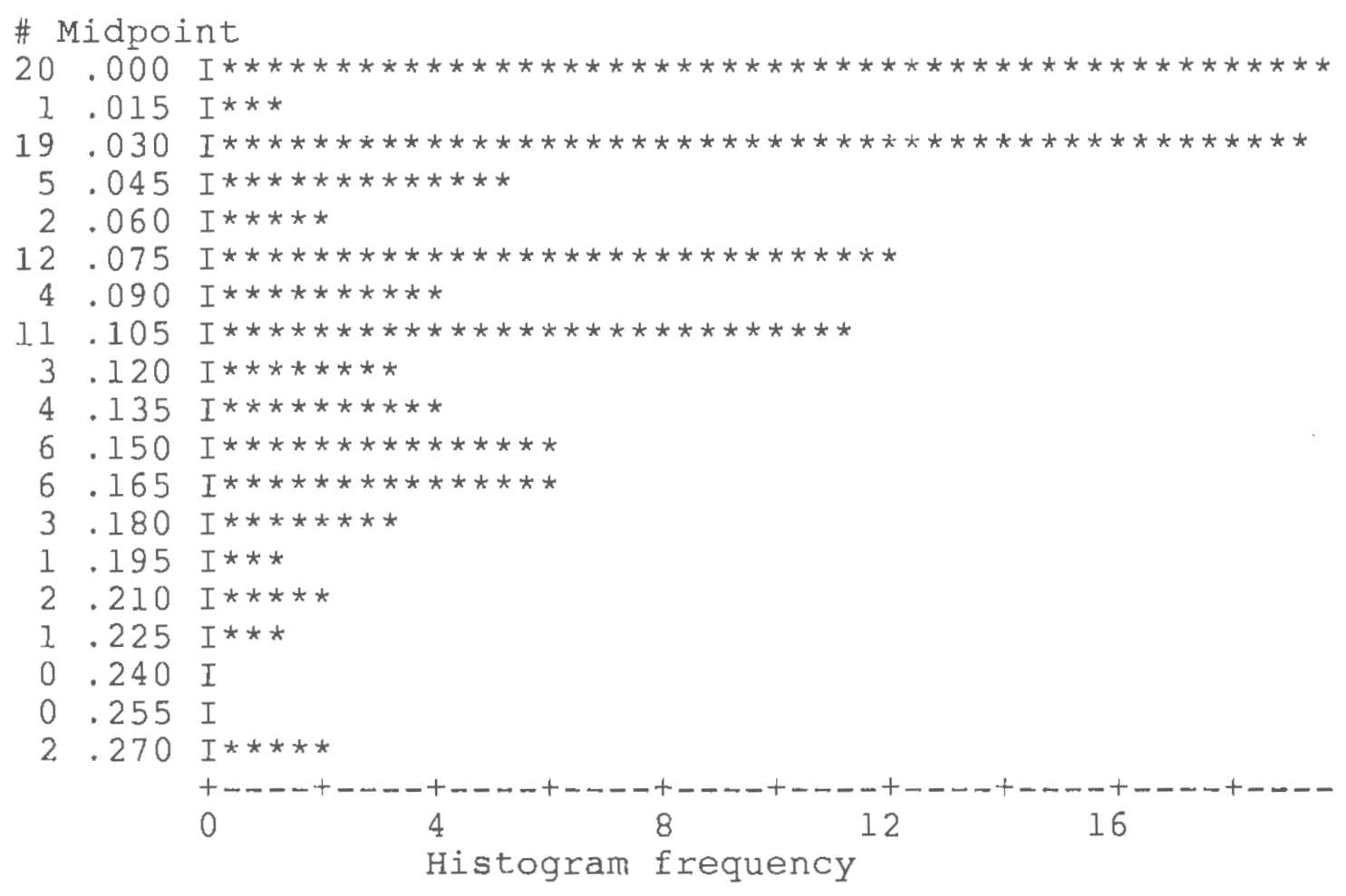

Figure 9. Percent omission errors CPT1 
\# Midpoint

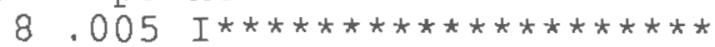

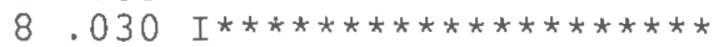

$2.055 I * * * * *$

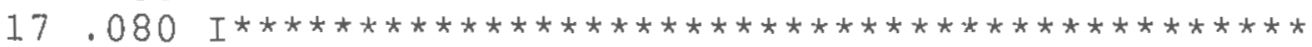

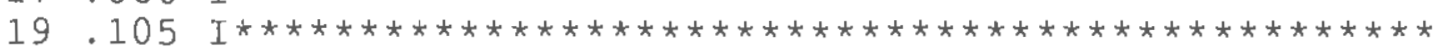

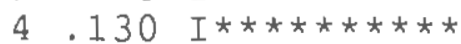

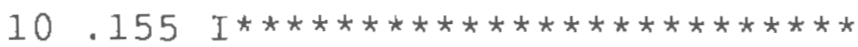

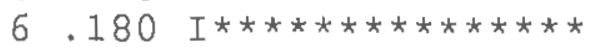

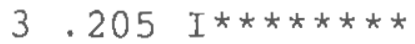

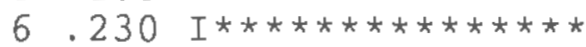

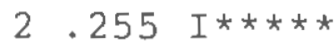

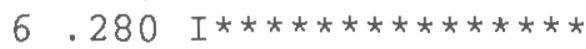

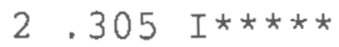

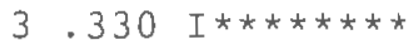

$2.355 I * \star * * *$

$1.380 \quad I * \star \star$

$1.405 I * * *$

$0.430 \mathrm{I}$

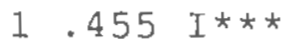

$0.480 \mathrm{I}$

$1.505 \mathrm{I} * * *$

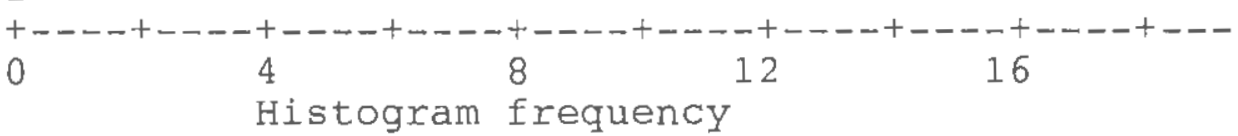

Figure 10. Percent omission errors CPT2

\# Midpoint

$2-.300 I * * * \star \star *$

$2-.275 I * \star \star \star * *$

$1-.250 I * \star \star$

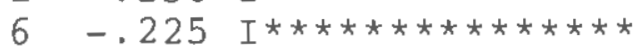

$2-.200 I * * \star \star * *$

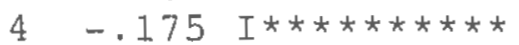

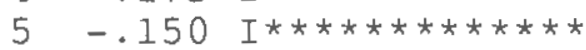

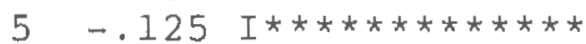

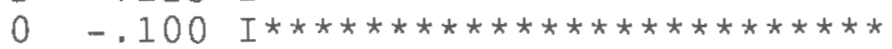

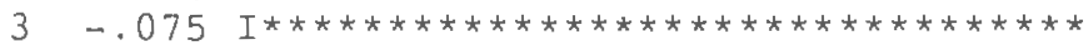

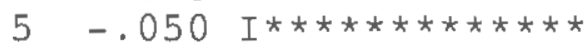

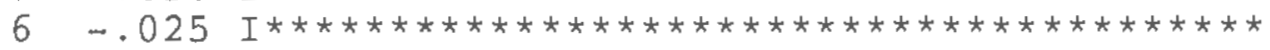

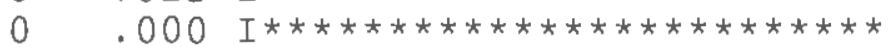

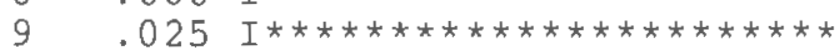

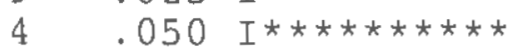

$3.075 I * * \star \star \star \star * \star * *$

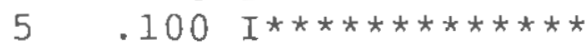

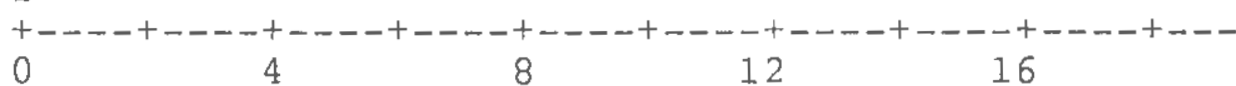

Figure 11. Change in percent omission errors CPT $\overline{1-C P T 2}$

Because attention may be variable, one possible way

to evaluate these reliability estimations is to assess 
reliability over shorter durations, for example, successive, one-minute periods. Another possibility is to correlate reliability during odd numbered epochs (i.e., one minute, three minute, five minute) with even numbered epochs (i.e., two minute, four minute, six minute). This would correct for interindividual differences in vigilance decrement. Of course, this would provide an indication of the measure's internal consistency rather than its stability.

The lack of reliability, for whatever reason, reduces the power of any statistical analysis in which it is used. Reliability is a necessary element of behavioral tasks that are performed during physiological monitoring (Gur, Erwin, \& Gur, 1992). It is possible that other measures such as reaction time would be more reliable, that the test could be made more difficult in order to eliminate the ceiling effect and spread the range of scores, or that reliabilities would be greater if used with a less homogeneous sample (i.e., one that included both control and head injured individuals).

Changes in Levels of EEG Activity

The fifth and sixth predictions were that the absolute power of beta activity during CPTl in channels 1 , $2,3,4,5$ and 6 would increase over resting levels and that the absolute power of alpha and theta activity would decrease between Resting and CPT. These predictions were supported for channels 3 of betal; channels 3, 4, 5, and 
7 of beta2; posterior theta; and channels 3,4, 5, and 6 of alpha. The left-sided beta findings are suggestive of changes that might be the result of activity in languge areas of the brain. This indicates that EEG is sensitive to these types of changes in brain activity. One unexpected finding was that frontal theta also increased between Resting and CPT1.

One possible explanation for this unexpected finding in frontal theta is that EEG activity below the artifact level, which may have been due to eye movement, was neither recorded separately nor removed. Eye movement theoretically could contaminate slow frequency bands such as delta, theta, and the lower ranges of alpha. For example, rhythmic muscle contractions could generate voltage changes that, if received at the frontal leads, would be recorded as brain-wave activity in these slowfrequency wave bands.

Randolph and Miller (1988) reported increases in delta at $\mathrm{T} 3$ and $\mathrm{T} 4$ referenced to $\mathrm{Cz}$. In the present study, the anterior channels, which used the T3 and T4 leads (channels 3 and 4), showed an increase in delta whereas the posterior channels (5 and 6) did not. It is possible that Randolph and Miller's report of increased delta at T3 and T4 may have been the result of contamination due to eye movement.

Finally, a variety of parameters may change between Resting and CPTI such as: anxiety, motivation, 
muscle tension, alertness, as well as level of attention and vigilance. These parameters need not all move in the same direction, at the same time. EEG may reflect some or all of these factors.

\section{Predicting Level of performance}

The seventh prediction was that component scores from components consisting of absolute-power beta from channels $1,2,3,4,5$, and 6 would be related to level of performance during CPT1. This prediction was not supported. None of the multiple regressions were significant; none predicted performance. Unreliability in the dependent variable results in an jncrease in the standard error of estimate, thus weakening tests of statistical significance (Pedhazur, 1982). This could be one explanation for the inability of the multipleregression equations to predict the unreliable (rtt $=.48$ ) omission error score. A component consisting of channels 1,2 , and 4 relative-power theta, however, was negatively correlated with the level of omission errors during CPTl. Predicting Changes in Level of Performance

The eighth prediction was that CPTI to CPT2 changes in component scores from components comprising absolutepower beta from channels 2 and 4 would be negatively correlated with CPT1 to CPT2 performance change (i.e., as the number of omission errors increased, beta would decrease). The ninth prediction was that changes in component scores from components comprising absolute-power 
beta from channels 7 and 8 would be negatively correlated with performance change. The tenth prediction was that changes in component scores from components comprising absolute-power theta and alpha from channels 7 and 8 would be positively correlated with performance change. None of these predictions were supported. None of the multiple regressions were significant; none predicted performance. As noted above, unreliability in the dependent variable results in an increase in the standard error of estimate, thus weakening tests of statistical significance (Pedhazur, 1982). Because difference scores are more unreliable than either score alone (Willis \& Goodwin, 1987), this could be one explanation for the inability of the multiple-regression equations to predict the omission error change score. Changes in certain components, however, were correlated with changes in omission errors. These included in : (a) negative correlations with channels 4 and 6 absolute-power betal and beta2, (b) positive correlations with channels 1 and 2 absolute-power beta2, (C) positive correlation with channel 2 absolutepower betal, (d) positive correlations with channels 6, 7, and 8 relative-power theta, and (e) positive correlation with channel 8 relative-power delta.

Because none of the multiple regressions was significant, it was not possible to demonstrate that components derived from absolute-power variables were superior to relative-power variables, transformed 
absolute-power, or transformed relative-power variables in predicting performance. The absolute-power, 12 - component extraction (AP12) multiple regression, however, explained more of the variance $\left(\underline{R}^{2}=.13\right)$ and came the closest to predicting performance $(\underline{p}=.10)$.

Post-hoc Analyses

A post hoc analysis was conducted on the data in order to derive hypotheses for future research studies. In the first step, component correlations were evaluated for every component $(\underline{N}=57)$.

The anterior relative-power theta component (RP5.4 or LRP9.4) was negatively correlated with omission errors. The anterior absolute-power beta component (AP12.2) was positively correlated with changes in omission errors. The right sided absolute-power beta component (AP8.6 or AP12.4) was negatively correlated with changes in omission errors. The posterior relative-power theta component (RP8.3 Or RP7.3) was positively correlated with changes in omission errors. The posterior relative-power theta component was expected from a review of EEG literature (e.g., Davies \& Parasuraman, 1982; Parasuraman, 1984). The right-sided absolute-power beta component could be explained if the electrodes recorded right parietal and temporoparietal activity suggested from PET studies (e.g., Buchsbaum et al., 1990).

There are multiple possible explanations for the failure of any absolute-power component to explain level 
of performance. For example, there was a large interindividual variability of absolute-power measures. If one person's baseline EEG activity were consistently greater than another's, high test-retest reliabilities and low correlations of level of absolute-power EEG activity and performance would be expected. Relative-power corrects for scale and, therefore should be more predictive of level of performance. Difference scores also correct, to some extent for scale, although it does not seem likely that one person's change from 200 microvolts to 198 microvolts would be equivalent to another person's change from 4 microvolts to 2 microvolts. Traditional vigilance tasks are often longer in duration which should lead to a greater vigilance decrement. It may be that the brief nature of the present task concealed an effect which might have emerged had the task been. longer in duration. Similarly, the task itself may not have been sufficiently difficult for some people and hence, they were able to perform well without exerting a great deal of attention. The limited range of error scores not only suggests that this is a viable hypothesis, but also, in effect, reduces the statistical power of the analyses. Many factors could contribute to changes in levels of performance including: attention level, attention capability, arousal, memory, effort. It is likely that no individual component or set of components reflect this complex combination of factors in any 
straightforward manner. It is also conceivable that the electrodes were not at the correct locations (i.e., not over the parietal lobe) or that the scalp EEG is too crude an instrument to detect subtle attentional changes manifesting themselves below the surface of the cerebral cortex. Additionally, not all available quantitative EEG measures (i.e., coherence and assymetry), were included in the analysis. It is possible that analyses using these measures may have been more productive.

Another possibility that might have contributed to being unable to predict performance was unreliability in the measures. Not only were the performance measures unreliable, but it has been shown that difference scores in neuropsychological research are less reliable than either variable alone (Willis \& Goodwin, 1987). As an alternative, willis and Goodwin (1987) suggested using an analysis of covariance with one element of the difference score used as the dependent variable and the other used as a covariate.

This technique was not directly applicable because in the present study independent variables were continuous rather than categorical. However, extending the technique, if absolute-power variables do not explain performance because of disparities in scale between individuals and if difference scores reduce the reliability and, therefore, the power of statistical analyses, it seems reasonable to expect that a multiple 
regression which used both CPT1 and CPT2 EEG component scores could predict level of performance in CPT2.

This was the rationale for the post-hoc multiple regression reported in the Results section. Although neither of the multiple regressions reached significance, the near-significant absolute-power result suggested the validity of using this multiple regression approach, and the need of a follow-up examination of the absolute-power solution. In order to validate the absolute-power multiple regression, the formula could be applied to an independent sample to determine the extent to which it could predict performance during CPT2.

Summary

For EEG collected on young adults during an auditory CPT, $\log 10(\mathrm{AP})$ produced the most normal distribution of absolute power scores and $\log 10(\mathrm{RP} / 1-\mathrm{RP})$ produced the most normal distribution of relative power scores. Absolute power was shown to have greater short-term reliability than relative power.

Left-sided beta2 and right-frontal and right-frontotemporal beta2 increased between Resting and CPT1. This finding is consistent with the literature and suggestive that EEG is, in fact, sensitive to the type of brainactivity changes that result when moving from a resting condition to an attentive condition. Alpha activity declined in fronto-temporal and temporal regions bilaterally. Frontal, temporal, temporal-occipital theta 
and anterior delta showed an unexpected increase in activity between Resting and CPTl. As expected, leftsided beta 2 ; right-sided, fronto-temporal beta2, and leftsided, fronto-temporal betal increased between resting and cPT1.

The majority of components derived from PCAs on these scores had short-term test-retest correlations greater than .80. A component comprising frontal relative-power theta was negatively correlated with omission errors during CPT1. CPTl - CPT2 changes in components comprising right-sided, fronto-temporal and temporal absolute-power beta were negatively correlated with CPTl - CPT2 changes in omission errors. CPT1 - CPT2 changes in components comprising frontal absolute-power beta and posterior relative-power theta were positively correlated with CPTI - CPT2 changes in omission errors. However, none of the multiple regression equations based upon CPTl component scores predicted level of omission exrors in CPTl. None of the multiple regression equations based upon CPTI CPT2 component change scores predicted vigilance decrement. In post hoc analysis, none of the multiple regression equations that included component scores from CPTl and CPT2 as independent variables significantly predicted level of omission errors in CPT2. Frontal and right-sided absolute-power beta components (12.2 and 12.4) appeared, however to be promising, and seem to warrant a follow-up study for cross validation. The potential 
importance of this finding is that a physiological measure nearly predicted a behavioral measure of attention. The absolute-power, 12-component PCA solution, despite lacking empirical validation of it predictability, appeared to be superior to the other solutions from both a theoretical and empirical perspective. Thus, it is offered as the most promising arrangement of EEG variables during the auditory CPT. 
Appendix A

\section{Handedness Inventory}

\section{EEG Study \\ Adapted from the Edinburgh Inventory}

Have you ever had any tendency toward left-handedness?

Yes No

Is anyone in your family left-handed (i.e., Parents, siblings)?

Yes $\quad$ No

If you are left-handed, do you write with an inverted hand posture?

Yes No

Please indicate your preference in the use of hands in the following activities by putting a + in the appropriate column. Where the preference is so strong that you would never try to use the other hand unless absolutely forced to, put ++ . If in any case you are really indifferent, put + in both columns.

Please try to answer all the questions and only leave a blank if you have no experience at all of the objects or task.

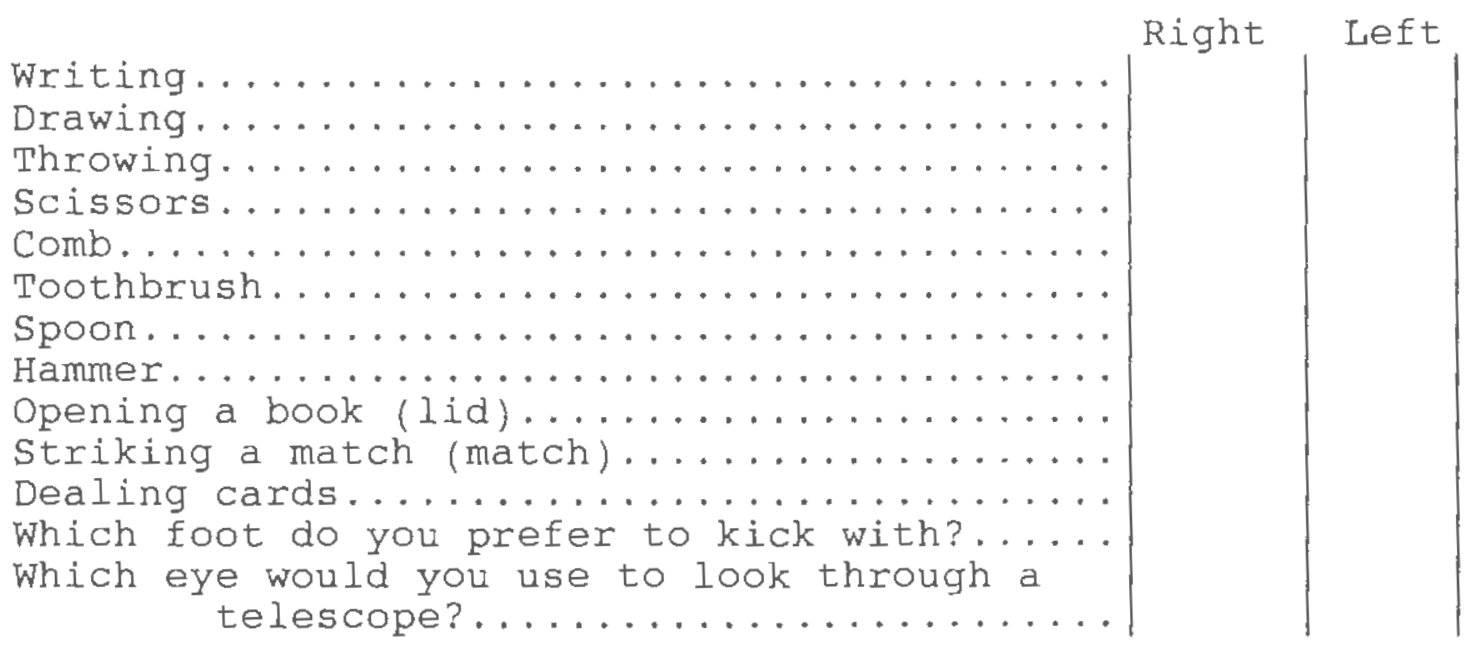


Appendix B

Table BI

Descriptive Statistics of Absolute Power EEG Collected During CPTI

\begin{tabular}{|c|c|c|c|c|}
\hline Variable & $\underline{M}$ & $\underline{S D}$ & Kurtosis & Skewness \\
\hline 1. Delta & 20.94 & 25.32 & 8.21 & 2.74 \\
\hline 2. Delta & 19.44 & 22.52 & 10.91 & 3.08 \\
\hline 3. Delta & 7.98 & 6.52 & 23.58 & 4.14 \\
\hline 4. Delta & 9.55 & 10.06 & 18.37 & 3.83 \\
\hline 5. Delta & 8.24 & 5.34 & 12.22 & 2.92 \\
\hline 6. Delta & 7.67 & 6.11 & 14.95 & 3.26 \\
\hline 7. Delta & 4.84 & 4.88 & 23.58 & 4.11 \\
\hline 8. Delta & 4.18 & 2.64 & 1.95 & 1.43 \\
\hline 1. Theta & 7.72 & 8.19 & 11.73 & 3.05 \\
\hline 2. Theta & 6.59 & 6.05 & 9.67 & 2.81 \\
\hline 3. Theta & 4.00 & 2.38 & 6.69 & 2.20 \\
\hline 4. Theta & 4.16 & 2.90 & 13.09 & 3.06 \\
\hline 5. Theta & 6.99 & 6.19 & 11.98 & 3.12 \\
\hline 6. Theta & 7.18 & 9.72 & 31.49 & 4.99 \\
\hline 7. Theta & 5.24 & 4.62 & 7.28 & 2.43 \\
\hline 8. Theta & 4.82 & 4.15 & 10.40 & 2.71 \\
\hline 1. Alpha & 3.88 & 3.43 & 16.13 & 3.50 \\
\hline 2.Alpha & 3.15 & 2.30 & 8.18 & 2.54 \\
\hline 3.Alpha & 4.82 & 3.40 & 5.13 & 2.02 \\
\hline 4.Alpha & 5.06 & 3.79 & 3.74 & 1.83 \\
\hline 5. Alpha & 26.07 & 28.90 & 6.31 & 2.23 \\
\hline 6.Alpha & 31.46 & 45.95 & 9.80 & 3.07 \\
\hline 7. Alpha & 25.81 & 41.52 & 46.37 & 5.94 \\
\hline 8.Alpha & 25.02 & 28.84 & 13.78 & 3.06 \\
\hline 1. Betal & 1.68 & 1.83 & 28.70 & 4.67 \\
\hline 2.Beta1 & 1.35 & 1.40 & 55.24 & 6.58 \\
\hline 3. Beta 1 & 2.80 & 2.07 & 3.71 & 1.80 \\
\hline 4. Beta 1 & 2.55 & 2.48 & 33.74 & 5.06 \\
\hline 5. Beta 1 & 5.45 & 3.41 & .65 & 1.05 \\
\hline 6. Beta 1 & 5.59 & 4.93 & 8.08 & 2.46 \\
\hline 7. Beta 1 & 3.68 & 2.40 & .80 & 1.01 \\
\hline 8. Beta 1 & 4.44 & 3.60 & 5.65 & 2.05 \\
\hline 1. Beta 2 & 3.87 & 6.30 & 11.66 & 3.38 \\
\hline 2. Beta2 & 3.12 & 6.35 & 64.43 & 7.44 \\
\hline 3. Beta 2 & 7.08 & 9.89 & 14.89 & 3.52 \\
\hline 4. Beta 2 & 6.07 & 8.38 & 18.88 & 3.93 \\
\hline 5. Beta 2 & 8.80 & 9.31 & 10.52 & 2.88 \\
\hline 6. Beta 2 & 8.99 & 11.59 & 12.03 & 3.22 \\
\hline 7 . Beta 2 & 4.61 & 4.35 & 4.38 & 2.10 \\
\hline 8. Beta 2 & 6.29 & 7.47 & 19.76 & 3.70 \\
\hline
\end{tabular}

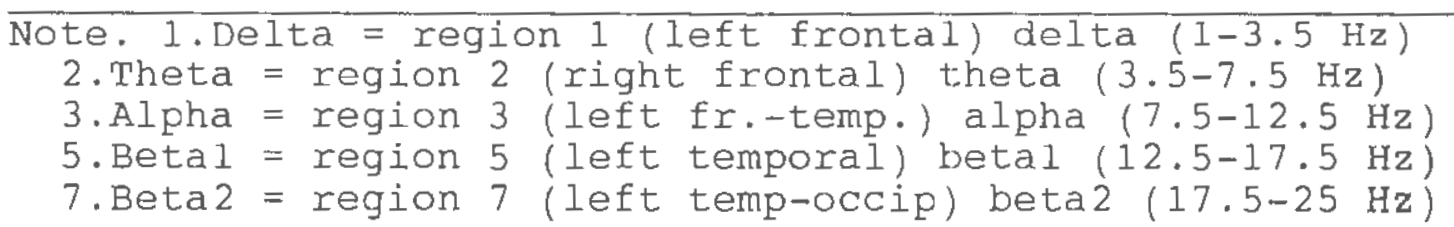


Table 82

Descriptive Statistics of Relative Power(RP) EEG Collected During CPT1

\begin{tabular}{|c|c|c|c|c|}
\hline Variable & $M$ & $\underline{\mathrm{SD}}$ & Kurtosis & Skewness \\
\hline 1.Delta & 49.29 & 17.98 & -.14 & -.40 \\
\hline 2. Delta & 52.52 & 15.90 & -.15 & -.29 \\
\hline 3. Delta & 31.41 & 14.23 & .22 & .68 \\
\hline 4. Delta & 34.18 & 15.64 & .55 & .80 \\
\hline 5. Delta & 18.32 & 10.09 & 4.21 & 1.64 \\
\hline 6. Delta & 16.66 & 8.72 & 1.59 & 1.15 \\
\hline 7. Delta & 14.28 & 10.97 & 11.41 & 2.85 \\
\hline 8. Delta & 12.02 & 7.00 & 2.56 & 1.54 \\
\hline 1. Theta & 20.30 & 6.81 & .02 & .35 \\
\hline 2. Theta & 20.03 & 5.64 & -.06 & -.07 \\
\hline 3. Theta & 15.94 & 5.42 & -.23 & .23 \\
\hline 4. Theta & 15.98 & 5.40 & .88 & .39 \\
\hline 5. Theta & 13.59 & 5.56 & -.50 & .45 \\
\hline 6. Theta & 12.75 & 5.29 & -.51 & .39 \\
\hline 7. Theta & 13.95 & 6.55 & .00 & .74 \\
\hline 8. Theta & 12.32 & 5.98 & 2.21 & 1.31 \\
\hline 1.Alpha & 13.13 & 9.12 & 7.50 & 2.29 \\
\hline 2. Alpha & 11.62 & 6.24 & .30 & .80 \\
\hline 3. Alpha & 19.39 & 10.65 & 2.27 & 1.41 \\
\hline 4. Alpha & 19.54 & 10.41 & .02 & .85 \\
\hline 5.Alpha & 39.38 & 18.74 & -1.03 & .20 \\
\hline 6.Alpha & 42.68 & 19.16 & -.96 & .13 \\
\hline 7.Alpha & 47.19 & 20.09 & -1.00 & -.03 \\
\hline 8.Alpha & 48.38 & 18.54 & -.97 & -.06 \\
\hline 1. Betal & 5.58 & 3.35 & 1.09 & .94 \\
\hline 2. Betal & 5.17 & 2.98 & -.22 & .57 \\
\hline 3. Betal & 10.49 & 4.36 & 3.76 & 1.02 \\
\hline 4. Betal & 9.59 & 4.06 & .19 & .22 \\
\hline 5. Betal & 11.29 & 5.77 & 1.27 & 1.20 \\
\hline 6. Betal & 11.06 & 5.84 & 3.87 & 1.40 \\
\hline 7 . Beta 1 & 10.89 & 5.93 & .11 & .81 \\
\hline 8. Betal & 11.51 & 5.73 & .08 & .76 \\
\hline 1. Beta 2 & 11.71 & 12.89 & 7.34 & 2.55 \\
\hline 2. Beta 2 & 10.67 & 11.06 & 10.11 & 2.84 \\
\hline 3. Beta 2 & 22.78 & 15.72 & .69 & 1.06 \\
\hline 4. Beta 2 & 20.71 & 15.25 & .24 & 1.00 \\
\hline 5 . Beta 2 & 17.42 & 12.71 & 1.58 & 1.31 \\
\hline 6. Beta 2 & 16.85 & 12.94 & 1.14 & 1.28 \\
\hline 7. Beta 2 & 13.69 & 10.82 & 2.04 & 1.53 \\
\hline 8. Beta 2 & 15.78 & 11.67 & 2.21 & 1.42 \\
\hline
\end{tabular}

\footnotetext{
Note. 1. Delta = region 1 (left frontal) delta $(1-3.5 \mathrm{~Hz}$ )

2. Theta $=$ region 2 (right frontal) theta $(3.5-7.5 \mathrm{~Hz}$ )

3. Alpha $=$ region 3 (left fr.-temp.) alpha $(7.5-12.5 \mathrm{~Hz}$ )

5. Betal = region 5 (left temporal) betal (12.5-17.5 $\mathrm{Hz}$ )

7. Beta 2 region 7 (left temp-occip) beta $2(17.5-25 \mathrm{~Hz}$ )
} 
Table B3

Descriptive Statistics of Loglo(AP) EEG Collected Duxing CPT 1

\begin{tabular}{|c|c|c|c|c|}
\hline Vaxiable & $\underline{M}$ & $\underline{\mathrm{SD}}$ & Kurtosis & Skewness \\
\hline$\overline{1 . D e 1 t a}$ & 1.11 & .42 & -.29 & .33 \\
\hline 2. Delta & 1.11 & .37 & .23 & .44 \\
\hline 3. Delta & .82 & .25 & .84 & .50 \\
\hline 4. Delta & .86 & .29 & 1.06 & .95 \\
\hline 5. Delta & .85 & .22 & .78 & .61 \\
\hline 6. Delta & .80 & .25 & .76 & .79 \\
\hline 7. Delta & .57 & .30 & .65 & .68 \\
\hline 8. Delta & .54 & .26 & -.26 & -.01 \\
\hline 1. Theta & .74 & .33 & .26 & .62 \\
\hline 2. Theta & .70 & .30 & .18 & .60 \\
\hline 3. Theta & .54 & .22 & .13 & .46 \\
\hline 4. Theta & .55 & .24 & .90 & .47 \\
\hline 5. Theta & .74 & .27 & .78 & .83 \\
\hline 6. Theta & .70 & .32 & 2.06 & 1.16 \\
\hline 7. Theta & .59 & .33 & -.11 & .17 \\
\hline 8. Theta & .57 & .31 & .17 & .25 \\
\hline 1.Alpha & .49 & .27 & .84 & .66 \\
\hline 2. Alpha & .42 & .25 & .36 & .53 \\
\hline 3. Alpha & .60 & .26 & -.27 & .36 \\
\hline 4. Alpha & .60 & .30 & .18 & -.02 \\
\hline 5. Alpha & 1.19 & .46 & -.80 & .04 \\
\hline 6. Alpha & 1.21 & .49 & -.15 & .24 \\
\hline 7. Alpha & 1.12 & .51 & -.52 & .00 \\
\hline 8.Alpha & 1.17 & .46 & -.49 & -.13 \\
\hline 1. Beta 1 & .11 & .29 & 1.51 & .88 \\
\hline 2. Beta 1 & .03 & .26 & 2.05 & .76 \\
\hline 3. Beta 1 & .35 & .29 & -.40 & .24 \\
\hline 4. Beta 1 & .30 & .28 & 1.48 & .27 \\
\hline 5.Beta 1 & .65 & .28 & -.58 & -.24 \\
\hline 6. Beta 1 & .62 & .32 & -.19 & .22 \\
\hline 7 . Beta 1 & .47 & .31 & -.75 & -.27 \\
\hline 8. Beta 1 & .53 & .32 & -.44 & .09 \\
\hline 1. Beta 2 & .32 & .42 & .91 & 1.02 \\
\hline 2 . Beta 2 & .27 & .37 & 2.42 & .95 \\
\hline 3. Beta 2 & .62 & .43 & .12 & .44 \\
\hline 4. Beta 2 & .56 & .42 & .03 & .37 \\
\hline 5. Beta 2 & .78 & .38 & -.17 & .18 \\
\hline 6. Beta 2 & .74 & .41 & -.05 & .39 \\
\hline 7. Beta 2 & .52 & .35 & -.33 & .25 \\
\hline 8. Beta 2 & .61 & .39 & -.24 & .38 \\
\hline
\end{tabular}

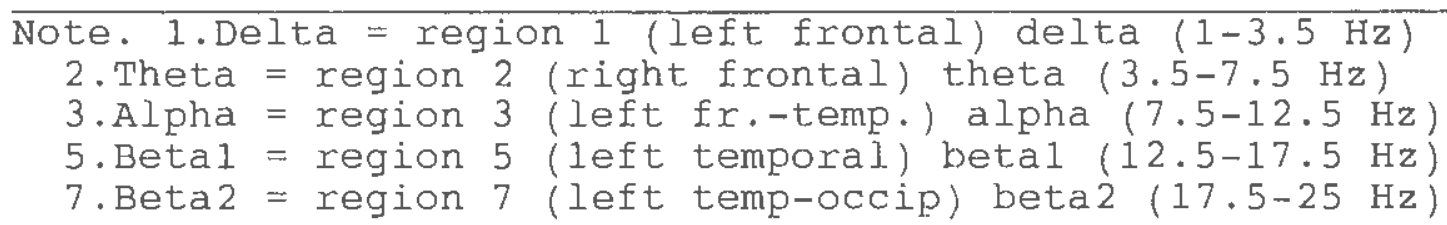


Table B4

Descriptive Statistics of the LOG10(RP/1-RP) EEG Collected During CPT1

\begin{tabular}{|c|c|c|c|c|}
\hline Variable & M & $\underline{\mathrm{SD}}$ & Kurtosis & Skewness \\
\hline$\overline{1 . \text { Delta }}$ & -.03 & .38 & 1.01 & -.74 \\
\hline 2. Delta & .04 & .32 & 1.35 & -.53 \\
\hline 3. Delta & -.38 & .31 & .59 & -.06 \\
\hline 4. Delta & -.32 & .34 & 1.54 & -.03 \\
\hline 5. Delta & -.70 & .28 & .59 & .50 \\
\hline 6. Delta & -.75 & .28 & .00 & .03 \\
\hline 7. Delta & -.86 & .33 & 2.36 & 1.08 \\
\hline 8. Delta & -.92 & .26 & -.27 & .62 \\
\hline 1. Theta & -.62 & .20 & .32 & -.43 \\
\hline 2. Theta & -.62 & .17 & 1.18 & -.85 \\
\hline 3. Theta & -.75 & .19 & .98 & -.71 \\
\hline 4. Theta & -.75 & .20 & 2.46 & -.94 \\
\hline 5. Theta & -.84 & .22 & -.40 & -.29 \\
\hline 6. Theta & -.88 & .22 & -.26 & -.42 \\
\hline 7. Theta & -.84 & .24 & -.61 & -.04 \\
\hline 8. Theta & -.90 & .23 & -.20 & .33 \\
\hline 1.Alpha & -.91 & .33 & .99 & .09 \\
\hline 2.Alpha & -.95 & .28 & -.02 & -.34 \\
\hline 3. Alpha & -.67 & .29 & .37 & .31 \\
\hline 4.Alpha & -.67 & .30 & -.56 & .08 \\
\hline 5.Alpha & -.22 & .38 & -.88 & -.06 \\
\hline 6.Alpha & -.15 & .39 & -.66 & -.04 \\
\hline 7.Alpha & -.06 & .41 & .06 & -.30 \\
\hline 8.Alpha & -.04 & .36 & -.63 & -.16 \\
\hline 1. Beta 1 & $-1 \cdot 33$ & .35 & 2.32 & -1.26 \\
\hline 2. Beta 1 & -1.36 & .34 & 1.43 & -1.11 \\
\hline 3. Betal & -.97 & .23 & 2.91 & -1.00 \\
\hline 4. Beta 1 & -1.03 & .26 & 2.72 & -1.41 \\
\hline 5. Betal & -.95 & .24 & -.37 & .26 \\
\hline 6. Beta 1 & -.96 & .26 & -.06 & .00 \\
\hline 7. Beta 1 & -.98 & .28 & -.36 & -.22 \\
\hline 8. Betal & -.94 & .26 & -.50 & -.16 \\
\hline 1. Beta 2 & -1.08 & .52 & 1.01 & .03 \\
\hline 2. Beta 2 & -1.10 & .48 & 1.42 & -.12 \\
\hline 3. Beta 2 & -.63 & .43 & .01 & -.02 \\
\hline 4. Beta 2 & -.70 & .45 & -.21 & -.12 \\
\hline 5. Beta 2 & -.78 & .39 & -.50 & .19 \\
\hline 6. Beta 2 & -.81 & .41 & -.55 & .24 \\
\hline 7. Beta 2 & -.91 & .38 & -.42 & .42 \\
\hline 8. Beta 2 & -.83 & .38 & -.52 & .28 \\
\hline
\end{tabular}

Note. 1. Delta $=$ region 1 (left frontal) delta $(1-3.5 \mathrm{~Hz})$ 2. Theta $=$ region 2 (right frontal) theta $(3.5-7.5 \mathrm{~Hz})$ 3. Alpha = region 3 (left fr.-temp.) alpha $(7.5-12.5 \mathrm{~Hz}$ ) 5. Betal = region 5 (left temporal) betal (12.5-17.5 Hz) 7 . Beta 2 region 7 (left temp-occip) beta $2(17.5-25 \mathrm{~Hz}$ ) 
Table B5

Descriptive Statistics of Logl0(1+AP) EEG Collected During CPT 1

\begin{tabular}{|c|c|c|c|c|}
\hline Variable & $\underline{M}$ & $\underline{\mathrm{SD}}$ & Kurtosis & Skewness \\
\hline 1.Delta & 1.16 & .38 & -.20 & .49 \\
\hline 2. Delta & 1.16 & .34 & .36 & .61 \\
\hline 3. Delta & .89 & .22 & 1.43 & .74 \\
\hline 4. Delta & .92 & .26 & 1.55 & 1.14 \\
\hline 5. Delta & .92 & .19 & 1.13 & .80 \\
\hline 6. Delta & .87 & .22 & 1.16 & .99 \\
\hline 7. Delta & .69 & .24 & 1.50 & 1.05 \\
\hline 8. Delta & .67 & .20 & -.26 & .34 \\
\hline 1. Theta & .83 & .29 & .67 & .89 \\
\hline 2. Theta & .79 & .25 & .62 & .86 \\
\hline 3. Theta & .66 & .17 & .59 & .74 \\
\hline 4. Theta & .67 & .19 & 1.52 & .88 \\
\hline 5. Theta & .83 & .24 & 1.27 & 1.06 \\
\hline 6. Theta & .79 & .27 & 3.04 & 1.50 \\
\hline 7. Theta & .71 & .26 & .15 & .56 \\
\hline 8. Theta & .69 & .24 & .41 & .68 \\
\hline 1.Alpha & .63 & .21 & 1.78 & 1.10 \\
\hline 2.Alpha & .57 & .19 & 1.08 & .95 \\
\hline 3.Alpha & .71 & .21 & .01 & .62 \\
\hline 4. Alpha & .72 & .23 & -.06 & .42 \\
\hline 5.Alpha & 1.23 & .42 & -.83 & .17 \\
\hline 6. Alpha & 1.26 & .45 & -.09 & .43 \\
\hline 7.Alpha & 1.17 & .46 & -.48 & .20 \\
\hline 8.Alpha & 1.22 & .42 & -.58 & .06 \\
\hline 1. Betal & .38 & .18 & 4.51 & 1.78 \\
\hline 2. Beta 1 & .34 & .15 & 8.00 & 1.98 \\
\hline 3.Betal & .53 & .20 & -.12 & .66 \\
\hline 4. Betal & .50 & .19 & 3.56 & 1.19 \\
\hline 5. Beta 1 & .75 & .23 & -.68 & .02 \\
\hline 6. Beta 1 & .73 & .26 & .06 & .56 \\
\hline 7. Beta 1 & .62 & .22 & -.86 & .05 \\
\hline 8. Betal & .66 & .24 & -.25 & .45 \\
\hline 1. Beta 2 & .53 & .31 & 2.26 & 1.58 \\
\hline 2. Beta 2 & .49 & .26 & 5.70 & 1.94 \\
\hline 3. Beta 2 & .74 & .34 & .65 & .89 \\
\hline 4. Beta 2 & .70 & .33 & .59 & .85 \\
\hline 5. Beta 2 & .86 & .32 & -.03 & .50 \\
\hline 6. Beta 2 & .84 & .35 & .31 & .73 \\
\hline 7 . Beta 2 & .66 & .27 & -.02 & .66 \\
\hline 8. Beta 2 & .73 & .31 & .20 & .74 \\
\hline
\end{tabular}

Note. 1. Delta $=$ region 1 (left frontal) delta $(1-3.5 \mathrm{~Hz}$ ) 2. Theta $=$ region 2 (right frontal) theta $(3.5-7.5 \mathrm{~Hz})$ 3. Alpha = region 3 (left fr.-temp.) alpha $(7.5-12.5 \mathrm{~Hz}$ ) 5. Betal = region 5 (left temporal) betal (12.5-17.5 $\mathrm{Hz}$ ) 7. Beta 2 region 7 (left temp-occip) beta2 (17.5-25 Hz) 
Table $B 6$

Descriptive statistics of the square Root (SQRT) of Absolute Power EEG Collected During CPT1

\begin{tabular}{|c|c|c|c|c|}
\hline Variable & $\underline{M}$ & $\underline{S D}$ & Kurtosis & Skewness \\
\hline 1.Delta & 4.04 & 2.15 & 2.55 & 1.54 \\
\hline 2. Delta & 3.97 & 1.93 & 3.77 & 1.77 \\
\hline 3. Delta & 2.69 & .88 & 7.49 & 2.00 \\
\hline 4.Delta & 2.86 & 1.17 & 6.65 & 2.22 \\
\hline 5. Delta & 2.77 & .77 & 4.26 & 1.63 \\
\hline 6.Delta & 2.63 & .87 & 4.83 & 1.83 \\
\hline 7. Delta & 2.04 & .82 & 6.65 & 2.06 \\
\hline 8. Delta & 1.96 & .60 & .27 & .75 \\
\hline 1. Theta & 2.54 & 1.13 & 3.71 & 1.76 \\
\hline 2. Theta & 2.39 & .94 & 3.29 & 1.63 \\
\hline 3. Theta & 1.93 & .52 & 2.20 & 1.25 \\
\hline 4. Theta & 1.95 & .58 & 4.52 & 1.64 \\
\hline 5. Theta & 2.48 & .91 & 4.54 & 1.89 \\
\hline 6. Theta & 2.42 & 1.15 & 10.98 & 2.85 \\
\hline 7. Theta & 2.13 & .85 & 2.04 & 1.26 \\
\hline 8. Theta & 2.05 & .78 & 2.65 & 1.38 \\
\hline 1.Alpha & 1.85 & .67 & 5.51 & 1.93 \\
\hline 2.Alpha & 1.69 & .54 & 2.88 & 1.48 \\
\hline 3.Alpha & 2.09 & .68 & 1.35 & 1.13 \\
\hline 4.Alpha & 2.12 & .75 & .88 & .97 \\
\hline 5.Alpha & 4.50 & 2.43 & .84 & 1.05 \\
\hline 6.Alpha & 4.76 & 2.99 & 3.50 & 1.78 \\
\hline 7. Alpha & 4.31 & 2.70 & 8.06 & 2.03 \\
\hline 8. Alpha & 4.42 & 2.36 & 2.15 & 1.21 \\
\hline 1. Beta 1 & 1.20 & .49 & 9.31 & 2.49 \\
\hline 2. Beta 1 & 1.09 & .39 & 17.14 & 3.04 \\
\hline 3. Beta 1 & 1.58 & .55 & .76 & 1.00 \\
\hline 4. Beta 1 & 1.50 & .55 & 10.34 & 2.34 \\
\hline 5. Beta 1 & 2.23 & .71 & -.39 & .42 \\
\hline 6. Beta 1 & 2.20 & .87 & 2.00 & 1.26 \\
\hline 7. Beta 1 & 1.82 & .61 & -.54 & .36 \\
\hline 8. Beta 1 & 1.97 & .75 & 1.07 & .99 \\
\hline 1. Beta 2 & 1.66 & 1.06 & 5.54 & 2.32 \\
\hline 2. Beta 2 & 1.52 & .91 & 21.81 & 3.86 \\
\hline 3. Beta 2 & 2.31 & 1.32 & 4.65 & 1.95 \\
\hline 4. Beta 2 & 2.15 & 1.20 & 5.41 & 1.96 \\
\hline 5. Beta 2 & 2.69 & 1.26 & 2.71 & 1.43 \\
\hline 6. Beta 2 & 2.64 & 1.43 & 3.81 & 1.78 \\
\hline 7. Beta 2 & 1.97 & .86 & 1.28 & 1.22 \\
\hline 8. Beta 2 & 2.24 & 1.12 & 4.13 & 1.68 \\
\hline
\end{tabular}

\footnotetext{
Note. 1.Delta $=$ region 1 (left frontal) delta $(1-3.5 \mathrm{~Hz}$ )

2 . Theta $=$ region 2 (right fxontal) theta $(3.5-7.5 \mathrm{~Hz}$ )

3.Alpha $=$ region 3 (left fr.-temp.) alpha $(7.5-12.5 \mathrm{~Hz}$ )

5. Betal 1 region 5 (left temporal) betal $(12.5-17.5 \mathrm{~Hz}$ )

7 . Beta 2 region 7 (left temp-occip) beta $2(17.5-25 \mathrm{~Hz}$ )
} 
Table B7

Descriptive statistics of the 1/SQRT(AP) EEG Collected During CPrl

\begin{tabular}{|c|c|c|c|c|}
\hline Variable & $\underline{M}$ & $\underline{\mathrm{S} D}$ & Kurtosis & Skewness \\
\hline 1.Delta & .31 & .14 & .38 & .75 \\
\hline 2. Delta & .30 & .12 & .67 & .77 \\
\hline 3. Delta & .41 & .11 & -.34 & .35 \\
\hline 4. Delta & .39 & .12 & -.35 & -.05 \\
\hline 5. Delta & .39 & .09 & -.04 & .17 \\
\hline 6. Delta & .41 & .11 & .19 & .06 \\
\hline 7. Delta & .55 & .17 & -.14 & .27 \\
\hline 8. Delta & .56 & .17 & .44 & .78 \\
\hline 1. Theta & .46 & .16 & -.33 & .33 \\
\hline 2. Theta & .47 & .15 & -.51 & .22 \\
\hline 3. Theta & .55 & .13 & -.34 & .18 \\
\hline 4. Theta & .55 & .14 & .98 & .54 \\
\hline 5. Theta & .44 & .13 & -.19 & .04 \\
\hline 6. Theta & .47 & .15 & .04 & .05 \\
\hline 7. Theta & .54 & .20 & .65 & .82 \\
\hline 8. Theta & .55 & .19 & 1.58 & .88 \\
\hline 1. Alpha & .60 & .18 & .15 & .33 \\
\hline 2. Alpha & .64 & .18 & -.11 & .29 \\
\hline 3. Alpha & .52 & .15 & -.46 & .31 \\
\hline 4. Alpha & .53 & .19 & 3.79 & 1.34 \\
\hline 5. Alpha & .29 & .15 & .48 & .92 \\
\hline 6. Alpha & .29 & .16 & .85 & 1.08 \\
\hline 7. Alpha & .33 & .20 & .84 & 1.12 \\
\hline 8.Alpha & .30 & .17 & 1.54 & 1.31 \\
\hline 1. Betal & .93 & .28 & .49 & .28 \\
\hline 2. Beta 1 & 1.00 & .28 & .42 & .38 \\
\hline 3. Beta 1 & .71 & .23 & .22 & .55 \\
\hline 4. Beta 1 & .74 & +25 & 2.36 & 1.14 \\
\hline 5. Beta 1 & .50 & .17 & .16 & .89 \\
\hline 6. Beta 1 & .52 & .19 & .33 & .71 \\
\hline 7. Betal & .62 & .23 & .04 & .88 \\
\hline 8. Beta 1 & .58 & .21 & .12 & .73 \\
\hline 1. Beta 2 & .76 & .31 & .51 & .31 \\
\hline 2 . Beta 2 & .80 & .31 & 4.09 & 1.14 \\
\hline 3. Beta 2 & .55 & .26 & 1.59 & .95 \\
\hline 4. Beta 2 & .59 & .27 & 1.33 & .95 \\
\hline 5. Beta 2 & .45 & .19 & .98 & .94 \\
\hline 6. Beta 2 & .47 & .21 & .38 & .76 \\
\hline 7 . Beta 2 & .60 & .24 & .06 & .67 \\
\hline 8. Beta 2 & .54 & .23 & -.19 & .58 \\
\hline
\end{tabular}

\footnotetext{
Note. l. Delta $=$ region 1 (left frontal) delta $(1-3.5 \mathrm{~Hz}$ ) 2. Theta $=$ region 2 (right frontal) theta $(3.5-7.5 \mathrm{~Hz}$ ) $3 . \mathrm{Alpha}=$ region 3 (left fr.-temp.) alpha (7.5-12.5 Hz) 5. Betal = region 5 (left temporal) betal (12.5-17.5 Hz) 7. Beta 2 region 7 (left temp-occip) beta2 (17.5-25 Hz)
} 
Table $B 8$

Descriptive Statistics of the Cube Root of Absolute Power EEG Collected During CPTI

\begin{tabular}{|c|c|c|c|c|}
\hline Variable & $\underline{\mathrm{M}}$ & $\underline{S D}$ & Kurtosis & Skewness \\
\hline 1. Delta & 2.47 & .84 & 1.21 & 1.13 \\
\hline 2. Delta & 2.45 & .75 & 2.12 & 1.31 \\
\hline 3. Delta & 1.91 & .40 & 4.31 & 1.41 \\
\hline 4. Delta & 1.98 & .51 & 4.14 & 1.75 \\
\hline 5. Delta & 1.96 & .35 & 2.70 & 1.26 \\
\hline 6. Delta & 1.89 & .40 & 2.95 & 1.45 \\
\hline 7 . Delta & 1.59 & .40 & 3.72 & 1.53 \\
\hline 8. Delta & 1.55 & .31 & -.04 & .50 \\
\hline 1. Theta & 1.83 & .51 & 2.14 & 1.36 \\
\hline 2. Theta & 1.76 & .44 & 1.90 & 1.27 \\
\hline 3. Theta & 1.54 & .27 & 1.28 & .97 \\
\hline 4. Theta & 1.55 & .30 & 2.81 & 1.23 \\
\hline 5. Theta & 1.81 & .42 & 2.90 & 1.51 \\
\hline 6. Theta & 1.77 & .51 & 6.87 & 2.23 \\
\hline 7. Theta & 1.63 & +42 & .97 & .88 \\
\hline 8. Theta & 1.59 & .39 & 1.36 & .99 \\
\hline 1.Alpha & 1.49 & .34 & 3.35 & 1.47 \\
\hline 2.Alpha & 1.40 & .29 & 1.76 & 1.15 \\
\hline 3. Alpha & 1.62 & .34 & .60 & .86 \\
\hline 4.Alpha & 1.63 & .38 & .36 & .66 \\
\hline 5.Alpha & 2.64 & .95 & -.05 & .70 \\
\hline 6.Alpha & 2.73 & 1.09 & 1.76 & 1.27 \\
\hline 7.Alpha & 2.55 & 1.03 & 2.76 & 1.13 \\
\hline 8.Alpha & 2.61 & .92 & .56 & .72 \\
\hline 1. Beta 1 & 1.11 & .28 & 5.59 & 1.89 \\
\hline 2. Beta 1 & 1.05 & .23 & 9.45 & 2.09 \\
\hline 3. Beta 1 & 1.34 & .31 & .18 & .75 \\
\hline 4. Beta 1 & 1.29 & .30 & 5.77 & 1.54 \\
\hline 5. Beta 1 & 1.69 & .36 & -.55 & .20 \\
\hline 6. Beta 1 & 1.66 & .43 & .91 & .90 \\
\hline 7. Beta 1 & 1.47 & .34 & -.73 & .15 \\
\hline 8. Beta 1 & 1.55 & .39 & .28 & .68 \\
\hline 1. Beta 2 & 1.36 & .53 & 3.66 & 1.90 \\
\hline 2. Beta 2 & 1.29 & .45 & 11.79 & 2.70 \\
\hline 3. Beta 2 & 1.70 & .61 & 2.47 & 1.42 \\
\hline 4. Beta 2 & 1.62 & .57 & 2.65 & 1.37 \\
\hline 5. Beta 2 & 1.89 & .57 & 1.22 & .99 \\
\hline 6. Beta 2 & 1.86 & .64 & 1.97 & 1.29 \\
\hline 7. Beta 2 & 1.54 & .44 & .53 & .90 \\
\hline 8. Beta 2 & 1.67 & .54 & 1.83 & 1.18 \\
\hline
\end{tabular}

\footnotetext{
Note. 1. Delta $=$ region 1 (left frontal) delta $(1-3.5 \mathrm{~Hz}$ ) 2. Theta $=$ region 2 (right frontal) theta $(3.5-7.5 \mathrm{~Hz}$ ) 3.Alpha = region 3 (left fr. temp.) alpha $(7.5-12.5 \mathrm{~Hz}$ ) 5. Betal = region 5 (left temporal) betal (12.5-17.5 Hz) 7 . Beta 2 region 7 (left temp-occip) beta2 (17.5-25 Hz)
} 
Table B9

Descriptive Statistics of the Arc Sin(SQRT(RP)) EEG Collected During CPT1

\begin{tabular}{|c|c|c|c|c|}
\hline Variable & $\underline{M}$ & $\underline{\mathrm{SD}}$ & Kurtosis & Skewness \\
\hline 1. Delta & .78 & .20 & .29 & -.53 \\
\hline 2. Delta & .81 & .17 & .39 & -.37 \\
\hline 3. Delta & .59 & .16 & .14 & .39 \\
\hline 4. Delta & .62 & .17 & .61 & .52 \\
\hline 5. Delta & .43 & .12 & 1.98 & 1.07 \\
\hline 6. Delta & .41 & .11 & .43 & .62 \\
\hline 7. Delta & .37 & .14 & 6.21 & 1.98 \\
\hline 8. Delta & .34 & .10 & .82 & 1.06 \\
\hline 1. Theta & .46 & .09 & -.05 & -.02 \\
\hline 2. Theta & .46 & .07 & .28 & -.42 \\
\hline 3. Theta & .41 & .08 & .00 & -.19 \\
\hline 4. Theta & .41 & .08 & .85 & -.19 \\
\hline 5. Theta & .37 & .08 & -.64 & .11 \\
\hline 6. Theta & .36 & .08 & -.60 & .02 \\
\hline 7. Theta & .37 & .09 & -.51 & .37 \\
\hline 8. Theta & .35 & .09 & .60 & .81 \\
\hline 1. Alpha & .36 & .12 & 3.17 & 1.23 \\
\hline 2.Alpha & .34 & .10 & -.37 & .29 \\
\hline 3. Alpha & .44 & .13 & 1.06 & .90 \\
\hline 4.Alpha & .45 & .13 & -.42 & .50 \\
\hline 5. Alpha & .67 & .20 & -.98 & .09 \\
\hline 6. Alpha & .71 & .21 & -.84 & .06 \\
\hline 7. Alpha & .75 & .22 & -.68 & -.11 \\
\hline 8. Alpha & .77 & .20 & -.82 & -.10 \\
\hline 1. Beta 1 & .23 & .08 & .14 & .03 \\
\hline 2. Beta 1 & .22 & .07 & -.38 & -.12 \\
\hline 3. Beta 1 & .32 & .07 & 1.50 & .07 \\
\hline 4. Betal & .31 & .07 & .48 & -.49 \\
\hline 5. Beta 1 & .33 & .09 & .18 & .74 \\
\hline 6. Betal & .33 & .09 & .91 & .66 \\
\hline 7 . Beta 1 & .33 & .09 & -.50 & .34 \\
\hline 8. Beta 1 & .34 & .09 & -.49 & .32 \\
\hline 1 . Beta 2 & .32 & .18 & 3.25 & 1.58 \\
\hline 2. Beta 2 & .31 & .16 & 4.19 & 1.63 \\
\hline 3. Beta 2 & .48 & .19 & -.01 & .63 \\
\hline 4. Beta 2 & .45 & .19 & -.37 & .56 \\
\hline 5. Beta 2 & .41 & .16 & .27 & .78 \\
\hline 6. Beta 2 & .40 & .17 & .05 & .81 \\
\hline 7. Beta 2 & .36 & .15 & .53 & 1.01 \\
\hline 8. Beta 2 & .39 & .15 & .49 & .86 \\
\hline
\end{tabular}

\footnotetext{
Note. 1.Delta = region 1 (left frontal) delta (1-3.5 $\mathrm{Hz}$ ) 2. Theta $=$ region 2 (right frontal) theta $(3.5-7.5 \mathrm{~Hz}$ ) 3. Alpha $=$ region 3 (left fr.-temp.) alpha $(7.5-12.5 \mathrm{~Hz}$ ) 5. Betal = region 5 (left temporal) betal (12.5-17.5 Hz) 7 . Beta 2 region 7 (left temp-occip) beta $2(17.5-25 \mathrm{~Hz}$ )
} 
Table B10

Descriptive Statistics of Relative Power (RP) and Log10(RP/1-RP) Component scores Collected During CPT1

\begin{tabular}{|c|c|c|c|c|c|}
\hline Variable & $\underline{S D}$ & Kurtosis & Skewness & Minimum & Maximum \\
\hline RP 5. 1 & 8.59 & 1.26 & .59 & -18.12 & 27.23 \\
\hline $\operatorname{RP} 5.2$ & 9.36 & -.86 & .37 & -16.40 & 19.50 \\
\hline RP 5. 3 & 6.63 & -.30 & .58 & -11.08 & 16.64 \\
\hline RP 5.4 & 2.64 & .56 & .28 & -6.21 & 8.77 \\
\hline RP7.1 & 6.60 & 1.27 & .63 & -13.75 & 21.30 \\
\hline $\operatorname{RP} 7.2$ & 6.60 & -.82 & .40 & -11.86 & 14.63 \\
\hline $\operatorname{RP} 7.3$ & 3.30 & .10 & .77 & -5.11 & 10.08 \\
\hline RP 7. 4 & 2.64 & .56 & .28 & -6.21 & 8.77 \\
\hline RP 7.5 & 3.29 & .37 & .86 & -5.35 & 10.06 \\
\hline RP 8.1 & 7.32 & -.80 & .43 & -12.83 & 16.04 \\
\hline RP 8. 2 & 6.60 & 1.27 & .63 & -13.75 & 21.30 \\
\hline $\operatorname{RP} 8.3$ & 3.30 & .10 & .77 & -5.11 & 10.08 \\
\hline RP 8. 4 & 2.64 & .56 & .28 & -6.21 & 8.77 \\
\hline RP 8. 5 & 2.60 & .69 & .94 & -4.30 & 8.53 \\
\hline RP 8. 6 & 3.48 & .21 & .25 & -8.94 & 10.39 \\
\hline $\mathrm{RP} 10.1$ & 5.19 & 1.72 & 1.01 & -8.83 & 18.00 \\
\hline RP10.2 & 4.33 & .86 & 1.03 & -5.69 & 14.12 \\
\hline $\operatorname{RP} 10.3$ & 3.40 & -.52 & .55 & -5.45 & 8.41 \\
\hline RPI0.4 & 2.64 & .56 & .28 & -6.21 & 8.77 \\
\hline $\mathrm{RP} 10.5$ & 3.29 & .37 & .86 & -5.35 & 10.06 \\
\hline RPI0.6 & 2.63 & .75 & -.89 & -8.76 & 4.62 \\
\hline RP10.9 & 2.63 & .30 & .85 & -4.00 & 7.57 \\
\hline LRP 5.1 & 8.84 & 1.42 & -.80 & -27.86 & 18.88 \\
\hline LRP 5.2 & 10.31 & -.85 & .03 & -23.45 & 20.99 \\
\hline LRP 5.3 & 6.13 & -.63 & .11 & -13.99 & 12.60 \\
\hline LRP 5.4 & 2.62 & .60 & -.54 & -8.15 & 6.60 \\
\hline LRP 7.1 & 9.50 & 1.50 & -.79 & -29.67 & 20.43 \\
\hline LRP 7.2 & 6.60 & -.82 & .07 & -15.48 & 13.00 \\
\hline LRP 7.3 & 3.99 & -.64 & .18 & -8.40 & 8.71 \\
\hline LRP7 . 4 & 2.62 & .60 & -.54 & -8.15 & 6.60 \\
\hline LRP7. 6 & 2.55 & -.38 & -.14 & -6.11 & 4.99 \\
\hline LRP 7.7 & 2.47 & .43 & -.53 & -7.60 & 4.59 \\
\hline LRP9. 1 & 8.16 & 1.13 & -.67 & -24.71 & 18.92 \\
\hline LRP9. 2 & 5.84 & -.81 & .05 & -13.00 & 11.81 \\
\hline LRP9.3 & 3.32 & -.57 & .14 & -6.79 & 7.97 \\
\hline LRP9. 4 & 2.62 & .60 & -.54 & -8.15 & 6.60 \\
\hline LRP9. 6 & 2.69 & -.52 & -.10 & -6.13 & 5.61 \\
\hline LRP9 .7 & 2.47 & .43 & -.53 & -7.60 & 4.59 \\
\hline
\end{tabular}

Note. RP5.1 = component 1 of the RP 5 component extraction.

LRP9. 7 = component 7 of the LRP 9 component extraction. 
Table B11

Descriptive Statistics of Absolute Power (AP) and Loglo(AP) Component Scores Collected During CPTI

\begin{tabular}{lrrrrr}
\hline Variable & SD & Kurtosis & Skewness & Minimum & Maximum \\
\hline AP8.1 & 6.69 & 15.56 & 3.27 & -6.18 & 42.09 \\
AP8.2 & 5.01 & 29.91 & 4.58 & -4.38 & 37.19 \\
AP8.3 & 6.57 & 13.24 & 2.93 & -6.33 & 40.04 \\
AP8.4 & 3.81 & .16 & .86 & -4.99 & 11.06 \\
AP8.5 & 2.63 & 23.83 & 3.81 & -2.58 & 18.59 \\
AP8.6 & 3.58 & 19.86 & 3.76 & -3.20 & 23.56 \\
AP12.1 & 6.69 & 15.56 & 3.27 & -6.18 & 42.09 \\
AP12.2 & 2.76 & 44.43 & 5.90 & -1.76 & 22.47 \\
AP12.3 & 3.63 & 8.01 & 2.64 & -3.10 & 16.51 \\
AP12.4 & 3.58 & 19.86 & 3.76 & -3.20 & 23.56 \\
AP12.5 & 2.67 & 19.28 & 3.42 & -2.56 & 17.89 \\
AP12.9 & 2.44 & 4.11 & 1.83 & -2.76 & 10.49 \\
AP12.10 & 3.54 & 7.12 & 2.28 & -3.84 & 16.02 \\
AP12.11 & 3.53 & 19.67 & 3.56 & -3.37 & 23.53 \\
LAP6.1 & 5.85 & -.44 & -.05 & -13.63 & 15.36 \\
LAP6.2 & 3.60 & 1.67 & .80 & -8.45 & 13.77 \\
LAP6.3 & 6.72 & .39 & .57 & -12.67 & 23.32 \\
IAP6.4 & 3.52 & -.83 & -.09 & -7.47 & 7.39 \\
LAP6.5 & 6.59 & -.34 & .01 & -16.53 & 16.07 \\
LAP6.6 & 6.59 & .66 & .51 & -13.77 & 21.36 \\
& & & & &
\end{tabular}

Note.AP8.1 = component 1 of the AP 8 component extraction. LAP6. $6=$ component 6 of the LAP 6 component extraction. 
Table B12

Descriptive Statistics of Relative Power (RP) and Log10 (RP/1-RP) Component Scores Collected During CPT2

\begin{tabular}{|c|c|c|c|c|c|}
\hline Variable & $\underline{\mathrm{SD}}$ & Kurtosis & Skewness & Minimum & Maximum \\
\hline RP5.1 & 8.46 & .48 & .36 & -20.46 & 22.55 \\
\hline RP 5.2 & 9.14 & -.56 & .41 & -15.82 & 23.34 \\
\hline $\operatorname{RP} 5.3$ & 6.78 & -.18 & .73 & -11.00 & 17.93 \\
\hline RP 5.4 & 2.72 & .81 & .43 & -5.22 & 9.91 \\
\hline RP 7.1 & 6.49 & .25 & .25 & -15.85 & 18.01 \\
\hline RP7. 2 & 6.52 & -.80 & .39 & -11.55 & 14.97 \\
\hline $\operatorname{RP} 7.3$ & 3.37 & .63 & 1.08 & -5.02 & 11.21 \\
\hline RP7. 4 & 2.72 & .81 & .43 & -5.22 & 9.91 \\
\hline RP7. 5 & 3.34 & .58 & .79 & -6.11 & 10.76 \\
\hline RP 8. 1 & 7.16 & -.72 & .43 & -12.61 & 17.87 \\
\hline RP8. 2 & 6.49 & .25 & .25 & -15.85 & 18.01 \\
\hline RP 8. 3 & 3.37 & .63 & 1.08 & -5.02 & 11.21 \\
\hline RP 8. 4 & 2.72 & .81 & .43 & -5.22 & 9.91 \\
\hline RP 8. 5 & 2.65 & .73 & .85 & -4.75 & 8.75 \\
\hline RP 8.6 & 3.39 & 1.39 & -.03 & -9.84 & 9.70 \\
\hline RP 10.1 & 5.07 & .11 & .49 & -9.40 & 14.55 \\
\hline $\operatorname{RP} 10.2$ & 4.25 & 1.38 & 1.11 & -6.11 & 14.26 \\
\hline $\operatorname{RP} 10.3$ & 3.47 & .71 & .98 & -5.29 & 11.63 \\
\hline $\operatorname{RP} 10.4$ & 2.72 & .81 & .43 & $-5 \cdot 22$ & 9.91 \\
\hline RP10.5 & 3.34 & .58 & .79 & -6.11 & 10.76 \\
\hline $\operatorname{RP} 10.6$ & 2.60 & 2.50 & -1.31 & -9.42 & 4.53 \\
\hline $\mathrm{RP} 10.9$ & 2.58 & 1.97 & 1.22 & -3.91 & 10.21 \\
\hline LRP 5.1 & 8.41 & 1.55 & -.77 & -32.17 & 18.57 \\
\hline LRP 5.2 & 10.29 & -.70 & -.02 & -22.76 & 23.82 \\
\hline LRP 5.3 & 6.24 & -.48 & .18 & -13.14 & 13.81 \\
\hline LRP 5.4 & 2.70 & .25 & -.43 & -6.85 & 7.26 \\
\hline LRP 7.1 & 9.01 & 1.68 & -.76 & -34.86 & 19.78 \\
\hline LRP 7.2 & 6.53 & -.74 & .04 & -14.94 & 14.33 \\
\hline LRP7. 3 & 4.05 & -.41 & .32 & -8.20 & 9.94 \\
\hline LRP 7.4 & 2.70 & 1.25 & -.43 & -6.85 & 7.26 \\
\hline LRP7.6 & 2.63 & -.54 & -.07 & -5.97 & 6.79 \\
\hline $\operatorname{LRP} 7.7$ & 2.37 & 2.03 & -.97 & -8.37 & 5.30 \\
\hline LRP9. 1 & 7.78 & 1.17 & -.64 & -28.22 & 18.44 \\
\hline LRP9. 2 & 5.77 & -.69 & .08 & -12.96 & $13 \cdot 6.3$ \\
\hline LRP9. 3 & 3.35 & -.34 & .40 & -6.96 & 8.75 \\
\hline LRP9. 4 & 2.70 & .25 & -.43 & -6.85 & 7.26 \\
\hline LRP9. 6 & 2.74 & -.44 & -.04 & -6.94 & 6.15 \\
\hline LRP9.7 & 2.37 & 2.03 & -.97 & -8.37 & 5.30 \\
\hline
\end{tabular}

Note. RP5.1 = component 1 of the RP 5 component extraction.

LRP9.7 = component 7 of the LRP 9 component extraction. 
Table B13

Descriptive Statistics of Absolute Power (AP) and Log10(AP) Component Scores Collected During CPT2

\begin{tabular}{lrrrrr}
\hline Variable & SD & Kurtosis & Skewness & Minimum & Maximum \\
\hline AP8.1 & 6.75 & 23.12 & 3.96 & -6.05 & 47.02 \\
AP8.2 & 5.14 & 29.79 & 4.57 & -3.90 & 38.11 \\
AP8.3 & 6.41 & 11.32 & 2.71 & -6.60 & 37.46 \\
AP8.4 & 3.97 & 4.53 & 1.75 & -4.78 & 17.17 \\
AP8.5 & 2.63 & 17.07 & 3.23 & -2.53 & 17.07 \\
AP8.6 & 3.41 & 9.99 & 2.62 & -3.17 & 19.35 \\
AP12.1 & 6.75 & 23.12 & 3.96 & -6.05 & 47.02 \\
AP12.2 & 2.80 & 20.29 & 3.91 & -1.90 & 18.69 \\
AP12.3 & 3.39 & 7.03 & 2.31 & -3.17 & 17.31 \\
AP12.4 & 3.41 & 9.99 & 2.62 & -3.17 & 19.35 \\
AP12.5 & 2.63 & 13.62 & 2.89 & -2.56 & 16.15 \\
AP12.9 & 2.44 & 6.94 & 2.39 & -2.29 & 12.21 \\
AP12.10 & 3.54 & 16.71 & 3.52 & -3.05 & 21.89 \\
AP12.11 & 3.50 & 11.54 & 2.85 & -3.43 & 20.15 \\
LAP6.1 & 5.91 & -.52 & .14 & -13.00 & 15.28 \\
LAP6. & 3.62 & .64 & .84 & -7.09 & 11.99 \\
LAP6.3 & 6.55 & .58 & .70 & -12.19 & 22.36 \\
LAP6.4 & 3.50 & -.28 & .01 & -7.58 & 9.07 \\
LAP6.5 & 6.52 & -.19 & .44 & -12.75 & 16.13 \\
LAP6.6 & 6.76 & .74 & .53 & -14.91 & 23.26
\end{tabular}

Note.AP8.1 $=$ component 1 of the AP 8 component extraction. LAP 6.6 component 6 of the LAP 6 component extraction. 
Table B14

Descriptive Statistics of Relative Power (RP) and Loglo (RP/1-RP) Component Scores Collected During Resting

\begin{tabular}{|c|c|c|c|c|c|}
\hline Variable & $\underline{\mathrm{SD}}$ & Kurtosis & Skewness & Minimum & Maximum \\
\hline RP5.1 & 7.70 & -.01 & .29 & -16.41 & 20.54 \\
\hline RP 5.2 & 9.33 & -.20 & .60 & -15.51 & 26.33 \\
\hline RP 5. 3 & 7.11 & -.67 & .52 & $-11 \cdot 32$ & 16.88 \\
\hline RP 5. 4 & 2.56 & -.64 & 11 & -5.43 & 6.15 \\
\hline RP7. 1 & 6.12 & -.10 & .21 & -14.22 & 16.27 \\
\hline RP7. 2 & 6.53 & -.33 & .57 & -11.19 & 16.67 \\
\hline RP 7. 3 & 3.43 & .12 & .66 & -5.50 & 10.53 \\
\hline RP 7.4 & 2.56 & -.64 & .11 & -5.43 & 6.15 \\
\hline $\mathrm{RP} 7.5$ & 3.41 & -.58 & .39 & -6.29 & 8.87 \\
\hline RP8. 1 & 7.17 & -.25 & .59 & -11.96 & 19.57 \\
\hline RP 8. 2 & 6.12 & -.10 & .21 & -14.22 & 16.27 \\
\hline RP 8. 3 & 3.43 & .12 & .66 & -5.50 & 10.53 \\
\hline RP 8. 4 & 2.56 & -.64 & .11 & -5.43 & 6.15 \\
\hline RP8. 5 & 2.70 & -.65 & .28 & -5.07 & 6.69 \\
\hline RP 8.6 & 3.39 & -.09 & .44 & -9.13 & 8.43 \\
\hline RP10.1 & 5.00 & .17 & .60 & -9.86 & 13.58 \\
\hline RP10.2 & 4.43 & 1.57 & 1.17 & -6.67 & 16.16 \\
\hline $\operatorname{RP} 10.3$ & 3.59 & .23 & .68 & -5.91 & 11.50 \\
\hline $\operatorname{RP} 10.4$ & 2.56 & -.64 & .11 & -5.43 & 6.15 \\
\hline $\operatorname{RP} 10.5$ & 3.41 & -.58 & .39 & -6.29 & 8.87 \\
\hline RP10.6 & 2.40 & 1.07 & -1.01 & -8.35 & 3.97 \\
\hline RP10.9 & 2.56 & 4.07 & 1.45 & -3.65 & 12.08 \\
\hline LRP 5.1 & 8.03 & .55 & -.55 & -26.67 & 16.65 \\
\hline LRP 5.2 & 10.46 & -.46 & .06 & -22.54 & 25.17 \\
\hline LRP 5.3 & 6.57 & -.84 & -.01 & -12.93 & 12.72 \\
\hline LRP 5.4 & 2.57 & -.49 & -.32 & -6.57 & 5.06 \\
\hline LRP 7.1 & 8.50 & .57 & -.53 & -28.61 & 17.88 \\
\hline LRP7 . 2 & 6.60 & -.41 & -.05 & $-15 \cdot 30$ & 14.00 \\
\hline LRP 7.3 & 4.16 & -.62 & -.08 & -8.96 & 9.15 \\
\hline LRP 7.4 & 2.57 & -.49 & -.32 & -6.57 & 5.06 \\
\hline LRP 7.6 & 2.58 & -.44 & .37 & -5.27 & 6.60 \\
\hline LRP 7.7 & 2.29 & -.51 & -.07 & -5.42 & 4.77 \\
\hline LRP9. 1 & 7.57 & .35 & -.51 & -23.98 & 14.88 \\
\hline LRP9. 2 & 5.78 & -.41 & -.03 & $-13,17$ & 12.64 \\
\hline LRP9. 3 & 3.49 & -.45 & -.12 & -7.69 & 7.99 \\
\hline LRP 9.4 & 2.57 & -.49 & -.32 & -6.57 & 5.06 \\
\hline LRP9. 6 & 2.75 & -.78 & .30 & -5.68 & 5.63 \\
\hline LRP9.7 & 2.29 & -.51 & -.07 & -5.42 & 4.77 \\
\hline
\end{tabular}

Note. RP5.1 = component 1 of the RP 5 component extraction.

LRP9.7 = component 7 of the LRP 9 component extraction. 
Table B15

Descriptive Statistics of Absolute Power (AP) and Log10(AP) Component Scores collected During Resting

\begin{tabular}{|c|c|c|c|c|c|}
\hline Variable & $\underline{S D}$ & Kurtosis & Skewness & Minimum & Maximum \\
\hline AP 8.1 & 6.60 & 19.64 & 3.53 & -6.57 & 44.27 \\
\hline AP 8.2 & 4.11 & 1.82 & 1.32 & -5.46 & 14.25 \\
\hline AP 8.3 & 5.83 & 4.73 & 1.86 & -7.66 & 25.21 \\
\hline AP 8. 4 & 3.90 & .73 & 1.10 & -5.09 & 11.54 \\
\hline AP 8. 5 & 2.57 & 16.06 & 3.10 & -2.61 & 16.44 \\
\hline AP 8.6 & 3.17 & 3.31 & 1.71 & -3.59 & 13.07 \\
\hline AP12.1 & 6.60 & 19.64 & 3.53 & -6.57 & 44.27 \\
\hline $\operatorname{AP} 12.2$ & 2.59 & 5.21 & 2.16 & -2.51 & 10.81 \\
\hline $\mathrm{AP} 12.3$ & 3.30 & 15.10 & 3.19 & -3.31 & 20.52 \\
\hline AP12. 4 & 3.17 & 3.31 & 1.71 & -3.59 & 13.07 \\
\hline $\mathrm{AP} 12.5$ & 2.60 & 11.29 & 2.77 & -2.63 & 14.95 \\
\hline AP 12.9 & 2.59 & 3.77 & 1.76 & -2.88 & 11.29 \\
\hline AP 12.10 & 3.32 & 4.91 & 1.75 & -4.28 & 15.92 \\
\hline AP 12.11 & 3.23 & 3.51 & 1.61 & -4.36 & 13.25 \\
\hline LAP 6.1 & 6.15 & -.45 & -.34 & -14.94 & 14.20 \\
\hline LAP 6.2 & 3.58 & .01 & .53 & -6.54 & 10.00 \\
\hline LAP 6.3 & 6.32 & .33 & .23 & -14.86 & 17.68 \\
\hline LAP 6.4 & 3.59 & -.51 & -.18 & -8.44 & 7.16 \\
\hline LAP 6.5 & 6.48 & -.73 & -.14 & -14.00 & 13.61 \\
\hline LAP 6.6 & 6.80 & .49 & .27 & -14.99 & 21.84 \\
\hline
\end{tabular}


Table B16

Descriptive Statistics of Relative Power (RP) and Log10(RP/1-RP) CPT1-CPT2 Component Change scores

\begin{tabular}{|c|c|c|c|c|c|}
\hline Variable & $\underline{\mathrm{SD}}$ & Kurtosis & Skewness & Minimum & Maximum \\
\hline$\overline{\text { CRP5.1 }}$ & 8.77 & .93 & .58 & $-19 \cdot 95$ & $\overline{29.41}$ \\
\hline CRP 5.2 & 8.01 & .25 & -.32 & -22.21 & 19.93 \\
\hline CRP 5.3 & 6.66 & 1.02 & -.94 & -20.04 & 13.07 \\
\hline CRP 5.4 & 2.73 & -.38 & -.18 & -6.82 & 5.82 \\
\hline CRP7. 1 & 6.67 & .58 & .27 & -15.63 & 20.40 \\
\hline CRP7. 2 & 5.62 & .05 & -.43 & -15.02 & 12.07 \\
\hline CRP 7.3 & 3.16 & .17 & -.23 & -7.18 & 7.66 \\
\hline CRP7. 4 & 2.73 & -.38 & -.18 & -6.82 & 5.82 \\
\hline CRP 7.5 & 3.42 & 2.26 & -.14 & -13.46 & 9.94 \\
\hline CRP8. 1 & 6.21 & .17 & -.29 & $-16 \cdot 32$ & 15.87 \\
\hline CRP8. 2 & 6.67 & .58 & .27 & -15.63 & 20.40 \\
\hline CRP 8. 3 & 3.16 & .17 & -.23 & -7.18 & 7.66 \\
\hline CRP 8.4 & 2.73 & -.38 & -.18 & -6.82 & 5.82 \\
\hline CRP 8. 5 & 2.73 & 2.18 & .58 & -8.78 & 9.12 \\
\hline CRP 8. 6 & 3.64 & 1.37 & -1.09 & $-10 \cdot 30$ & 8.15 \\
\hline CRP10.1 & 5.05 & .99 & .22 & -13.46 & 16.04 \\
\hline CRPI0.2 & 4.46 & 1.62 & -.86 & -16.96 & 8.38 \\
\hline $\operatorname{CRP} 10.3$ & 3.79 & -.02 & .11 & -8.98 & 9.85 \\
\hline CRPI0.4 & 2.73 & -.38 & -.18 & -6.82 & 5.82 \\
\hline CRP10.5 & 3.42 & 2.26 & -.14 & -13.46 & 9.94 \\
\hline $\operatorname{CRP} 10.6$ & 2.51 & 2.20 & -.77 & -8.12 & 6.61 \\
\hline CRP 10.9 & 2.34 & 3.26 & .77 & -7.68 & 9.00 \\
\hline CLRP 5.1 & 9.15 & 2.63 & -.90 & -36.50 & 19.70 \\
\hline CLRP 5.2 & 7.46 & -.16 & .34 & -17.53 & 19.20 \\
\hline CLRP 5.3 & 6.38 & .72 & -.69 & -18.52 & 14.15 \\
\hline CLRP 5.4 & 2.73 & .03 & -.59 & -7.26 & 4.69 \\
\hline CLRP 7.1 & 9.89 & 2.41 & -.84 & -38.66 & 21.13 \\
\hline CLRP 7.2 & 5.40 & -.09 & .21 & -12.17 & 14.60 \\
\hline CLRP 7.3 & 3.99 & .40 & -.45 & -10.69 & 9.05 \\
\hline CLRP 7.4 & 2.73 & .03 & -.59 & -7.26 & 4.69 \\
\hline CLRP 7.6 & 1.99 & .33 & -.22 & -6.02 & 4.88 \\
\hline CLRP 7.7 & 2.45 & -.20 & -.36 & -6.14 & 4.90 \\
\hline CLRP 9.1 & 8.34 & 2.42 & -.79 & -32.79 & 18.78 \\
\hline CLRP 9.2 & 4.57 & .05 & .37 & -10.00 & 13.73 \\
\hline CLRP 9.3 & 3.34 & -.03 & -.08 & -8.56 & 8.00 \\
\hline CLRP 9.4 & 2.73 & .03 & -.59 & -7.26 & 4.69 \\
\hline CLRP9.6 & 2.87 & 1.35 & .28 & -8.02 & 8.90 \\
\hline CLRP9.7 & 2.45 & -.20 & -.36 & -6.14 & 4.90 \\
\hline
\end{tabular}

Note. CRP5.1 = change in component scores (CPT1-CPT2) of component 1 Relative Power 5 component extraction. 
Table B17

Descriptive Statistics of Absolute Power (AP) and Log10(AP) CPT1-CPT2 Component Change Scores

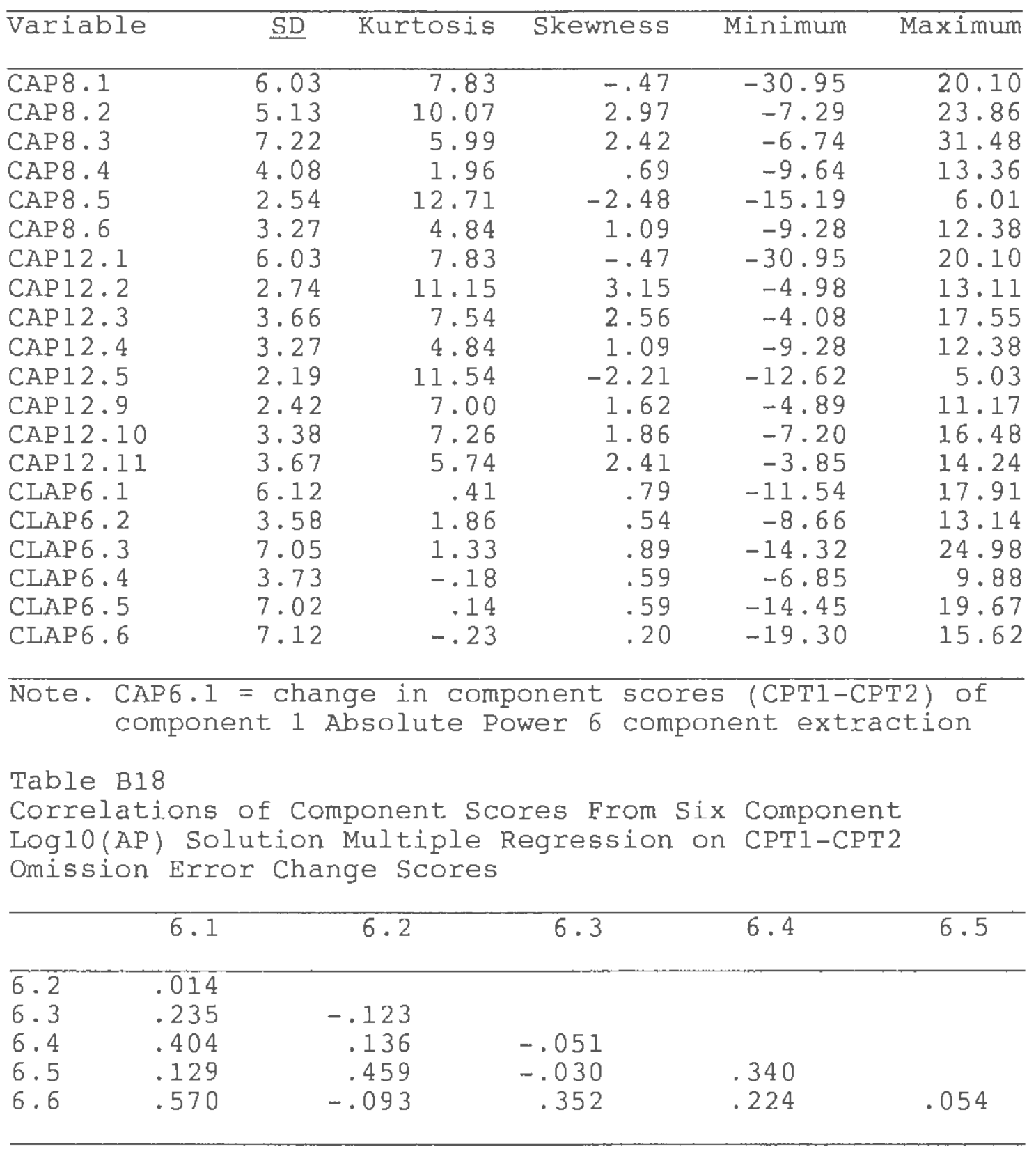


Table B 19

Standard Multiple Regression of Component Scores From Six Component Log10(AP) Solution on Change in Percent Omission Errors (CPT1-CPT2)

$\begin{array}{lllll}\text { Component } & \text { Beta } & \text { Semi Partial } & \underline{F} & p\end{array}$

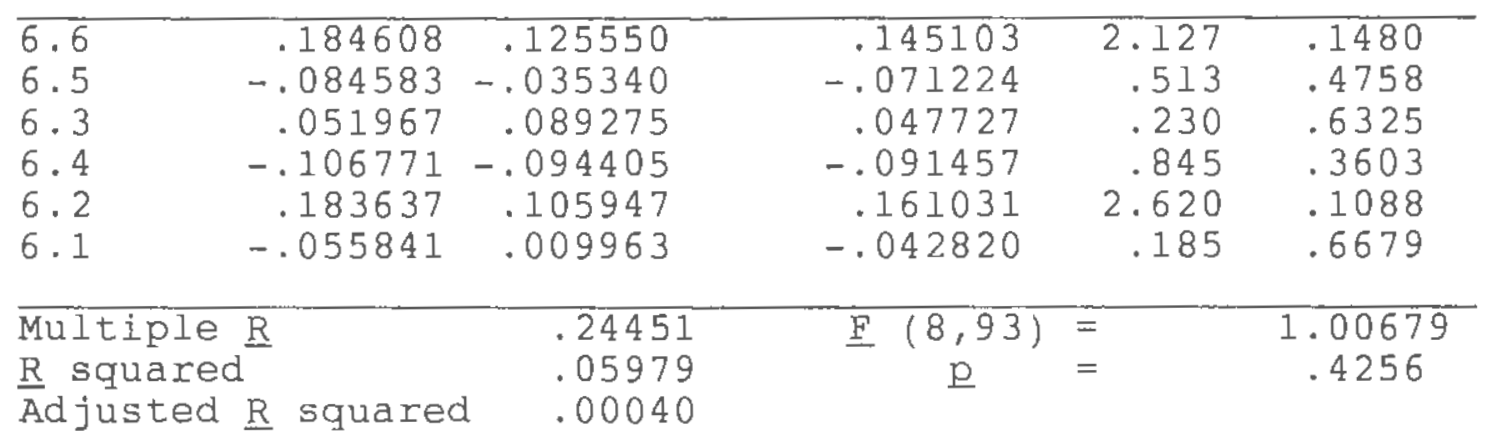

Table 820

Standard Multiple Regression of Component Scores From Five Component Relative Power (RP) Solution on Change in Percent Omission Exrors (CPT1-CPT2)

$\begin{array}{llllll}\text { Component } & \text { Beta } & r & \begin{array}{l}\text { Semi Partial } \\ \text { Correlation }\end{array} & \underline{F} & \underline{p}\end{array}$

\begin{tabular}{lrrrrr}
\hline 5.4 & -.039185 & -.023523 & -.037764 & .143 & .7062 \\
5.3 & .169797 & .168237 & .166962 & 2.794 & .0978 \\
5.1 & .021525 & -.032355 & .018739 & .035 & .8516 \\
5.2 & -.066728 & -.053513 & -.057849 & .335 & .5638 \\
\hline $\begin{array}{l}\text { Multiple R } \\
\text { R squared }\end{array}$ & .17990 & $\underline{F}(4,97)$ & $=$ & .81103 \\
Adjusted R squared & -.00754 & $\mathrm{p}$ & $=$ & .5211 \\
\hline
\end{tabular}

Table B2l

Correlations of Component Scores From Five Component Relative Power (RP) Solution Multiple Regression on CPT1CPT2 Omission Error Change Scores
5.1
$5+2$
$5 \cdot 3$

$5 \cdot 2$

.463

5.3

$-.176$

5.4

$-.175$

$-.041$

$-.259$ .013 
Table B22

Standard Multiple Regression of Component Scores From Ten Component Relative Power (RP) Solution on Change in Percent Omission Errors (CPT1-CPT2)

\begin{tabular}{|c|c|c|c|c|c|}
\hline Component & Beta & $r$ & $\begin{array}{l}\text { Semi Partial } \\
\text { Correlation }\end{array}$ & $\underline{F}$ & $p$ \\
\hline $\begin{array}{l}10.9 \\
10.5 \\
10.3 \\
10.4 \\
10.1 \\
10.2 \\
10.6\end{array}$ & $\begin{array}{r}-.110911 \\
-.067730 \\
.098635 \\
.047436 \\
.100324 \\
-.136950 \\
-.178114\end{array}$ & $\begin{array}{r}-.102962 \\
-.036515 \\
.092407 \\
-.023523 \\
.045795 \\
-.086403 \\
-.056029\end{array}$ & $\begin{array}{r}-.085874 \\
-.057434 \\
.091593 \\
.038816 \\
.082607 \\
-.0105707 \\
-.123314\end{array}$ & $\begin{array}{r}.728 \\
.326 \\
.829 \\
.149 \\
.674 \\
1.104 \\
1.502\end{array}$ & $\begin{array}{l}.3956 \\
.5695 \\
.3650 \\
.7005 \\
.4137 \\
.2962 \\
.2234\end{array}$ \\
\hline $\begin{array}{l}\text { Multiple } \\
\text { R squared } \\
\text { Adjusted }\end{array}$ & squared & $\begin{array}{r}.21977 \\
.04830 \\
-.02257\end{array}$ & $\begin{array}{c}F(7,94) \\
p\end{array}$ & & $\begin{array}{l}.68149 \\
.6873\end{array}$ \\
\hline
\end{tabular}

Table B23

Correlations of Component scores From Ten Component Relative Power (RP) Solution Multiple Regression on CPT1CPT2 Omission Error Change Scores

\begin{tabular}{rrrrrrr}
\hline & 10.1 & 10.2 & 10.3 & 10.4 & 10.5 & 10.6 \\
\hline 10.2 & .320 & & & & & \\
10.3 & -.081 & -.108 & & & & \\
10.4 & -.140 & -.167 & .118 & & & \\
10.5 & .296 & -.136 & .023 & .325 & & \\
10.6 & -.343 & -.495 & .283 & .519 & .237 & \\
10.9 & .335 & .544 & -.302 & -.208 & -.068 & -.471 \\
\hline
\end{tabular}


Table B24

Standard Multiple Regression of Component Scores From Five Component Logl0(RP/l-RP) Solution on Change in Percent Omission Errors (CPT1-CPT2)

\begin{tabular}{llllll}
\hline Component & Beta & $r$ & $\begin{array}{l}\text { Semi Partial } \\
\text { Correlation }\end{array}$ & $\underline{E}$ & p
\end{tabular}

\begin{tabular}{lrrrrr}
\hline 5.4 & -.090179 & -.040856 & -.082695 & .682 & .4109 \\
5.3 & .127080 & .126831 & .122649 & 1.500 & .2236 \\
5.1 & .011114 & -.034174 & .010499 & .011 & .9167 \\
5.2 & -.102975 & -.076535 & -.092678 & .857 & .3570 \\
\hline $\begin{array}{l}\text { Multiple R } \\
\text { R squared }\end{array}$ & .16524 & $\underline{\mathrm{F}}(4,97)$ & $=$ & .68070 \\
Adjusted $\underline{R}$ squared & -.01281 & $\mathrm{P}$ & $=$ & .6070 \\
\end{tabular}

Table $B 25$

Correlations of Component Scores From Five Component

Log10(RP/l-RP) Solution Multiple Regression on CPTl-CPT2 Omission Error Change Scores

\begin{tabular}{llll}
\hline & 5.1 & 5.2 & 5.3 \\
\hline 5.2 & & & \\
5.3 & -.226 & -.093 & \\
5.4 & -.117 & -.396 & .077 \\
\hline
\end{tabular}

Table B26

Standard Multiple Regression of Component Scores From Five Component Logl0(RP/l-RP) Solution on Change in Percent Omission Errors (CPT1-CPT2)

\begin{tabular}{llllll}
\hline Component & Beta & $r$ & $\begin{array}{l}\text { Semi Partial } \\
\text { Correlation }\end{array}$ & $\underline{\mathrm{F}}$ & $\mathrm{p}$
\end{tabular}

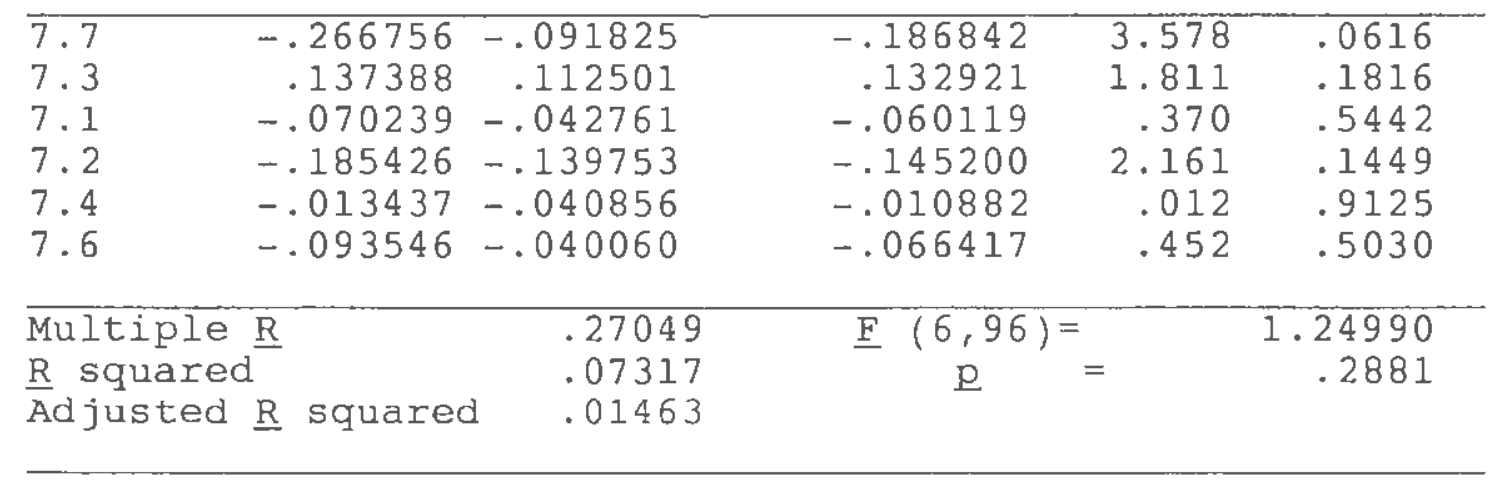


Table 827

Correlations of Component Scores From Seven Component Log10(RP/1-RP) Solution Multiple Regression on CPT1-CPT2 Omission Error Change Scores

\begin{tabular}{|c|c|c|c|c|c|}
\hline & 7.1 & 7.2 & 7.3 & 7.4 & 7.6 \\
\hline $\begin{array}{l}7.2 \\
7.3 \\
7.4 \\
7.6 \\
7.7\end{array}$ & $\begin{array}{r}.277 \\
-.156 \\
-.138 \\
-.064 \\
-.347\end{array}$ & $\begin{array}{r}-.089 \\
-.332 \\
.529 \\
-.459\end{array}$ & $\begin{array}{l}.032 \\
.034 \\
.183\end{array}$ & $\begin{array}{r}-.458 \\
.547\end{array}$ & -.510 \\
\hline
\end{tabular}

Table B28

Standard Multiple Regression of Component Scores From Nine Component Log10(RP/1-RP) Solution on Change in Percent Omission Errors (CPT1-CPT2)

\begin{tabular}{|c|c|c|c|c|c|}
\hline Component & Beta & $r$ & $\begin{array}{l}\text { Semi Partial } \\
\text { Correlation }\end{array}$ & $\underline{\mathrm{F}}$ & $\mathrm{P}$ \\
\hline $\begin{array}{l}9.7 \\
9.3 \\
9.1 \\
9.2 \\
9.4 \\
9.6\end{array}$ & $\begin{array}{r}-.238277 \\
.165119 \\
-.014408 \\
-.214140 \\
.005762 \\
-.010723\end{array}$ & $\begin{array}{r}-.091825 \\
.0139750 \\
-.011821 \\
-.133397 \\
-.040856 \\
.022743\end{array}$ & $\begin{array}{r}-.166030 \\
.154663 \\
-.012004 \\
-.173270 \\
.004627 \\
-.007509\end{array}$ & $\begin{array}{r}2.826 \\
2.452 \\
.015 \\
3.077 \\
.002 \\
.006\end{array}$ & $\begin{array}{l}.0961 \\
.1207 \\
.9035 \\
.0826 \\
.9627 \\
.9396\end{array}$ \\
\hline $\begin{array}{l}\text { Multiple } \underline{R} \\
R \text { squared } \\
\text { Adjusted } \underline{R}\end{array}$ & squared & $\begin{array}{l}.27058 \\
.07321 \\
.01468\end{array}$ & $\begin{array}{c}\mathrm{F} \quad(6,95) \\
\mathrm{p}\end{array}$ & & $\begin{array}{c}1.25076 \\
.2877\end{array}$ \\
\hline
\end{tabular}

Table B29.

Correlations of Component Scores From Nine Component Logl0(RP/1-RP) Solution Multiple Regression on CPT1-CPT2 Omission Error Change Scores

$\begin{array}{lllll}9.1 & 9.2 & 9.3 & 9.4 & 9.6\end{array}$

9. 2 .242

9.3

$-.149$

$-.113$

9.4

$-.119$

$-.310$

.066

9.6

$-.188$

.452

9.7

$-.326$

$-.460$

.129

.213 


\section{Appendix Cl}

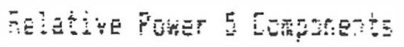

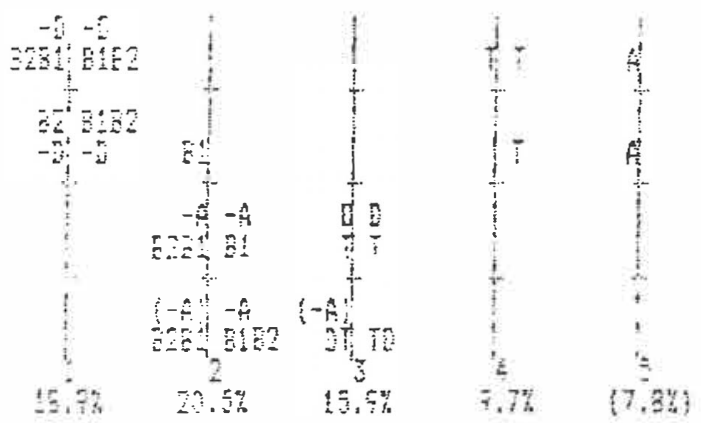

PEletive Punar ó Compjeatte

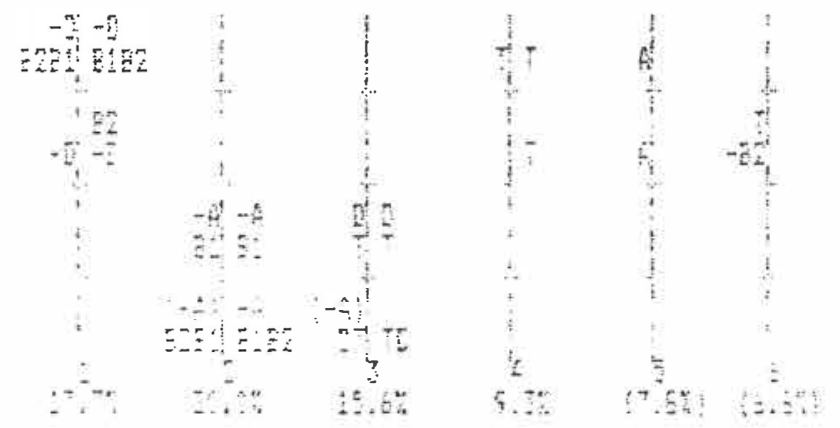

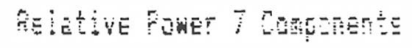

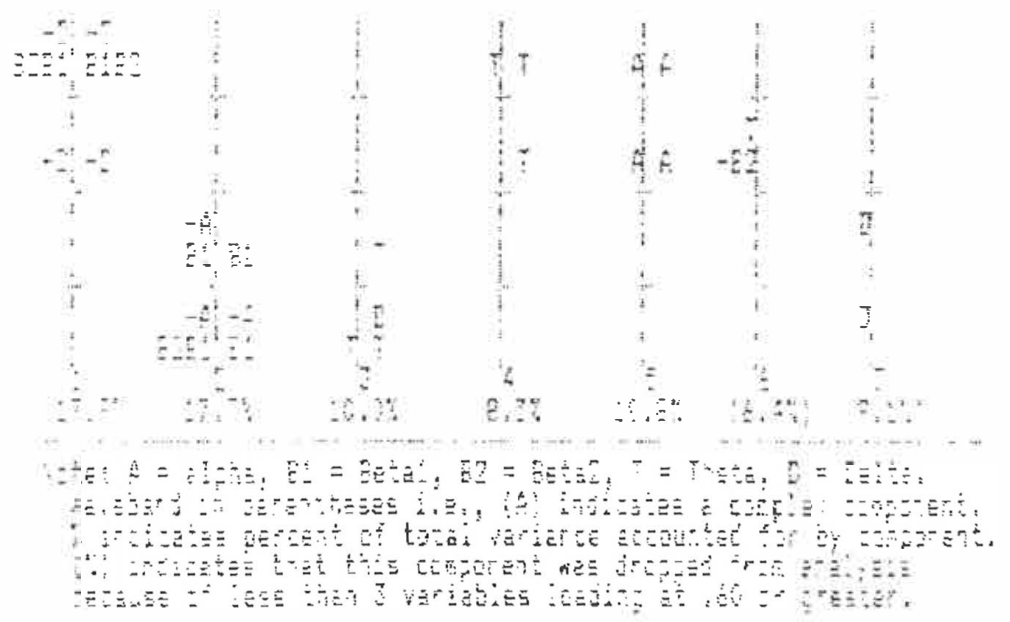


Fintive Pres a Corprente
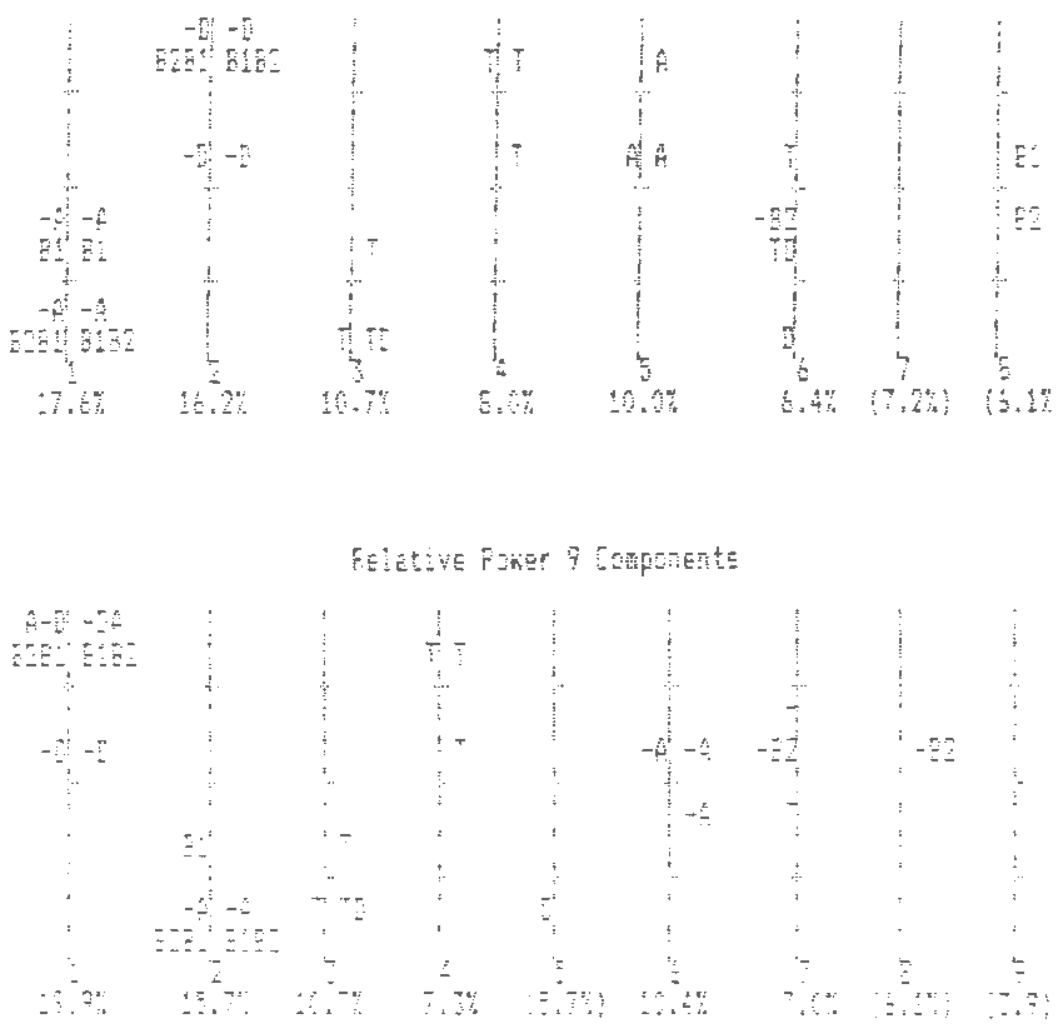

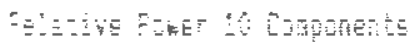

20

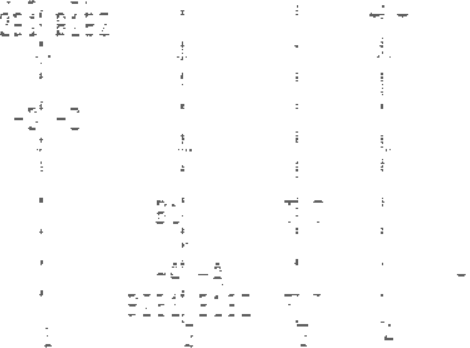

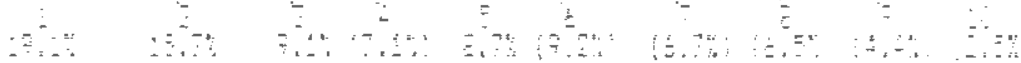

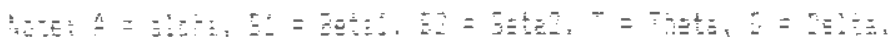

a

a

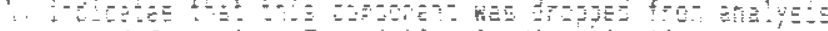

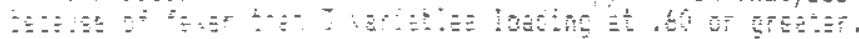


Znd

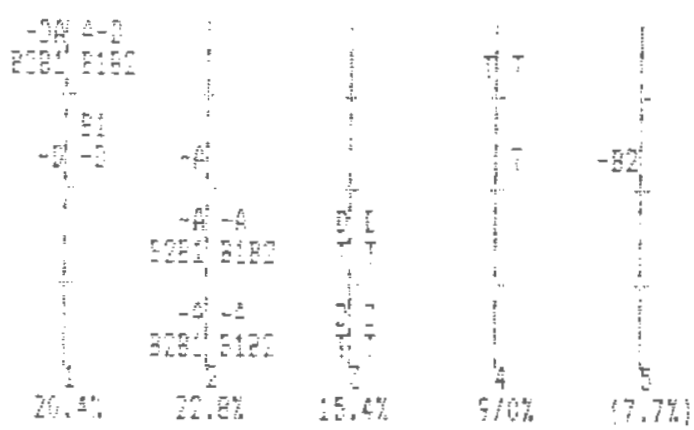

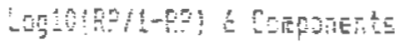

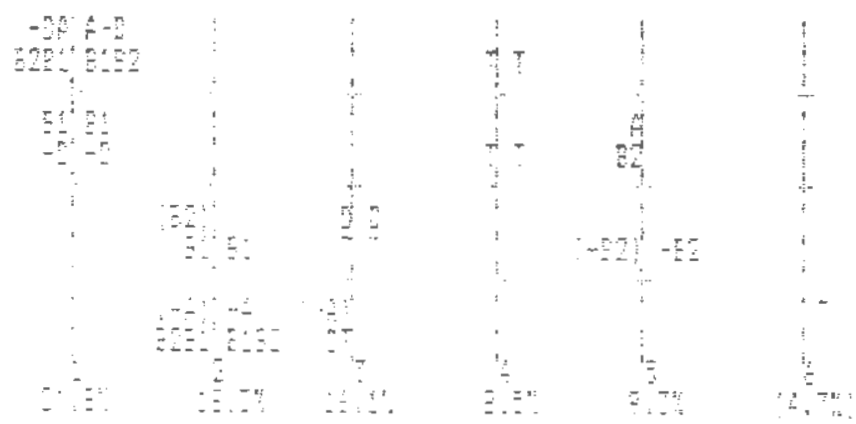

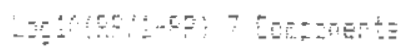

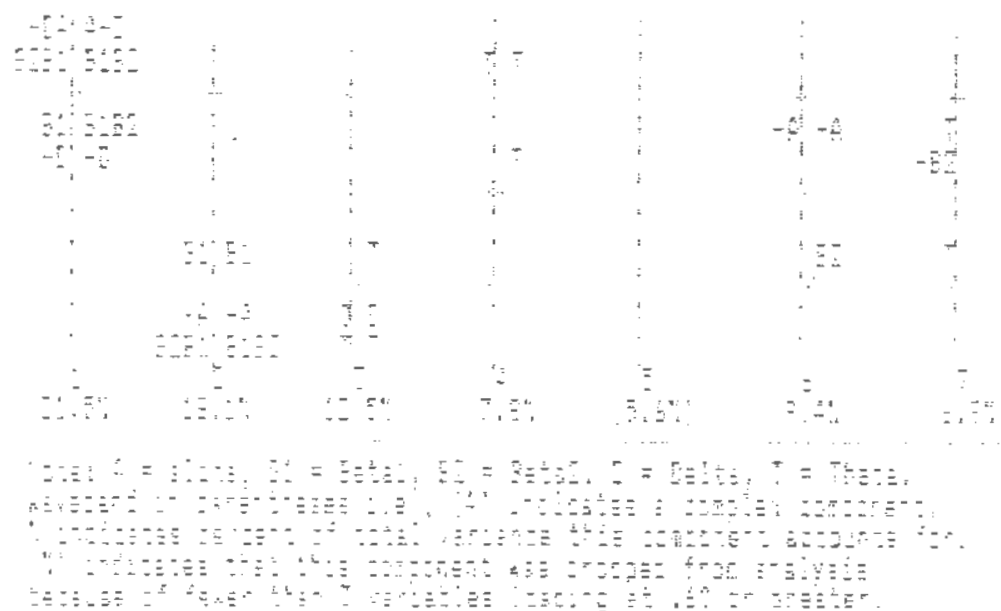




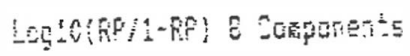

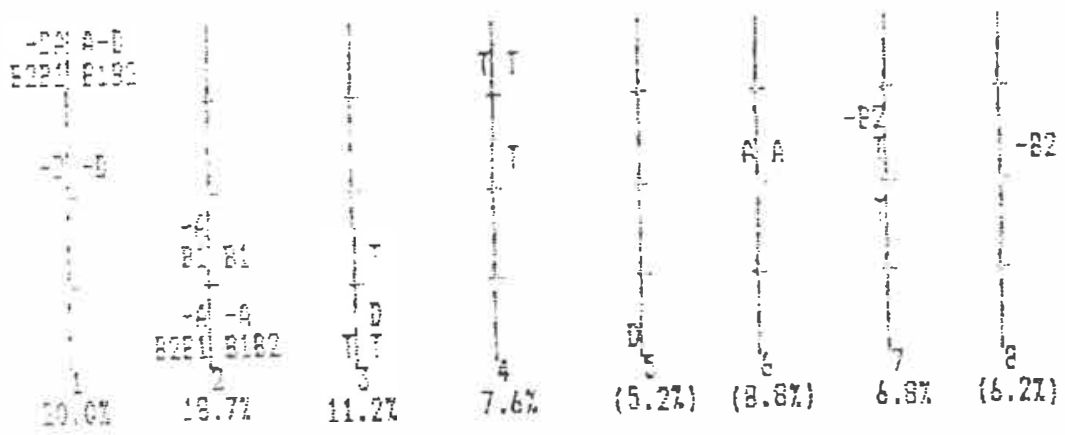

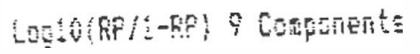

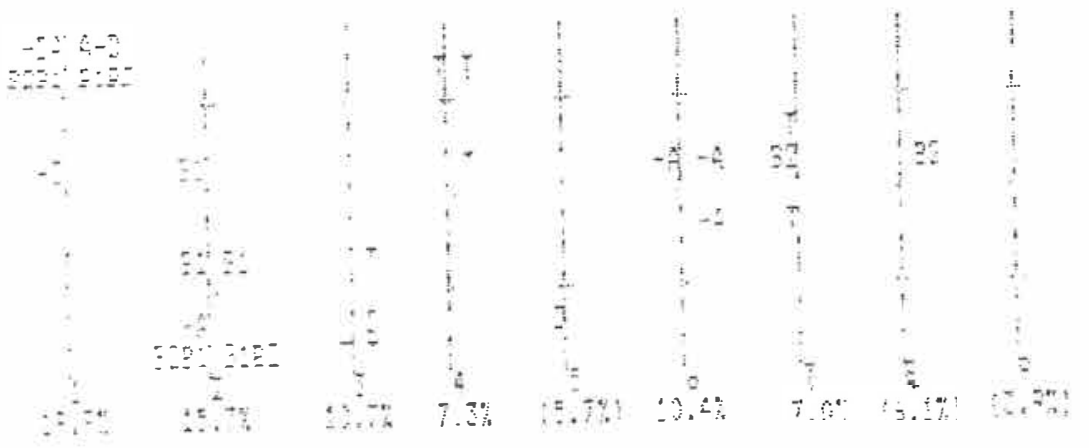

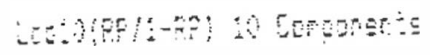

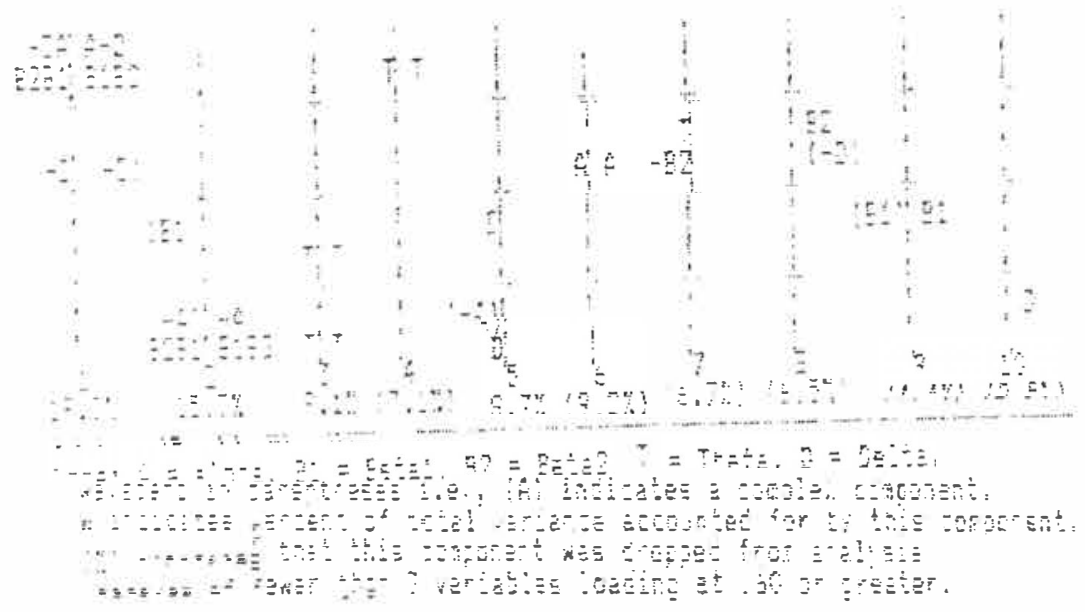




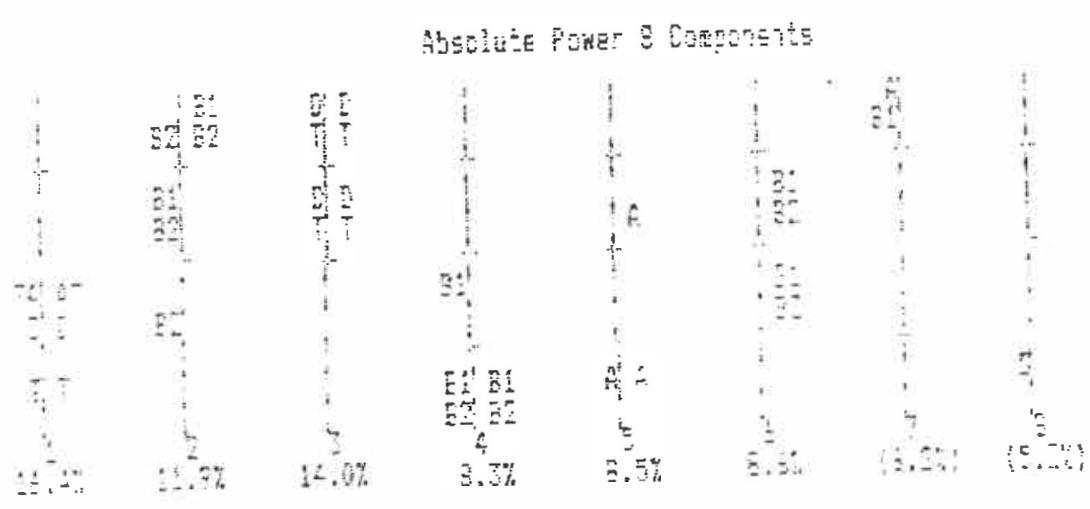

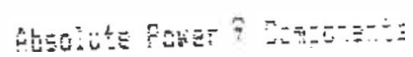
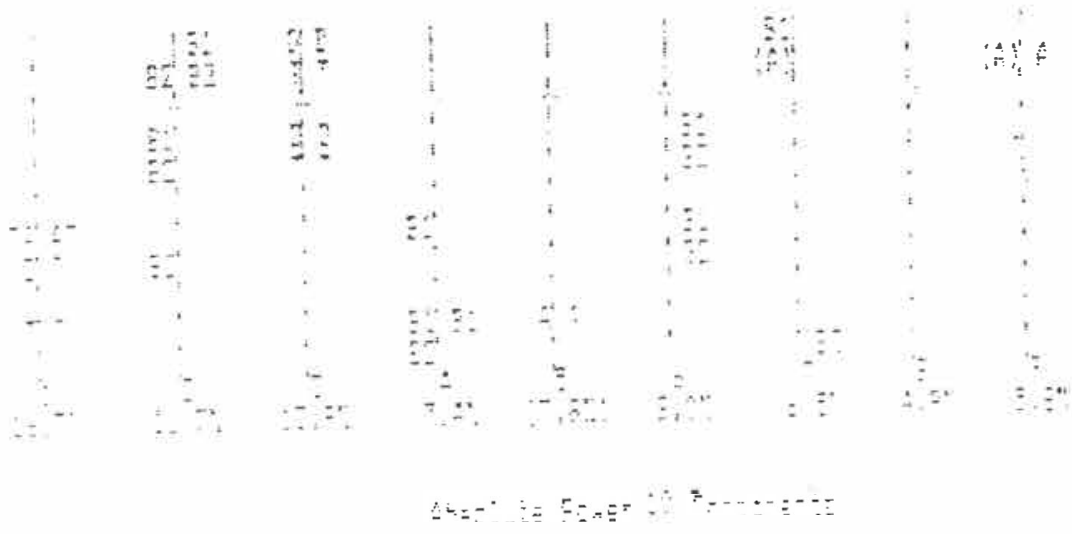

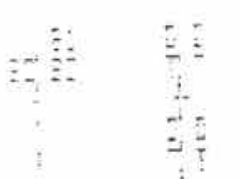
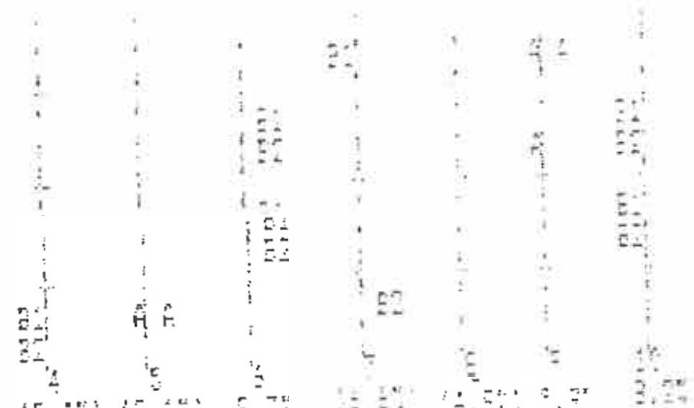

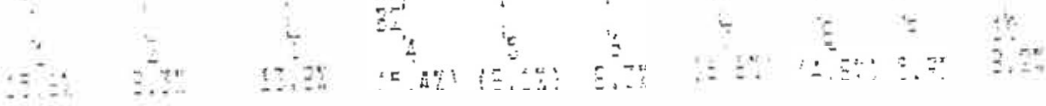

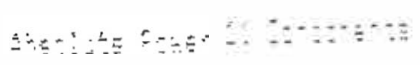

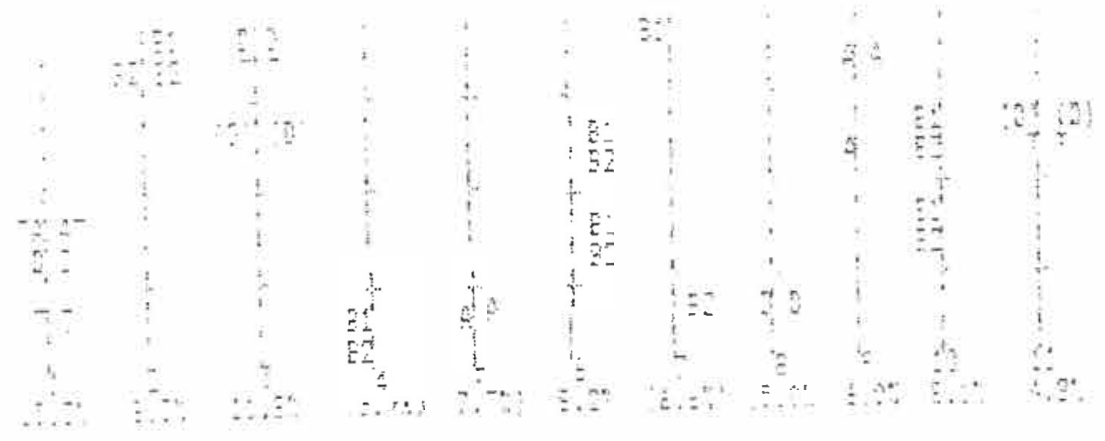



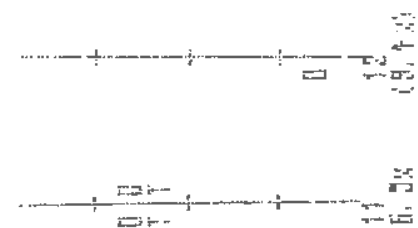

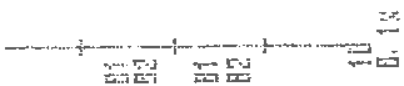
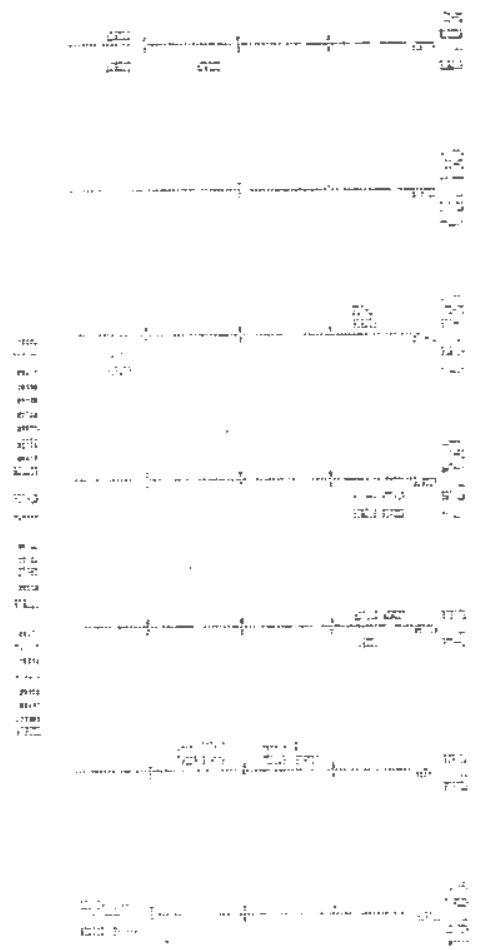

...

tin

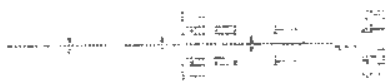

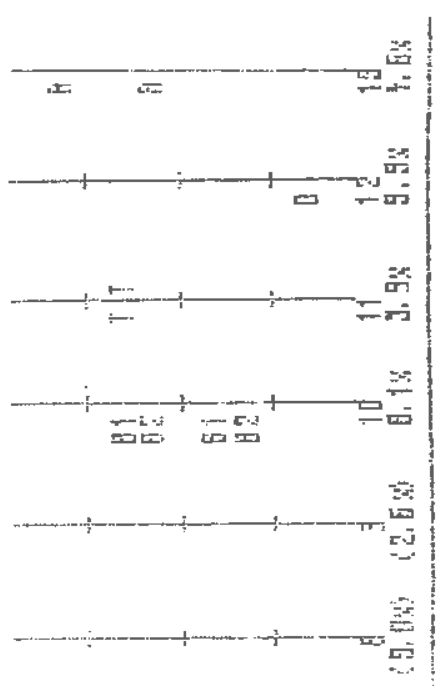

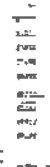

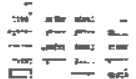
. $= \pm$ $=\lim _{i=1}$

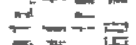
$=$

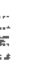

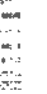

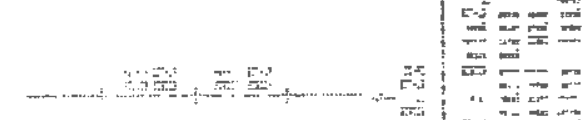

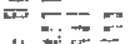

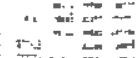
政 i dit

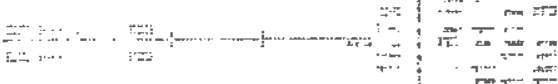

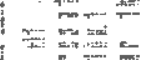
$t_{1}=$ …… (1) 군 $+3=+2$ 

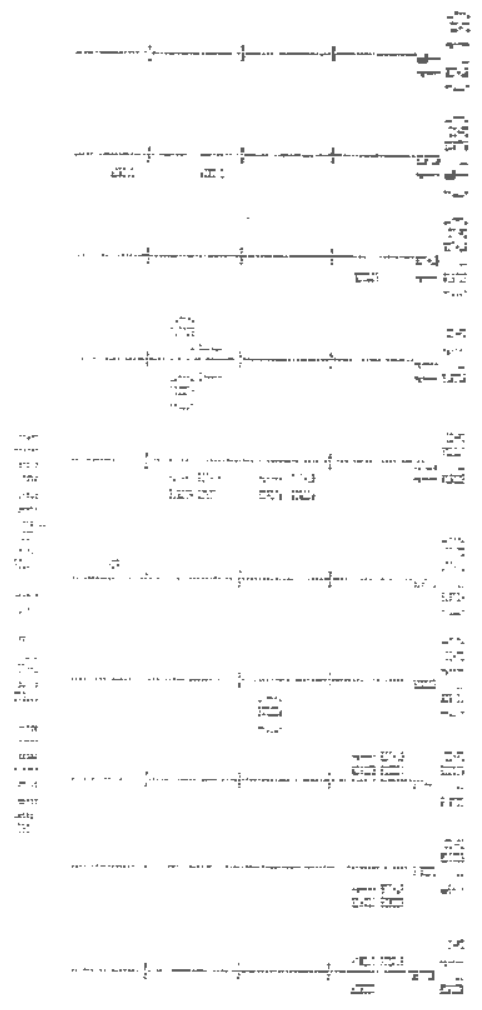

… $\quad b^{2}-z_{2}+\ldots$

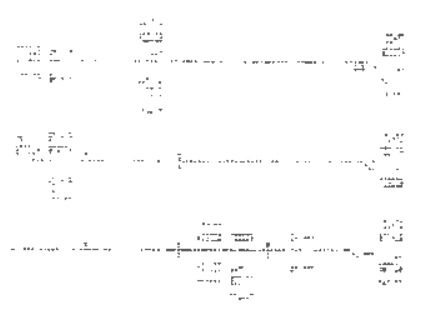

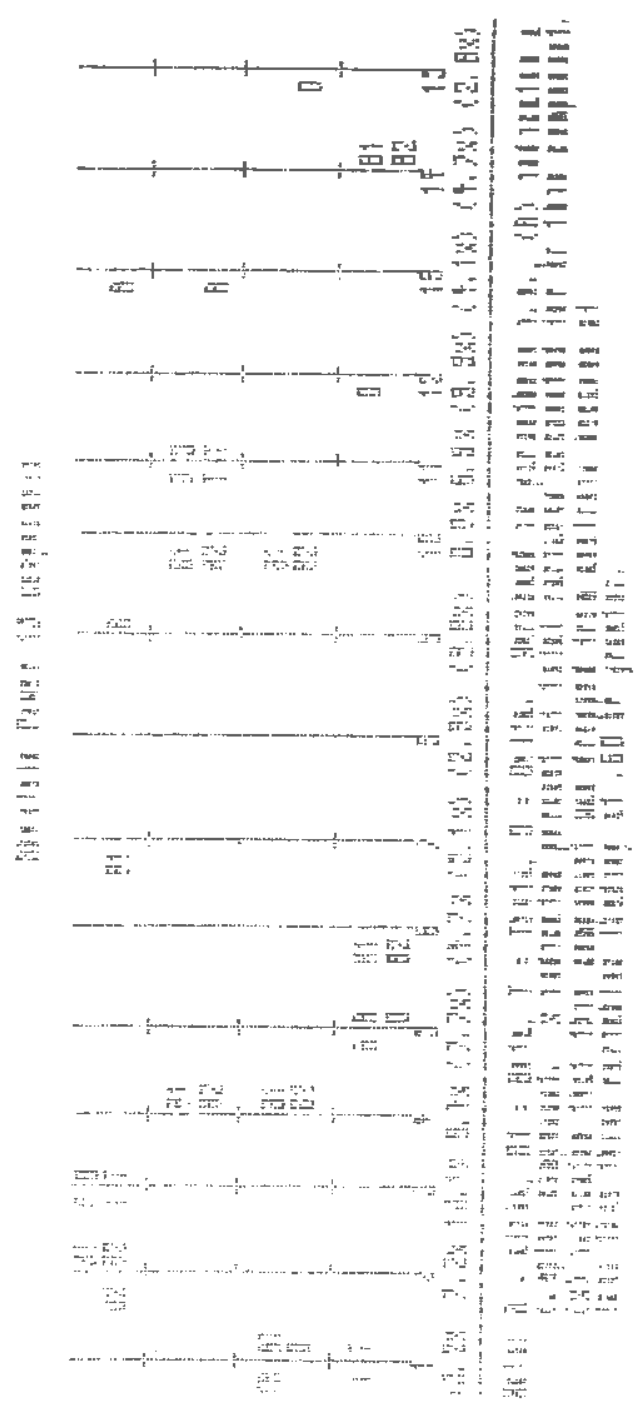



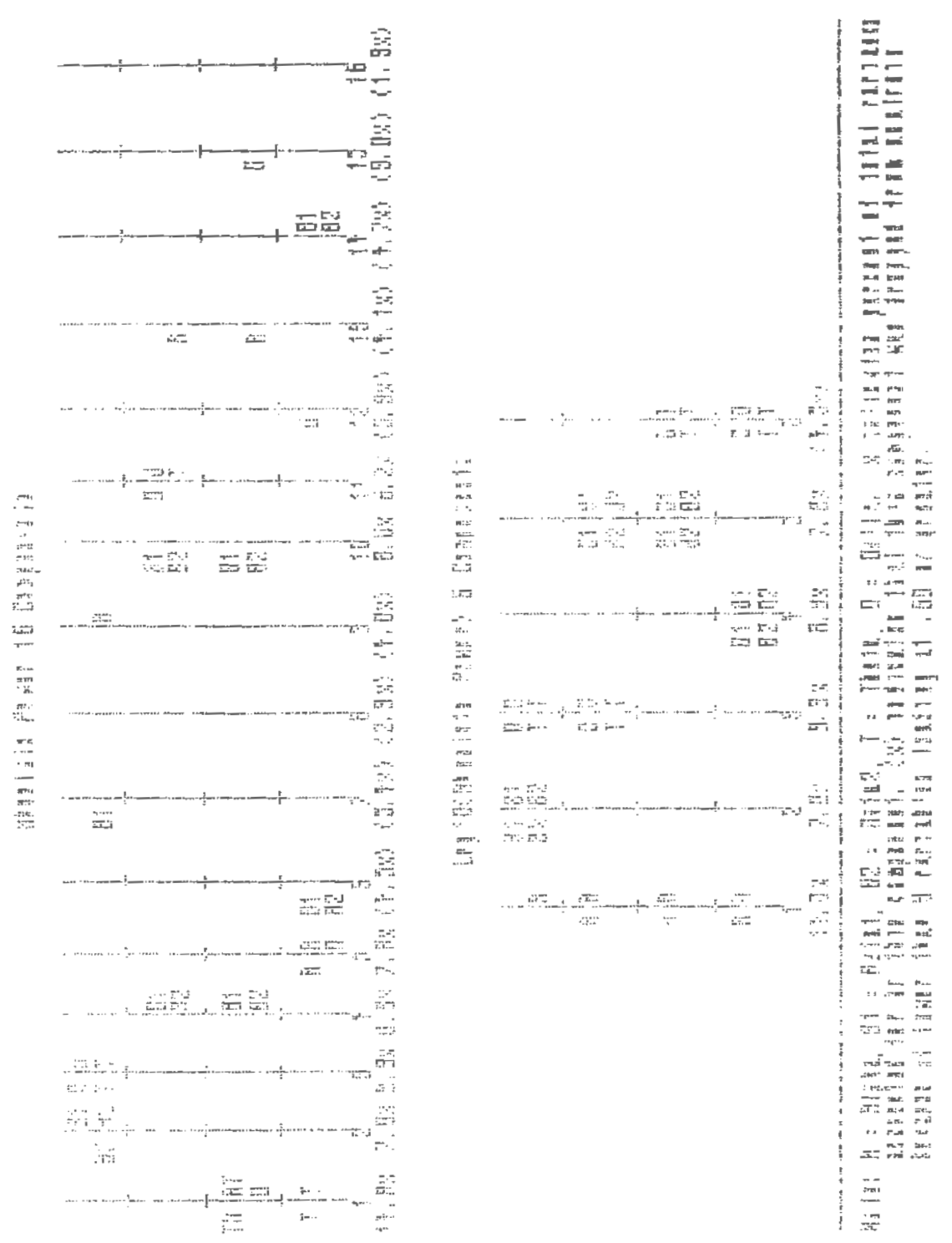
Appendix DI

VARIMAX ROTATED COMPONENT PATTERN

\begin{tabular}{|c|c|c|c|c|c|c|}
\hline & 1 & 2 & 3 & 4 & 5 & 6 \\
\hline $1 . A$ & 0.034 & 0.100 & 0.041 & 0.016 & -0.012 & -0.068 \\
\hline 2. A & 0.359 & 0.302 & 0.231 & 0.036 & 0.164 & 0.155 \\
\hline 3. A & 0.366 & 0.011 & -0.058 & -0.036 & 0.309 & -0.019 \\
\hline $4 . A$ & 0.451 & 0.277 & 0.083 & 0.216 & 0.480 & 0.104 \\
\hline $5 . A$ & 0.783 & -0.101 & 0.109 & 0.044 & 0.256 & -0.010 \\
\hline $6 . A$ & 0.713 & -0.090 & 0.199 & 0.182 & 0.404 & 0.066 \\
\hline $7 . A$ & 0.216 & -0.011 & 0.048 & -0.006 & 0.854 & 0.163 \\
\hline 8. A & 0.145 & -0.033 & -0.040 & 0.027 & 0.947 & 0.058 \\
\hline 1.D & 0.056 & -0.079 & 0.928 & -0.058 & 0.055 & -0.027 \\
\hline $2 . D$ & 0.026 & -0.051 & 0.954 & -0.044 & -0.012 & -0.008 \\
\hline 3. D & 0.032 & -0.062 & 0.583 & -0.070 & 0.015 & -0.015 \\
\hline 4. D & 0.041 & -0.009 & 0.575 & -0.083 & 0.064 & -0.027 \\
\hline $5 . D$ & 0.629 & 0.000 & 0.307 & -0.027 & -0.085 & 0.054 \\
\hline $6 . D$ & 0.910 & -0.035 & 0.127 & 0.060 & 0.038 & 0.094 \\
\hline $7 . \mathrm{D}$ & 0.223 & -0.039 & 0.080 & -0.033 & 0.197 & 0.064 \\
\hline 8. D & 0.317 & 0.021 & 0.099 & 0.051 & 0.648 & 0.092 \\
\hline $1 . \mathrm{T}$ & 0.018 & -0.049 & 0.724 & -0.043 & 0.007 & -0.047 \\
\hline $2 . \mathrm{T}$ & 0.057 & 0.006 & 0.848 & -0.021 & -0.031 & 0.042 \\
\hline $3 . \mathrm{T}$ & 0.194 & 0.003 & 0.322 & -0.030 & 0.005 & -0.020 \\
\hline $4 . \mathrm{T}$ & 0.209 & 0.082 & 0.385 & -0.025 & 0.012 & 0.044 \\
\hline $5 . \mathrm{T}$ & 0.846 & 0.019 & 0.027 & 0.031 & -0.013 & 0.029 \\
\hline $6 . \mathrm{T}$ & 0.943 & -0.048 & -0.060 & 0.073 & 0.026 & 0.039 \\
\hline $7 . \mathrm{T}$ & 0.685 & 0.029 & -0.078 & 0.045 & 0.345 & 0.105 \\
\hline $8 . \mathrm{T}$ & 0.774 & 0.036 & -0.122 & 0.146 & 0.436 & 0.031 \\
\hline $1 . \mathrm{B} 1$ & -0.098 & 0.418 & -0.009 & 0.196 & -0.088 & -0.016 \\
\hline 2. B1 & -0.023 & 0.892 & -0.068 & 0.075 & 0.012 & 0.093 \\
\hline $3 . \mathrm{B} 1$ & 0.018 & 0.357 & -0.014 & 0.167 & -0.060 & 0.003 \\
\hline 4. B1 & 0.050 & 0.166 & -0.069 & 0.940 & 0.036 & 0.077 \\
\hline 5. BI & 0.286 & -0.070 & 0.008 & 0.161 & 0.014 & 0.336 \\
\hline 6.81 & 0.334 & -0.150 & -0.051 & 0.704 & 0.035 & 0.301 \\
\hline $7 . \mathrm{BI}$ & 0.195 & -0.067 & -0.039 & 0.062 & 0.283 & 0.841 \\
\hline $8 . \mathrm{BI}$ & 0.229 & -0.163 & -0.095 & 0.187 & 0.263 & 0.416 \\
\hline 1. B2 & -0.112 & 0.721 & -0.070 & 0.380 & -0.018 & -0.128 \\
\hline 2. $B 2$ & -0.039 & 0.924 & -0.065 & 0.068 & -0.009 & -0.019 \\
\hline $3 . \mathrm{B} 2$ & 0.009 & 0.546 & -0.018 & 0.168 & -0.017 & -0.119 \\
\hline $4 . \mathrm{B} 2$ & 0.033 & 0.270 & -0.101 & 0.916 & 0.044 & -0.028 \\
\hline 5.82 & 0.111 & 0.280 & 0.047 & 0.139 & -0.045 & 0.095 \\
\hline 6.82 & 0.165 & 0.040 & 0.018 & 0.759 & 0.017 & 0.043 \\
\hline 7.82 & -0.012 & 0.060 & 0.010 & 0.084 & 0.014 & 0.901 \\
\hline $8 . B 2$ & 0.074 & 0.026 & 0.023 & 0.146 & 0.091 & 0.289 \\
\hline
\end{tabular}




\begin{tabular}{|c|c|c|c|c|c|c|}
\hline & 7 & 8 & 9 & 10 & 11 & 12 \\
\hline $1 . \mathrm{A}$ & 0.527 & -0.044 & 0.721 & -0.012 & 0.098 & 0.222 \\
\hline $2 . A$ & -0.154 & 0.021 & 0.636 & 0.142 & 0.172 & -0.003 \\
\hline 3. A & 0.034 & 0.098 & 0.672 & 0.183 & 0.095 & 0.129 \\
\hline 4. A & -0.081 & -0.120 & 0.513 & 0.063 & 0.048 & -0.148 \\
\hline $5 . A$ & -0.084 & 0.088 & 0.188 & 0.113 & -0.162 & -0.184 \\
\hline $6 . \mathrm{A}$ & 0.000 & -0.343 & 0.144 & 0.082 & -0.157 & -0.010 \\
\hline $7 . A$ & -0.017 & -0.155 & 0.172 & -0.079 & -0.080 & 0.107 \\
\hline 8.A & 0.030 & 0.037 & 0.080 & -0.026 & 0.022 & 0.049 \\
\hline $1 . \mathrm{D}$ & 0.028 & 0.037 & -0.069 & -0.012 & 0.160 & -0.049 \\
\hline $2 . D$ & -0.073 & -0.019 & -0.035 & -0.030 & 0.109 & 0.071 \\
\hline $3 . \mathrm{D}$ & -0.019 & -0.060 & -0.133 & -0.034 & 0.707 & 0.034 \\
\hline 4.D & 0.008 & -0.097 & -0.132 & -0.128 & 0.664 & 0.057 \\
\hline $5 . D$ & -0.001 & 0.579 & 0.092 & -0.036 & 0.061 & 0.212 \\
\hline $6 . D$ & 0.099 & -0.032 & -0.011 & 0.032 & 0.168 & 0.131 \\
\hline $7 . \mathrm{D}$ & 0.010 & 0.079 & 0.146 & -0.012 & 0.100 & 0.878 \\
\hline 8.D & 0.081 & 0.493 & -0.058 & 0.006 & 0.219 & 0.230 \\
\hline 1.T & 0.485 & 0.110 & 0.224 & 0.031 & 0.234 & -0.062 \\
\hline $2 . \mathrm{T}$ & -0.089 & 0.068 & 0.249 & 0.080 & 0.282 & 0.064 \\
\hline $3 . T$ & 0.005 & 0.213 & 0.348 & 0.150 & 0.747 & 0.092 \\
\hline 4.T & -0.054 & 0.062 & 0.281 & 0.057 & 0.767 & 0.058 \\
\hline $5 . \mathrm{T}$ & -0.005 & 0.404 & 0.190 & 0.063 & 0.084 & 0.023 \\
\hline $6 . T$ & 0.041 & -0.142 & 0.047 & 0.101 & 0.108 & 0.064 \\
\hline $7 . \mathrm{T}$ & -0.038 & 0.122 & 0.152 & -0.003 & 0.200 & 0.430 \\
\hline $8 . T$ & 0.060 & 0.114 & 0.050 & 0.107 & 0.175 & 0.112 \\
\hline 1. B1 & 0.784 & 0.064 & 0.204 & 0.085 & -0.025 & 0.099 \\
\hline 2.B.1 & 0.018 & -0.007 & 0.231 & 0.234 & 0.050 & -0.012 \\
\hline $3 . \mathrm{BI}$ & 0.107 & 0.049 & 0.172 & 0.822 & 0.059 & 0.167 \\
\hline 4. BI & -0.008 & 0.049 & 0.109 & 0.129 & -0.006 & -0.001 \\
\hline 5. B1 & 0.095 & 0.207 & 0.146 & 0.744 & -0.003 & -0.166 \\
\hline $6 . \mathrm{B} 1$ & 0.250 & -0.129 & 0.041 & 0.254 & -0.045 & -0.042 \\
\hline $7 . \mathrm{BI}$ & 0.108 & 0.199 & 0.071 & 0.140 & 0.067 & 0.067 \\
\hline $8 . \mathrm{BI}$ & 0.441 & 0.101 & -0.157 & 0.450 & 0.056 & -0.046 \\
\hline 1. B2 & 0.414 & 0.082 & -0.029 & 0.155 & -0.037 & 0.006 \\
\hline 2. B2 & 0.045 & -0.017 & 0.016 & 0.229 & -0.016 & -0.035 \\
\hline $3 . \mathrm{B2}$ & 0.084 & -0.067 & -0.014 & 0.768 & 0.011 & 0.034 \\
\hline 4.82 & 0.020 & 0.048 & -0.097 & 0.149 & -0.030 & 0.010 \\
\hline 5.82 & 0.135 & -0.143 & 0.024 & 0.851 & -0.005 & -0.061 \\
\hline $6 . \mathrm{B} 2$ & 0.538 & -0.075 & 0.007 & 0.103 & -0.096 & -0.026 \\
\hline 7.82 & 0.061 & -0.114 & -0.007 & 0.040 & -0.050 & 0.034 \\
\hline 8.82 & 0.820 & -0.044 & -0.075 & 0.269 & -0.073 & -0.088 \\
\hline
\end{tabular}


Appendix D2

OBLIQUE FACTOR PATTERN

\begin{tabular}{|c|c|c|c|c|c|c|}
\hline & 1 & 2 & 3 & 4 & 5 & 6 \\
\hline $1 . \mathrm{A}$ & 0.095 & 0.144 & 0.064 & 0.097 & 0.040 & -0.021 \\
\hline 2. A & 0.454 & 0.276 & 0.282 & 0.159 & 0.296 & 0.264 \\
\hline 3. A & 0.464 & 0.012 & -0.010 & 0.093 & 0.428 & 0.154 \\
\hline 4. A & 0.598 & 0.237 & 0.130 & 0.365 & 0.615 & 0.287 \\
\hline $5 . A$ & 0.820 & -0.202 & 0.145 & 0.177 & 0.457 & 0.214 \\
\hline $6 . A$ & 0.842 & -0.169 & 0.239 & 0.308 & 0.602 & 0.301 \\
\hline 7. A & 0.401 & -0.078 & 0.064 & 0.080 & 0.896 & 0.323 \\
\hline 8. A & 0.325 & -0.087 & -0.035 & 0.107 & 0.953 & 0.236 \\
\hline I. D & 0.108 & -0.131 & 0.935 & -0.125 & 0.051 & -0.007 \\
\hline $2 . \mathrm{D}$ & 0.076 & -0.089 & 0.956 & -0.128 & -0.016 & -0.012 \\
\hline $3 . \mathrm{D}$ & 0.076 & -0.085 & 0.655 & -0.154 & 0.022 & -0.015 \\
\hline $4 . D$ & 0.082 & -0.042 & 0.644 & -0.164 & 0.065 & -0.037 \\
\hline $5 . \mathrm{D}$ & 0.570 & -0.119 & 0.300 & 0.036 & 0.105 & 0.147 \\
\hline $6 . \mathrm{D}$ & 0.917 & -0.162 & 0.181 & 0.191 & 0.312 & 0.276 \\
\hline $7 . \mathrm{D}$ & 0.285 & -0.051 & 0.065 & -0.007 & 0.298 & 0.122 \\
\hline G. D & 0.411 & -0.075 & 0.080 & 0.131 & 0.729 & 0.246 \\
\hline 1. $\mathrm{T}$ & 0.076 & -0.077 & 0.733 & -0.043 & 0.019 & -0.007 \\
\hline $2 . \mathrm{T}$ & 0.130 & -0.010 & 0.874 & -0.066 & 0.000 & 0.066 \\
\hline $3 . \mathrm{T}$ & 0.248 & 0.007 & 0.404 & -0.021 & 0.088 & 0.056 \\
\hline $4 . T$ & 0.268 & 0.068 & 0.478 & -0.025 & 0.097 & 0.096 \\
\hline $5 . \mathrm{T}$ & 0.804 & -0.097 & 0.058 & 0.167 & 0.235 & 0.200 \\
\hline $6 . \mathrm{T}$ & 0.947 & -0.150 & 0.006 & 0.224 & 0.303 & 0.243 \\
\hline $7 . T$ & 0.745 & -0.058 & -0.042 & 0.166 & 0.558 & 0.279 \\
\hline $8 . \mathrm{T}$ & 0.845 & -0.062 & -0.086 & 0.309 & 0.654 & 0.269 \\
\hline 1.BI & -0.085 & 0.437 & -0.070 & 0.327 & -0.077 & -0.025 \\
\hline 2. BI & -0.015 & 0.902 & -0.100 & 0.254 & 0.018 & 0.058 \\
\hline 3. BI & 0.093 & 0.440 & -0.065 & 0.350 & -0.009 & 0.108 \\
\hline $4 . \mathrm{BI}$ & 0.177 & 0.240 & -0.119 & 0.962 & 0.131 & 0.179 \\
\hline 5.81 & 0.388 & -0.082 & -0.017 & 0.342 & 0.167 & 0.516 \\
\hline $6 . \mathrm{BI}$ & 0.480 & -0.148 & -0.074 & 0.794 & 0.229 & 0.475 \\
\hline $7 . \mathrm{BI}$ & 0.332 & -0.187 & -0.059 & 0.188 & 0.447 & 0.916 \\
\hline 8. B1 & 0.355 & -0.222 & -0.131 & 0.347 & 0.397 & 0.581 \\
\hline 1. B2 & -0.113 & 0.758 & -0.151 & 0.510 & -0.041 & -0.145 \\
\hline 2. B2 & -0.066 & 0.930 & -0.114 & 0.237 & -0.033 & -0.069 \\
\hline 3. B2 & 0.055 & 0.622 & -0.073 & 0.358 & -0.007 & -0.036 \\
\hline 4. B2 & 0.127 & 0.341 & -0.168 & 0.946 & 0.109 & 0.058 \\
\hline $5 . \mathrm{B} 2$ & 0.198 & 0.328 & 0.010 & 0.338 & 0.026 & 0.22 \\
\hline $6 . \mathrm{B2}$ & 0.272 & 0.066 & -0.036 & 0.832 & 0.132 & 0.16 \\
\hline 7. B2 & 0.095 & -0.033 & -0.017 & 0.165 & 0.130 & 0.863 \\
\hline $8 . B 2$ & 0.156 & -0.022 & -0.030 & 0.305 & 0.169 & 0.373 \\
\hline
\end{tabular}


7

\begin{tabular}{|c|c|c|c|c|c|c|}
\hline & 7 & 8 & 9 & 10 & 11 & \\
\hline 1. A & 0.446 & 0.116 & 0.692 & 0.106 & 0.158 & 0.257 \\
\hline $2 . A$ & -0.188 & 0.217 & 0.806 & 0.295 & 0.274 & 0.006 \\
\hline $3 . \mathrm{A}$ & -0.040 & 0.293 & 0.783 & 0.294 & 0.149 & 0.134 \\
\hline 4. A & -0.105 & 0.023 & 0.696 & 0.268 & 0.089 & -0.123 \\
\hline 5.A & -0.135 & 0.220 & 0.403 & 0.258 & -0.070 & -0.216 \\
\hline $6 . \mathrm{A}$ & -0.017 & -0.179 & 0.342 & 0.232 & -0.055 & -0.037 \\
\hline 7. A & -0.063 & -0.079 & 0.294 & 0.012 & -0.011 & 0.142 \\
\hline 8. A & -0.004 & 0.079 & 0.207 & 0.056 & 0.062 & 0.102 \\
\hline 1.D & 0.017 & 0.105 & 0.043 & -0.040 & 0.436 & -0.035 \\
\hline $2 . D$ & -0.073 & 0.055 & 0.066 & -0.076 & 0.400 & 0.069 \\
\hline $3 . D$ & -0.028 & 0.091 & -0.026 & -0.067 & 0.839 & 0.137 \\
\hline 4.D & -0.017 & 0.051 & -0.023 & -0.149 & 0.799 & 0.177 \\
\hline $5 . D$ & -0.040 & 0.746 & 0.322 & 0.105 & 0.272 & 0.195 \\
\hline $6 . D$ & 0.065 & 0.224 & 0.255 & 0.219 & 0.282 & 0.144 \\
\hline $7 . \mathrm{D}$ & -0.001 & 0.294 & 0.264 & 0.016 & 0.267 & 0.871 \\
\hline 8.D & 0.073 & 0.600 & 0.168 & 0.138 & 0.353 & 0.273 \\
\hline 1.T & 0.440 & 0.217 & 0.283 & 0.083 & 0.463 & -0.027 \\
\hline $2 . \mathrm{T}$ & -0.095 & 0.206 & 0.364 & 0.079 & 0.542 & 0.068 \\
\hline $3 . T$ & -0.027 & 0.450 & 0.488 & 0.204 & 0.849 & 0.172 \\
\hline $4 . T$ & -0.084 & 0.300 & 0.432 & 0.120 & 0.867 & 0.157 \\
\hline $5 . \mathrm{T}$ & -0.054 & 0.604 & 0.444 & 0.258 & 0.189 & 0.015 \\
\hline $6 . \mathrm{T}$ & 0.005 & 0.105 & 0.289 & 0.278 & 0.151 & 0.066 \\
\hline $7 . \mathrm{T}$ & -0.073 & 0.372 & 0.396 & 0.160 & 0.293 & 0.459 \\
\hline $8 . T$ & 0.042 & 0.319 & 0.321 & 0.308 & 0.223 & 0.140 \\
\hline $1 . \mathrm{BI}$ & 0.805 & 0.098 & 0.208 & 0.258 & 0.012 & 0.114 \\
\hline 2.81 & 0.067 & 0.046 & 0.370 & 0.381 & 0.046 & 0.009 \\
\hline 3. B1 & 0.233 & 0.155 & 0.298 & 0.867 & 0.102 & 0.060 \\
\hline 4.B1 & 0.184 & 0.007 & 0.150 & 0.334 & -0.061 & -0.077 \\
\hline 5.BI & 0.202 & 0.295 & 0.278 & 0.854 & 0.036 & -0.309 \\
\hline $6 . \mathrm{B1}$ & 0.399 & -0.082 & 0.103 & 0.471 & -0.069 & -0.146 \\
\hline $7 . \mathrm{B1}$ & 0.169 & 0.284 & 0.174 & 0.331 & 0.114 & 0.003 \\
\hline 8.B1 & 0.534 & 0.164 & -0.053 & 0.598 & 0.071 & -0.123 \\
\hline $1 . \mathrm{B} 2$ & 0.509 & 0.047 & 0.050 & 0.321 & -0.046 & 0.019 \\
\hline $2 . \mathrm{B} 2$ & 0.104 & -0.007 & 0.160 & 0.347 & -0.022 & -0.01 \\
\hline 3.82 & 0.212 & -0.009 & 0.135 & 0.807 & 0.028 & -0.04 \\
\hline 4.82 & 0.224 & -0.021 & -0.034 & 0.334 & -0.090 & -0.05 \\
\hline 5.82 & 0.264 & -0.057 & 0.156 & 0.900 & 0.025 & -0.17 \\
\hline $6 . \mathrm{B2}$ & 0.670 & -0.081 & 0.036 & 0.330 & -0.098 & -0.084 \\
\hline $7 . \mathrm{B} 2$ & 0.149 & -0.090 & 0.006 & 0.190 & -0.039 & -0.040 \\
\hline $8 . B 2$ & 0.871 & -0.013 & -0.045 & 0.436 & -0.034 & -0.12 \\
\hline
\end{tabular}


Appendix D3

12-Component, Absolute-Power Oblique Rotation

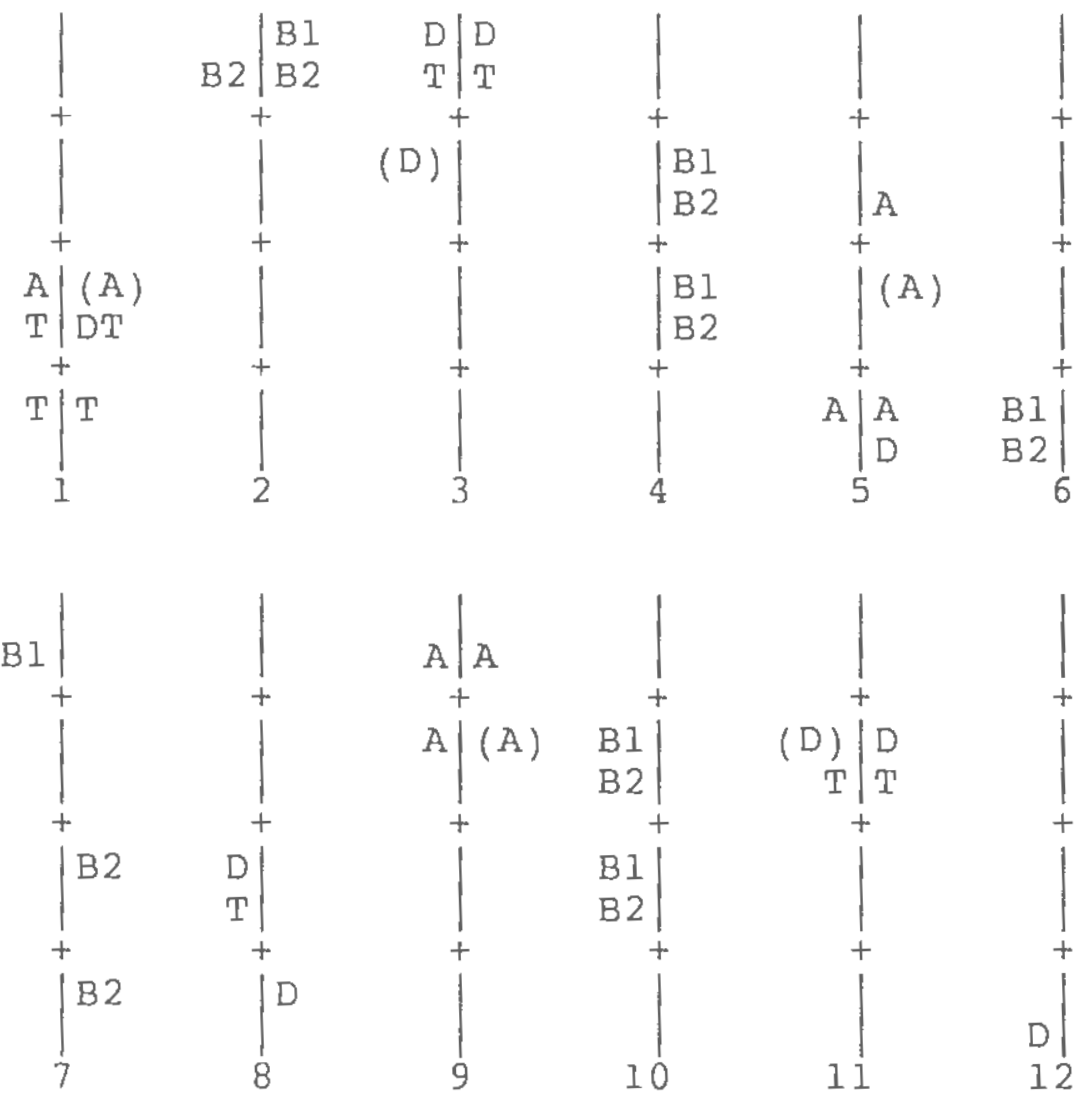




\section{Bibliography}

Amador, A. A., Sosa, V., Marqui, R. D. P., Garcia, L. G., Lirio, R. B., \& Bayard, J. B. (1989). On the structure of EEG development. Electroencephalography and Clinical Neurophysiology, $73,10-19$.

Anderson, T. W., \& Rubin, H. (1956). Statistical inference in factor analysis. Proceedings of the third Berkeley symposium on mathematical statistics and probability, 5, 111-150.

Bente, D. (1979). Vigilance and evaluation of psychotrophic drug effects on EEG.

pharmakopsychiatry, 12, 137-147.

Buchsbaum, M. S., Coppola, R., \& Cappelletti, J. (I982). Positron emission tomography: New approaches to local function in pharmaco-electroencephalography. In $W . M$. Hermann (Ed.) EEG in drug research (PP. 193-207). New York: Gustav Fischer.

Buchsbaum, M. S., Nuechterlein, K. H., Haier, R. J. , Wu, J., Sicotte, N., Hazlett, E., Asarnow, R., Potkin, S., \& Guich (1990). Glucose metabolic rate in normals and schizophrenics during the continuous performance test assessed by positron emission tomography. British Journal of Psychiatry, 156, 216-227.

Byring, R. F., Salmi, T. K., Sainio, K. O., \& Orn, H. P. (1991). EEG in children with spelling disabilities. Electroencephalography and Clinical Neurophysiology, 79, 247-255.

Cattel, R. B. (1966). The scree test for the number of factors. Multivariate Behavioral Research, $1,289-$ 325 .

Cohen, R. M., Semple, W. E., Gross, M., Nordahl, T. E., Delisi, L. E., Holcomb, H. H., King, A. C., Morihisa, J. M., \& Pickat, D. (1987). Dysfunction in a prefrontal substrate of sustained attention in schizophrenia. Life Sciences, 40, 2031-2039.

Davies, D. R., \& Parasuraman, R. (1982). Viqilance and the brain. The psychology of vigilance (pp. 180-207). New York: Academic Press.

Dunteman, G. H. (1982). Principal components analysis. Newbury Park, CA: Sage Publications.

Eliason, M. J., \& Richman, L. C. (1987). The continuous performance test in learning disabled and nondisabled 
children. Journal of Learning Disabilities, 20, 614 619.

Fava, J. L., \& Velicer, W. F. (in press a). An empirical comparison of factor, image, component, and scale scores. Multivariate Behavioral Research.

Fava, J. I., \& Velicer, W. F. (in press b). The effects of overextraction on factor and component analysis.

Fein, G., Galin, D., Johnstone, J., Yingling, C. D., Marcus, M., \& Kiersch, M. E. (1983). EEG power spectra in normal and dyslexic children. I. Reliability during passive conditions. Electroencephalography and clinical Neurophysiology, $55,399-405$.

Friedman, D. Cornblatt, B. Vaughan, H., \& ErlenmeyerKimling, L. (1986). Event-related potentials in children at risk for schizophrenia during two versions of the continuous performance test. Psychiatry Research, 18, 161-177.

Gasser, T., Bacher, P., \& Mocks, J. (1982).

Transformations towards the normal distribution of broad band spectral parameters of the EEG.

Electroencephaloqraphy and Clinical Neurophysiology, 53. $119-124$.

Gasser, T., Bacher, P., \& Steinberg. H. (1985). Testretest reliability of spectral parameters of the EEG. Electroencephalography and clinical Neurophysiology, 60, 312-319.

Gasser, T. Jennen-Steinmetz, C., Sroka, I., Verleger, R. , \& Mocks, J. (1988). Development of the EEG of schoolage children and adolescents. II Topography.

Electroencephalography and clinical Neurophysiology, 69, $100-109$.

Gasser, T., Mocks, J., \& Bacher, P., (1983). Topographic factor analysis of the EEG with applications to development and to mental retardation. Electroencephalography and Clinical Neurophysiology, 5. $5,45-463$.

Gordon, M., \& Bilinski Mettelman, B., (1988). The assessment of attention: I. Standardization and reliability of a behavior-based measure. Journal of Clinical Psychology, 44, 683-690.

Grant, M. L., Ilai, D., Nussbaum, N. L., \& Bigler, E. D. (1990). The relationship between continuous performance tasks and neuropsychological tests in 
children with attention-deficit hyperactivity

disorder. Perceptual and Motor Ski11s, 70, 435-445.

Gur, R. C., Erwin, R. J., \& Bur, R. E. (1992).

Neurobehavioral probes for physiologic neuroimaging

studies. Archives of General Psychiatry, 49,409-414.

Halperin, J. M., Sharma, V., Greenblatt, E., \& Schwartz,

S. T. (1991). Assessment of the continuous

performance test: Reliability and validity in a

nonreferred sample. Psychological Assessment, 3, 603608 .

Halperin, J. M., Wolf, L. E., Pascualvaca, D. M., Newcorn, J. H., Healey, J. M., O'Brien, J. D., Morganstein, A., \& Young, J.G. (1988). Differential assessment of attention and impulsivity in children. Journal of the Amexican Academy of Child and Adolescent Psychiatry, $27,326-329$.

Herning, R. I., Hooker, W. D., \& Jones, R. T., Cocaine effects on electroencephalographic cognitive eventrelated potentials and performance.

Electroencephalography and Clinical Neurophysiology, 66, 34-42.

Hiscock, M. \& Kinsbourne, M. (1987). Specialization of the cerebral hemispheres: Implications for learning. Journal of Learning Disabilities, 20, 130-143.

Homan, R. W., Herman, J., \& Puxdy, P. (1987). Cerebral location of international 10-20 system electrode placement. Electroencephalography and clinical Neurophysiology, 66, $376-382$.

Horn, J. L. (1965). A rationale and test for the number of factors in factor analysis. Psychometrika, 30, $179-185$.

Jasper, H. H. (1958). Report of committee on methods of clinical examination in electroencephalography. Electroencephalography and Clinical Neurophysiology, $10,370-375$.

John, E. R., Ahn, H., \& Prichep, I., (1980). Developmental equations for the electroencephalogram. Science, 210, 1255-1258.

John, E. R., Karmel, B. Z., Corning, W. C., Easton, P, Brown, D., Ahn, H., John, M., Harmony, T., Prichep, L., Toro, A., Gerson, I., Bartlett, R., Thatcher, R., Kaye, H., Valdes, P., \& Schwartz, E. (1977). Neurometrics. Science, 196, 1393-1410. 
John, E. R., Prichep, L. S., Fridman, J., E Easton, P. (1988). Neurometrics: Computer-assisted differential diagnosis of brain dysfunctions. Science, 239, 162169 .

Mackworth, N. H. (1948). The breakdown of vigilance during prolonged visual search. Quarterly Journal of Experimental Psychology, 1, 6-21.

Marascuilo, L. A., \& MCSweeney, M. (1977). Nonparametric and distribution-free methods for the social sciences. Monterey, CA: Brooks/Cole Publishing Co.

Matejcek, M. (1982). Vigilance and the EEG: Psychological, physiological and pharmacological aspects. In W. M. Hermann (Ed.) EEG in drug research (pp. 405-441). New York: Gustav Fischer.

Matousek, M., \& petersen, I., (1973). Frequency analysis of the EEG in normal children and adolescents. In $P$. Kellaway \& I. Petersen (Eds.), Automation of Clinical Electroencephalography. New York: Raven Press.

O'Dougherty, M. Nuechterlein, K. H., \& Drew, B. (1984). Hyperactive and hypoxic children: Signal detection, sustained attention, and behavior. Journal of Aonormal Psychology, 93, 178-191.

Oken, B. S., \& Chiappa, K. H. (1988). Short-term variability in EEG frequency analysis.

Electroencephalography and Clinical Neurophysiology, 69, $191-198$.

Oldfield, R. C. (1971). The assessment and analysis of handedness: The Edinburgh inventory.

Neuropsychologia, 9, 97-113.

Ott, H., McDonald, R. J., Fichte, K., \& Hermann, W. M. (1982). Interpretation of correlations between EEGpower-spectra and psychological performance variables within the concepts of subvigilance, attention and psychomotoric impulsion. In W. M. Herrmann (Ed.) EEG in drug research (pp. 227-247). New York: Gustav Fischer.

Parasuraman, R. (1984). The psychobiology of sustained attention. In J. S, Warm (Ed.), Sustained attention in human performance (pp. 61-101). New York: John Wiley \& Sons.

Pedhazur, E. J. (1982). Multiple Regression in behavioral research: Explanation and prediction (2nd ed.). New York: Holt, Rinehart, winston. 
Petersen, S. E., Fox, P. T., Posner, M. I., Mintum, M. \& Raichle, M. E. (1988). Positron emission tomographic studies of the cortical anatony of single-word processing. Nature, 33, 585-588.

Pigache, R. M*, (1976). Comparison of scoring methods for tests of attention, including an error index for use with schizophrenic patients. Perceptual and Motor Skills, 42, 243-253.

Pollock, V. E., Schneider, L. S., \& Lyness, S. A. (1990). EEG amplitudes in healthy, late-middle-aged and elderly adults: normality of the distributions and correlations with age. Electroencephalography and Clinical Neurophysiology, 75, 276-288.

Pollock, V. E., Schneider, I. S., \& Lyness, S. A. (1991). Reliability of topographic quantitative EEG amplitude in healthy late-middle-aged and elderly subjects. Electroencephalography and Clinical Neurophysiology, 29, $20-26$.

Posner, M. I., Petersen, S. E., Fox, P. T., \& Raichle, M. E. (1988). Localization of cognitive operations in the human bxain. Science, 240, 1627-1631.

Randolph, C. \& Miller, M. H. (1988). EEG and cognitive performance following closed head injury. Neuropsychobiology, 20, 43-50.

Rosvold, H. E., Mirsky, A. F., Sarason, I., Bransome, E. D., \& Beck, L. N. (1956). A continuous performance test of brain damage. Journal of Consulting Psychology, 20, 343-350.

Schenk, G. K., Eiller, W., Ranft, W., Zerbin, D., Dokk, D. , Haverkorn, J., Lemke, E., \& Windelschmidt, R. (1982). Factor-analytical reliability studies with quantitative EEG parameters. In W. M. Hermann (Ed.) EEG in druq research (pP. 209-225). New York: Gustav Fischer.

SPSS Inc. (1986). Statistical package for the social Sciences [Computer program]. Chicago: SPSS Inc.

Stevens, J. (1986). Applied multivariate statistics for the social sciences. Hillsdale, NJ: Lawrence Erlbaum Associates.

Swets, J. A., Tanner, W. P., \& Birdsal1, T. G. (1961). Decision processes in perception. Psychological Review, $68,301-340$. 
Tukey, J. W. (1977). Exploratory data analysis. Reading, MA: Addison-Wesley.

Velicer, W. F. (1974). A comparison of the stability of factor analysis, principal component analysis, and rescaled image analysis. Educational and.

Psycholoqical Measurement, 34, 563-572.

Velicer, W. F. (1976). Determining the number of components from the matrix of partial correlations. Psychometrika, 41, 321-327.

Velicer, W. F. (1977). An empirical comparison of the similarity of principal component, image, and factor patterns. Multivariate Behavioral Research, 12, 3-22.

Velicer, W. F., \& Fava, J. L. (1987). An evaluation of the effects of variable sampling on component, image, and factor analysis. Multivariate Behavioral. Research, 22, 193-210.

Velicer, W. F., \& Fava, J. L. (1990). The effects of variable and subject sampling on factor pattern recovery Manuscript under review

Velicer, W. F., Fava, J. L., Zwick, W. R., \& Harrop, J. (1988). Component Analysis Extended [Computer program]. Kingston, RI: University of Rhode Island.

Velicer, W. F., Peacock, A. C., \& Jackson, D. N. (1982). A comparison of component and factor patters: A Monte Carlo approach. Multivariate Behavioral Research, 17, 371-388.

Warm, J. S. (1984). An introduction to vigilance. In J. S. Warm (Ed.), sustained attention in human. performance. (pp. I-14). New York: John Wiley \& Sons.

Willis, W. G., \& Goodwin, L. D. (1987). An alternative to interference indexes in neuropsychological timesharing research. Neuropsychologia, 25, 719-724.

Zwick, W. R., \& Velicer, W. F. (1982) Factors influencing four rules for determining the number of components to retain. Multivariate Behavioral Research, 17, 253269.

Zwick, W. R., \& Velicer, W. F. (1986). A comparison of five rules for determining the number of components to retain. Psychological Bulletin, 99, 432-442. 